Article

\title{
Novel Isoxazolidine and $\gamma$-Lactam Analogues of Homonucleosides
}

\author{
Dorota G. Piotrowska ${ }^{1, * \mathbb{D}}$, Iwona E. Głowacka ${ }^{1} \mathbb{1}$, Dominique Schols ${ }^{2}$, Robert Snoeck ${ }^{2}$, \\ Graciela Andrei ${ }^{2}$ (D) and Joanna Gotkowska ${ }^{1}$ \\ 1 Bioorganic Chemistry Laboratory, Faculty of Pharmacy, Medical University of Lodz, Muszynskiego 1, 90-151 \\ Lodz, Poland; iwona.glowacka@umed.lodz.pl (I.E.G.); joanna.gotkowska@umed.lodz.pl (J.G.) \\ 2 Rega Institute for Medical Research, KU Leuven, Herestraat 49, B-3000 Leuven, Belgium; \\ Dominique.Schols@rega.kleuven.be (D.S.); Robert.Snoeck@rega.kleuven.be (R.S.); \\ Graciela.Andrei@rega.kleuven.be (G.A.) \\ * Correspondence: dorota.piotrowska@umed.lodz.pl; Tel.: +48-42-677-92-33; Fax: +48-42-678-83-98
}

Received: 2 October 2019; Accepted: 5 November 2019; Published: 6 November 2019

check for updates

\begin{abstract}
Homonucleoside analogues cis-16 and trans-17 having a (5-methoxycarbonyl)isoxazolidine framework were synthesized via the 1,3-dipolar cycloaddition of nucleobase-derived nitrones with methyl acrylate. Hydrogenolysis of the isoxazolidines containing thymine, dihydrouracil, theophylline and adenine moieties efficiently led to the formation of the respective $\gamma$-lactam analogues. $\gamma$-Lactam analogues having 5-bromouracil and 5-chlorouracil fragments were synthesized by treatment of uracil-containing $\gamma$-lactams with NBS and NCS. Isoxazolidine and $\gamma$-lactam analogues of homonucleosides obtained herein were evaluated for activity against a broad range of DNA and RNA viruses. None of the compounds that were tested exhibited antiviral or cytotoxic activity at concentrations up to $100 \mu \mathrm{M}$. The cytostatic activities of all compounds toward nine cancerous cell lines was tested. $\gamma$-Lactams trans-15e (Cl-Ura) and cis-15h (Theo) appeared the most active toward pancreatic adenocarcinoma cells (Capan-1), showing $\mathrm{IC}_{50}$ values 21.5 and $18.2 \mu \mathrm{M}$, respectively. Isoxazolidine cis-15e (Cl-Ura) inhibited the proliferation of colorectal carcinoma (HCT-116).
\end{abstract}

Keywords: isoxazolidines; $\gamma$-lactams; nucleoside analogues; cytostatic activity

\section{Introduction}

Nucleoside analogues belong to a group of important antiviral and antitumor drugs [1-4]. However, resistance to drugs and their toxicity are considered major factors limiting the effectiveness of therapies. Structural modifications of available drugs from a class of nucleoside analogues, including sugar and/or nucleobase residues, resulted in the discovery of a variety of therapeutically-useful antiviral [5] (e.g., azidothymidine (AZT) [6], carbovir [7], lobucavir [8], dioxolane T [9] and lamivudine [10]) and anticancer [11,12] (e.g., cladribine [13], gemcitabine [14], azacitidine [15] and cytarabine [14,16], clofarabine [17]) agents (Figure 1).

On the other hand, the introduction of a methylene bridge between a nucleobase and the sugar partly led to the formation of homonucleosides, which are known for their resistance to hydrolytic or enzymatic cleavage, as well as for the rotational freedom when compared with the natural nucleosides. Furthermore, it was shown that homonucleosides are substrates for cellular kinases and are able to pair with other nucleosides by Watson-Crick interactions without appreciable modifications of the structure of DNA (or RNA) molecules [18]. 1'-Homonucleosides containing adenine 1 or guanine 2 were found to be active against herpes simplex virus (minimum inhibitory concentration $(\mathrm{MIC})=5-20$ $\mu \mathrm{g} / \mathrm{mL})$ and vaccinia virus [19-21], while compound $3\left(\mathrm{IC}_{50}=25.2 \mu \mathrm{g} / \mathrm{mL}\right)$ showed activity against the influenza type virus AH1N1 (Figure 2) [22]. Homonucleoside analogue of 2' -deoxyuridine 4 has been 
described as a selective inhibitor of viral uracil-DNA glycosylase (UDG), while exerting only small effect on the human enzymes [23].<smiles>Cc1cn(C2CCC(CO)O2)c(=O)[nH]c1=O</smiles>

AZT<smiles>Nc1nc2c(ncn2C2C=CC(CO)C2)c(=O)[nH]1</smiles>

carbovir<smiles>Nc1nc2c(ncn2C2CC(CO)C2CO)c(=O)[nH]1</smiles>

lobucavir<smiles>Cc1cn(C2COC(CO)O2)c(=O)[nH]c1=O</smiles>

dioxolane T<smiles></smiles>

lamivudine

azidothymidine<smiles>Cc1nc(N)c2ncn(C3C[C@H](O)[C@@H](CO)O3)c2n1</smiles><smiles>Nc1ccn(C2OC(CO)[C@@H](O)C2(F)F)c(=O)n1</smiles><smiles>Nc1ncn([C@@H]2O[C@H](CO)[C@@H](O)[C@H]2O)c(=O)n1</smiles><smiles>Nc1ccn(C2OC(CO)[C@@H](O)C2O)c(=O)n1</smiles><smiles>Nc1nc(Cl)nc2c1ncn2C1OC(CO)[C@@H](O)C1F</smiles>

Figure 1. Examples of biologically-active nucleoside analogues.<smiles>Nc1ncnc2c1ncn2C[C@H]1C[C@H](O)[C@@H](CO)O1</smiles>

1

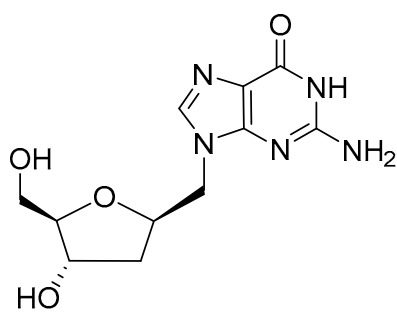

2<smiles>O=c1[nH]cnc2c1ncn2C[C@H]1C[C@@H](O)[C@@H](CO)O1</smiles>

3<smiles>O=c1ccn(C[C@H]2C[C@H](O)[C@@H](CO)O2)c(=O)[nH]1</smiles>

Figure 2. Examples of biologically active $1^{\prime}$-homonucleosides.

Incorporation of the isoxazolidine ring into a nucleoside framework as a sugar part replacer was first proposed by Tronchet and co-workers [24,25] with the intention to study antiviral [20,26-31], antibacterial [32] and antifungal [33] activities of the compounds. Other research groups then intensively explored this field further. Thus, a compound 5 [34] and phosphonylated derivatives 6 [35] and 7 [36-38] inhibited the reverse transcriptase activity of avian Moloney virus (AMV) and human immunodeficiency virus (HIV) at a level comparable with that of tenofovir (1 nM) and 10-fold higher than that of AZT $(10 \mathrm{nM})$. Moreover, their cytotoxicity was significantly lower $(50 \%$ cytotoxic concentration $\left.\left(\mathrm{CC}_{50}\right)>500 \mu \mathrm{M}\right)$ in comparison with that of $\mathrm{AZT}\left(\mathrm{CC}_{50}=12.14 \mu \mathrm{M}\right)$ (Figure 3). In order to obtain compounds with a sufficient stability for hydrolytic or enzymatic cleavage, analogues of 1'-homonucleosides 8-11 (Figure 3) were also synthesized [39-43].

In the isoxazolidine nucleoside/nucleotide analogues described so far, a nucleobase is attached to C5; therefore, the 1,3-dipolar cycloaddition of nitrones and $\mathrm{N}$-vinyl or $\mathrm{N}$-allyl nucleobases has been found a convenient method for their preparation [44]. Recently, we designed isoxazolidine analogues of 1'-homonucleos(t)ides 12 (Figure 3), in which nucleobases were attached to C3 to underscore the fundamental difference to the already-described ones [45,46]. In the synthesis of homonucleosides 12, the 1,3-dipolar cycloaddition was also employed, but in that case, nucleobase-derived nitrones and selected alkenes were applied [45,46]. Since no significant activity of compounds $\mathbf{1 2}$ toward the viruses tested was noticed, we wondered whether the replacement of an isoxazolidine moiety with a $\gamma$-lactam ring would lead to an improvement of antiviral properties of newly-designed compounds 15. The idea of incorporation of the $\gamma$-lactam moiety has been supported by the presence of this subunit in many natural products (Figure 4), which showed antiviral [47,48], cytotoxic [49-53], 
anti-inflammatory [53-55] and antimicrobial [56,57] properties, among others. For this reason the assumption that homonucleoside analogues 15 (Scheme 1) having the $\gamma$-lactam moiety could possess interesting biological properties as antiviral or cytotoxic is justified [58].

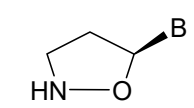

5

$$
\text { B = Ura, Thy, Cyt, }
$$

Ade, Gua, 5-FUra

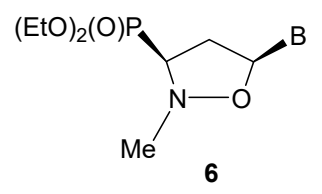

TPCOANs

$\mathrm{B}=$ Thy, 5-FUra
$\mathrm{P}(\mathrm{O})(\mathrm{OEt})_{2}$

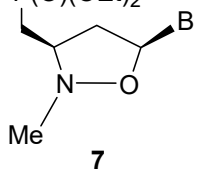

PCOANs

$\mathrm{B}=$ Thy, 5-FUra, Cy

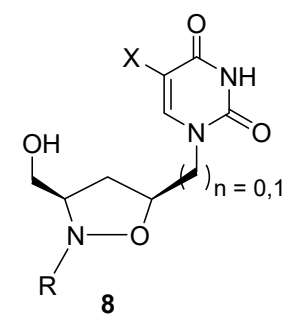

$\mathrm{R}=\mathrm{Me}, \mathrm{H}$

$X=M e, F$<smiles>[X]c1cn(C[C@@H]2C[C@@H]3[C@H](O)CCN3O2)c(=O)[nH]c1=O</smiles>

9

$\mathrm{X}=\mathrm{Me}, \mathrm{F}$<smiles>[X]c1cn(CC2C[C@H]3[C@H](O)[C@@H](O)CN3O2)c(=O)[nH]c1=O</smiles>

10

$\mathrm{X}=\mathrm{Me}, \mathrm{F}$<smiles>[R]C1CC(OCC2C=C([N+](C)(C)C)C(=O)NC2=O)ON1C</smiles>

11

$\mathrm{R}=\mathrm{CH}_{2} \mathrm{OH}, \mathrm{CO}_{2} \mathrm{Et}$,

$\mathrm{CH}_{2} \mathrm{P}(\mathrm{O})(\mathrm{OEt})_{2}$, $\mathrm{CH}_{2} \mathrm{OSi}(\mathrm{Ph})_{2} t-\mathrm{Bu}$<smiles>[R]C1CC(C[B])N(C)O1</smiles>

12
Ura, Thy, 5-FUra, 5-BrUra, Ade $\mathrm{R}=\mathrm{CH}_{2} \mathrm{OH}, \mathrm{CH}_{2} \mathrm{P}(\mathrm{O})(\mathrm{OEt})_{2}, \mathrm{P}(\mathrm{O})(\mathrm{OEt})_{2}$, $\mathrm{CH}_{2} \mathrm{OCH}_{2} \mathrm{P}(\mathrm{O})(\mathrm{OEt})_{2}$, $\mathrm{OCH}_{2} \mathrm{P}(\mathrm{O})(\mathrm{Oi}-\mathrm{Pr})_{2}$

Figure 3. Examples of isoxazolidine nucleoside/nucleotide analogues.<smiles>[R]C(O)[C@@H](C)C[C@H]1OC(=O)[C@]2(CO)N(C)C(=O)[C@H](C)[C@]12O</smiles>

neooxazolomycin<smiles>CC12NC(=O)C([C@H](O)[C@H]3C=CCCC3)(OC1=O)C2CCCl</smiles>

salinosporamide $\mathrm{A}$<smiles>CC(C)[C@H](O)C12NC(=O)C(CCCl)[C@]1(C)OC2=O</smiles>

antiprotealide

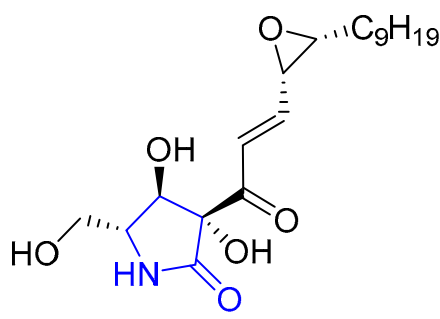

(-)-pramancin<smiles>[R]=COc1cnc(C/C=C/C=C/C=C(\C)C(O)C(C)(C)C(=O)NC/C=C/C=C/C(C)C)o1</smiles><smiles>CN1C(=O)[C@H](O)[C@@H](c2ccccc2)C1C(O)c1ccccc1</smiles>

(-)-clausenamide<smiles>Cn1cncc1C1CNC(=O)/C1=C/c1ccccc1</smiles>

anatin<smiles>Cn1cnc(C2CNC(=O)/C2=C\c2ccccc2)c1</smiles>

isoanatin<smiles>CN1CC(c2cn(C)cn2)C(C(O)c2ccccc2)C1=O</smiles>

cynometrine

Figure 4. Examples of some bioactive natural molecules containing a $\gamma$-lactam core. 


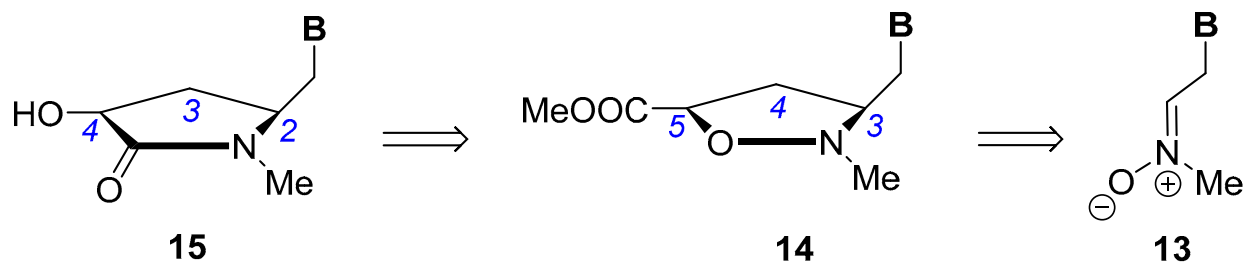

$\mathbf{B}=$ nucleobase

Scheme 1. Retrosynthesis of $\gamma$-lactam analogues of $1^{\prime}$-homonucleosides 15.

\section{Results and Discussion}

\subsection{Chemistry}

The synthetic strategy for $\gamma$-lactam homonucleosides 15 relies on the 1,3-dipolar cycloaddition of nucleobase-derived nitrones $\mathbf{1 3}$ with methyl acrylate, followed by the hydrogenolysis of the $\mathrm{N}-\mathrm{O}$ bond in an isoxazolidine scaffold, which was accompanied by the intramolecular cyclization to transform cycloadducts 14 into compounds 15 (Scheme 1).

Nucleobase-derived nitrones 13 were synthesized from $\mathrm{N}$-(2-oxoethyl)nucleobases and $\mathrm{N}$-methylhydroxylamine, as described previously $[45,46]$. The 1,3-dipolar cycloadditions of the nucleobase-derived nitrones 13 to methyl acrylate were carried out at $60{ }^{\circ} \mathrm{C}$ in methanol for $24 \mathrm{~h}$ (Scheme 2, Table 1) and afforded mixtures of diastereoisomeric isoxazolidines cis-14 and trans-14. The cis/trans ratios of the isoxazolidines were calculated from the ${ }^{1} \mathrm{H}-\mathrm{NMR}$ spectra of the crude reaction mixtures by the comparison of diagnostic resonances of the $\mathrm{H}_{2} \mathrm{C}-4$ protons in the isoxazolidine ring, as well as the signals of the respective protons of nucleobase moieties. In some cases, differences in resonances of the $\mathrm{CH}_{3}-\mathrm{N}$ protons for diastereoisomeric isoxazolidines cis-14 and trans-14 were also diagnostic. The crude reaction mixtures of the diastereoisomers were subjected to column chromatography; however, only pure isomeric isoxazolidines cis-14a and trans-14a were isolated (Table 1, entry a). In the other cases the respective fractions enriched in the isomers cis-14b-14i or trans-14b-14i were collected. The subsequent separation of diastereoisomeric mixture of isoxazolidines cis-14b-14h or trans-14b-14h on an HPLC column allowed us to obtain pure isomers cis-14b-14h and trans-14b-14h (Table 1 , entry $\mathrm{b}-\mathrm{h}$ ), and the amounts, however small, were sufficient to perform a full characterization of the newly-synthesized compounds and their further biological screening. Unfortunately, the attempts at separating diastereoisomeric isoxazolidines cis-14i and trans-14i appeared fruitless, even with HPLC.

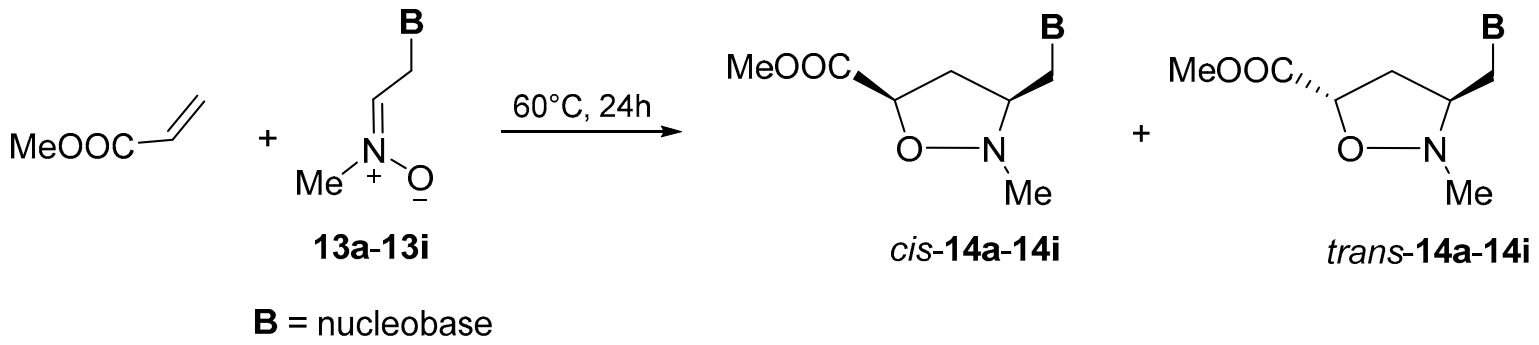

Scheme 2. Synthesis of isoxazolidine analogues of 1'-homonucleosides trans-14 and cis-14. 
Table 1. Isoxazolidines trans-14 and cis-14 obtained according to Scheme 2.

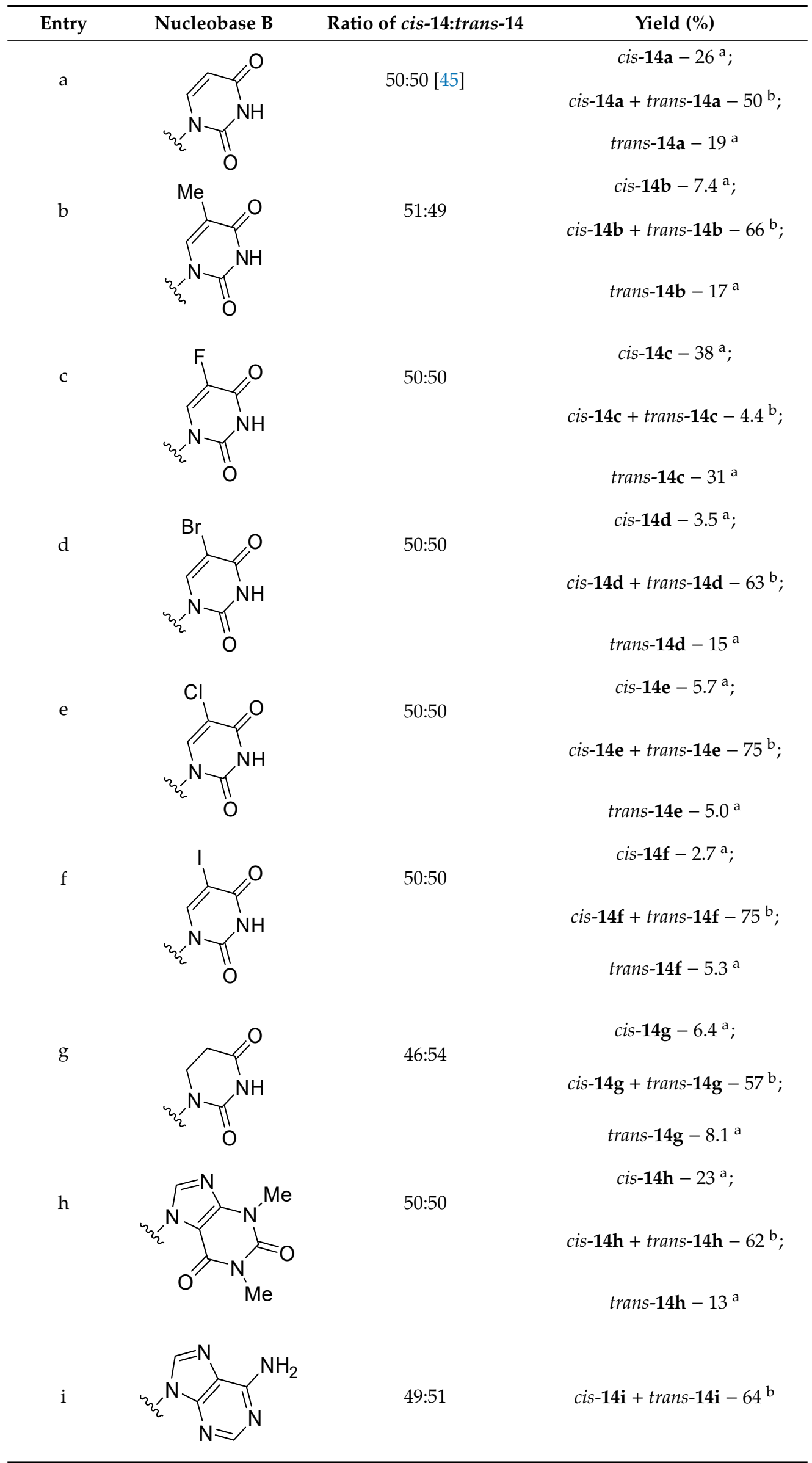

${ }^{a}$ Yield of a pure diastereoisomer; ${ }^{b}$ yield of a pure mixture of diastereoisomers; 
The relative configurations of isoxazolidines cis-14a and trans-14a have already been established [45]. As we have recently described, (5-methoxycarbonyl)isoxazolidine cis-14a was reduced with sodium borohydride in ethanol to the known (5-hydroxymethyl)isoxazolidine cis-16 [45] (Scheme 3). During this transformation, the structure of the isoxazolidine skeleton remains unchanged, and therefore, a relative configuration of the isoxazolidine cis-14a was unambiguously established. Consequently, the isomeric (5-methoxycarbonyl)isoxazolidine was identified as trans-14a. Since similar spectral patterns for the respective isoxazolidine protons ( $\mathrm{H} 3, \mathrm{H} 4 \alpha, \mathrm{H} 4 \beta$ and $\mathrm{H} 5$ ) were observed in series of cis-14b-14i and trans-14b-14i when compared to those observed for cycloadducts cis-14a and trans-14a, their configurations were analogously assigned.

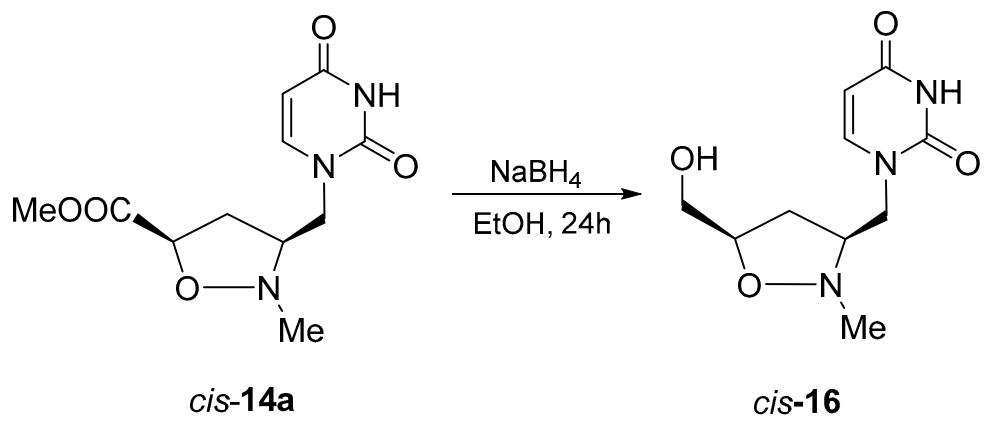

Scheme 3. Synthesis of the isoxazolidine cis-16 [45].

A detailed conformational analysis for isoxazolidines cis-14a-14i and trans-14a-14i was performed based on $\mathrm{HCCH}$ vicinal coupling constants extracted from the ${ }^{1} \mathrm{H}-\mathrm{NMR}$ spectra. The vicinal couplings for cis-14a-14f and cis-14h-14i $(J(\mathrm{H} 3-\mathrm{H} 4 \alpha)=7.6-8.4 \mathrm{~Hz}, J(\mathrm{H} 3-\mathrm{H} 4 \beta)=2.0-3.3 \mathrm{~Hz}, J(\mathrm{H} 4 \alpha-\mathrm{H} 5)=9.7-9.9$ $\mathrm{Hz}, J(\mathrm{H} 4 \beta-\mathrm{H} 5)=5.0-5.3 \mathrm{~Hz})$ suggest the ${ }^{2} E$ conformation of the isoxazolidine ring in which the sterically bulky nucleobase- $\mathrm{CH}_{2}$ units are located pseudoequatorially (Figure 5, structure 17). The coupling constant values extracted for trans-14a-14f and trans-14h-14i $(J(\mathrm{H} 3-\mathrm{H} 4 \alpha)=7.4-7.8 \mathrm{~Hz}, J(\mathrm{H} 3-\mathrm{H} 4 \beta)$ $=2.0-3.4 \mathrm{~Hz}, J(\mathrm{H} 4 \alpha-\mathrm{H} 5)=7.4-7.5 \mathrm{~Hz}, J(\mathrm{H} 4 \beta-\mathrm{H} 5)=8.7-9.0 \mathrm{~Hz})$ bring to mind the ${ }^{2} E$ conformation of the isoxazolidine ring in which the nucleobase- $\mathrm{CH}_{2}$ substituents again adopt pseudoequatorial positions (Figure 5, structure 18). Surprisingly, the preferred conformations for dihydrouacil-containing isoxazolidines cis-14g and trans-14g could not be assigned, and sets of couplings indicate the existence of conformational equilibrium of isoxazolidine ring.

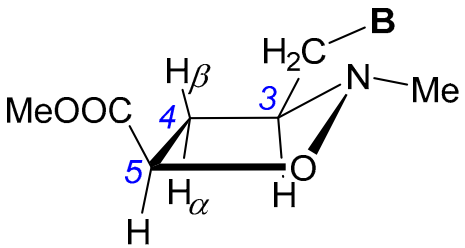

17

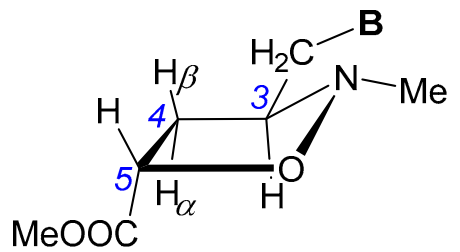

18

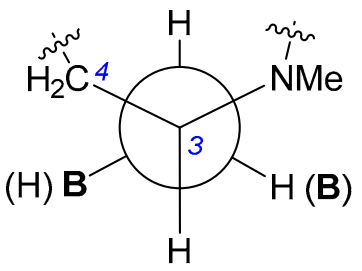

19

Figure 5. Preferred conformations 17 and 18 of isoxazolidines cis-14a-14i and trans-14a-14i, respectively, and the Newman projection 19.

For the either cis or trans isoxazolidines containing uracil or substituted uracil residues 14a-14f, we also noticed that diastereotopic hydrogen atoms in $\mathrm{CH}_{2}$-base units which resonate at a lower field (4.05-3.89 ppm) showed significantly smaller vicinal coupling constants to $\mathrm{H}-\mathrm{C} 3(3.3-3.9 \mathrm{~Hz})$ than those associated with higher field signals (3.59-3.32 ppm) when values of 9.1-9.7 Hz were observed. One may conclude that high-field hydrogens are antiperiplanar to $\mathrm{H}-\mathrm{C} 3$, while low-field ones are oriented gauche, as depicted by the Newman projection 19 (Figure 5). Although real reasons for the restricted 
rotation around $\mathrm{C} 3-\mathrm{CH}_{2}$ Base bond remain obscure to us at the moment, they may simply reflect repulsive interactions of sterically bulky $\mathrm{CH}_{2}$-base groups with $\mathrm{Me}-\mathrm{N}$ and $\mathrm{H} \beta-\mathrm{C} 4-\mathrm{H} \alpha$ fragments.

Finally, attempts at transformation of isoxazolidine cycloadducts cis-14/trans-14 into $\gamma$-lactam derivatives trans-15/cis-15 were made, following the procedure applied previously for transformation of cis-14a into trans-15g [45]. It was expected that since hydrogenation of the $\mathrm{N}-\mathrm{O}$ bond in the isoxazolidine scaffold releases the amino group, the subsequent intramolecular cyclization to $\gamma$-lactams trans-15/cis-15 should occur spontaneously (Scheme 4). Consequently, the isoxazolidine cis-14 would provide trans-15, while isoxazolidine trans-14 should be a substrate for the synthesis of cis-configured $\gamma$-lactam cis-15. With that in mind, we concluded that not only can pure diastereoisomers cis-14 and trans-14 be used for the synthesis of trans-15/cis-15, but so can mixtures of the respective isomers cis-14/trans-14, although significantly enriched in one diastereoisomer to maintain control on the stereochemistry of the products formed.

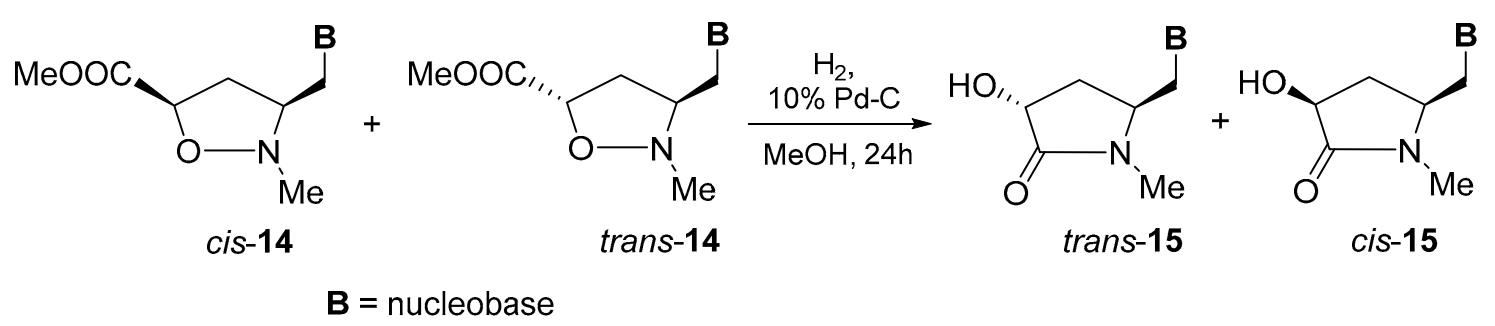

Scheme 4. Synthesis of $\gamma$-lactam analogues of $1^{\prime}$-homonucleosides trans-15 and cis-15.

As we recently reported [45], the hydrogenation of uracil-containing isoxazolidine homonucleoside cis-14a ( $\mathrm{B}=\mathrm{Ura}$ ) proceeded smoothly and the intramolecular cyclization of intermediary $\gamma$-aminocarboxylic ester to a $\gamma$-lactam was accompanied by hydrogenation of the uracil residue to produce the lactam trans-15g $(\mathrm{B}=\mathrm{diH}-\mathrm{Ura})$ in a good yield $(80 \%)$ instead of the expected compound trans-15a $(\mathrm{B}=\mathrm{Ura})$ (Table 2, entry a). Similarly, cis-15g $(\mathrm{B}=\mathrm{diH}-\mathrm{Ura})$ was obtained from trans-14a $(\mathrm{B}=\mathrm{Ura})(85 \%)$.

On the other hand, when a 80:20 mixture of thymine-containing isoxazolidines cis-14b and trans $\mathbf{- 1 4} \mathbf{b}(\mathrm{B}=$ Thy) was subjected to hydrogenation, the respective 80:20 mixture of $\gamma$-lactam trans-15b and cis-15b $(\mathrm{B}=$ Thy) was obtained. From this mixture pure diastereoisomers were isolated after column chromatography followed by HPLC (Table 2, entry b).

During the hydrogenation of 5-halogenated uracil derivatives cis-14/trans-14 (B = X-Ura), we faced the same problem as in case of uracil derivatives. Moreover, halogen atoms were removed from nucleobase skeletons. For example, hydrogenation of a 60:40 mixture of cis-14d and trans-14d isoxazolidines ( $\mathrm{B}=\mathrm{Br}-\mathrm{Ura}$ ) led to the formation of an inseparable mixture of trans-15a, cis-15a and trans-15g and cis-15g (53:35:8:2) (Table 2, entry d). Analogously, a mixture of trans-15a, cis-15a, trans-15g and cis-15g (4:2:74:20) was obtained from the 73:27 mixture of isoxazolidines cis-14e and trans-14e ( $\mathrm{B}=\mathrm{Cl}$-Ura) (Table 2, entry e). Similarly, hydrogenation of a cis-14c $(\mathrm{B}=\mathrm{F}-\mathrm{Ura})$ gave dihydrouracil-containing $\gamma$-lactam trans-15g ( $\mathrm{B}=$ diH-Ura) (Table 2, entry c).

Furthermore, the respective mixtures of isoxazolidines cis-14g/trans $-\mathbf{1 4 g}$, cis-14h/trans $-\mathbf{1 4 h}$ and cis-14i/trans-14i were successfully hydrogenated to provide $\gamma$-lactams containing dihydrouracil (trans-15g/cis-15g), theophylline (trans-15h/cis-15h) and adenine (trans-15i/cis-15i) as nucleobases (Table 2, entry g-i). 
Table 2. $\gamma$-Lactams trans-15 and cis-15 obtained according to Scheme 4.

\begin{tabular}{|c|c|c|c|c|}
\hline Entry & Nucleobase (B) & Substrates & Products & Yields [\%] \\
\hline \multirow{2}{*}{$\mathrm{a}$} & \multirow{2}{*}{ Ura } & cis-14a & trans-15g [45] & $80^{\mathrm{a}}$ \\
\hline & & trans-14a & cis-15g & $85^{\mathrm{a}}$ \\
\hline $\mathrm{b}$ & Thy & $\begin{array}{l}\text { cis-14b:trans-14b } \\
(80: 20)\end{array}$ & $\begin{array}{l}\text { trans-15b:cis-15b } \\
\quad(80: 20)\end{array}$ & 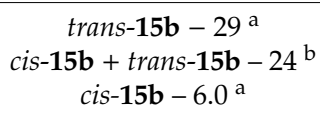 \\
\hline $\mathrm{c}$ & F-Ura & cis-14c & trans-15g & $70^{\mathrm{a}}$ \\
\hline d & Br-Ura & $\begin{array}{c}\text { cis-14d:trans-14d } \\
(60: 40)\end{array}$ & $\begin{array}{l}\text { trans-15a:cis-15a:trans-15g:cis-15g } \\
\qquad(53: 35: 8: 2)\end{array}$ & Inseparable $(77 \%)$ \\
\hline e & Cl-Ura & $\begin{array}{l}\text { cis-14e:trans-14e } \\
\text { (77:23) }\end{array}$ & $\begin{array}{l}\text { trans-15a:cis-15a:trans-15g:cis-15g } \\
\left(4: 2: 20: 74^{\mathrm{c}}\right)\end{array}$ & Inseparable $(80 \%)$ \\
\hline $\mathrm{f}$ & I-Ura & cis-14f:trans-14f & n.a. ${ }^{\mathrm{c}}$ & - \\
\hline g & Dihydro-Ura & $\begin{array}{l}\text { cis-14g:trans-14g } \\
\text { (86:14) }\end{array}$ & $\begin{array}{l}\text { trans-15g:cis-15g } \\
(81: 19)\end{array}$ & $\begin{array}{c}\text { trans }-\mathbf{1 5 g}-4.0^{a} \\
\text { cis-15g }+ \text { trans-15g-47 } \\
\text { cis-15g }-23^{\mathrm{a}}\end{array}$ \\
\hline \multirow[b]{2}{*}{$\mathrm{h}$} & \multirow[b]{2}{*}{ Theophylline } & cis-14h & trans-15h & trans $-15 \mathrm{~h}-41^{\mathrm{a}}$ \\
\hline & & $\begin{array}{l}\text { cis-14h:trans-14h } \\
\quad(77: 23)\end{array}$ & $\begin{array}{l}\text { trans-15h:cis-15h } \\
\quad(80: 20)\end{array}$ & $\begin{array}{c}\text { trans-15h }-34^{\mathrm{a}} \\
\text { cis-15h }+ \text { trans-15h }-10^{\mathrm{b}} \\
\operatorname{cis}^{-\mathbf{1 5}} \mathbf{h}-26^{\mathrm{a}}\end{array}$ \\
\hline \multirow{2}{*}{$\mathrm{i}$} & \multirow{2}{*}{ Ade } & $\begin{array}{l}\text { cis-14i:trans-14i } \\
(85: 15)\end{array}$ & $\begin{array}{l}\text { trans-15i:cis-15i } \\
87: 13\end{array}$ & $\begin{array}{c}\text { trans-15i }-28^{\mathrm{a}} \\
\text { cis-15i }+ \text { trans-15i }-7.3^{\mathrm{b}}\end{array}$ \\
\hline & & $\begin{array}{l}\text { cis-14i: } \text { trans-14i } \\
(42: 58)\end{array}$ & $\begin{array}{c}\text { trans-15i:cis-15i } \\
46: 54\end{array}$ & cis- $\mathbf{1 5} \mathbf{i}+$ trans $-\mathbf{1 5 i}-55^{b}$ \\
\hline
\end{tabular}

${ }^{a}$ Yield of a pure diastereoisomer; ${ }^{b}$ yield of a pure mixture of diastereoisomers; ${ }^{c}$ not applied: since the dehalogenation of 5-halogenated uracil derivatives 14c, 14d and 14e was observed, the hydrogenation of 5-iodouracil derivatives cis-14f/trans-14f was not performed.

To supplement a library of designed $\gamma$-lactam homonucleosides trans-15/cis-15 with analogues having bromine (trans-15d/cis-15d) and chlorine (trans-15e/cis-15e) atoms, the halogenation of uracil derivatives was proposed [59-61]. Treatment of the above-mentioned (Table 1, entry d), inseparable mixture of $\gamma$-lactams trans-15a, cis-15a, trans-15g and trans-15g (53:35:8:2) with $N$-bromosuccinimide (NBS) [59] led to the formation of the mixture of $\gamma$-lactams trans-15d, cis-15d, together with unreacted trans-15g and cis-15g (50:37:9:4) (Scheme 5). The purification of this mixture on a silica gel column followed by HPLC allowed us to isolate trans-15d and cis-15d in 30\% and 9.3\% yields, respectively. Similarly, the reaction of an analogous mixture of trans-15a, cis-15a, trans-15g and cis-15g with $\mathrm{N}$-chlorosuccinimide (NCS) [60] gave the respective mixture of compounds trans-15e, cis-15e, trans-15g and cis-15g (55:34:8:3), from which trans-15e and cis-15e were obtained in $6 \%$ and $4.2 \%$ yields, respectively (Scheme 5).

\subsection{Antiviral and Cytostatic Evaluation}

\subsubsection{Antiviral Activity}

All isoxazolidines 14 and $\gamma$-lactams 15 obtained were evaluated for their activities against a wide variety of DNA and RNA viruses using the following cell-based assays: (a) human embryonic lung (HEL) cell cultures: herpes simplex virus-1 (KOS strain), herpes simplex virus-2 (G strain), vaccinia virus, thymidine kinase deficient (acyclovir-resistant) herpes simplex virus- 1 (TK- $\mathrm{KOS} \mathrm{ACV}^{\mathrm{r}}$ ), adenovirus-2, human coronavirus (229E strain), cytomegalovirus (AD-169 and Davis strains) and varicella-zoster virus ( $\mathrm{TK}^{+} \mathrm{VZV}$ and $\mathrm{TK}^{-}$VZV strains); (b) HeLa cell cultures: vesicular stomatitis virus, Coxsackie virus B4 and respiratory syncytial virus; (c) Vero cell cultures: para-influenza-3 virus, reovirus-1, Sindbis virus, Coxsackie virus B4, Punta Toro virus and yellow fever virus; and (d) MDCK cell cultures: influenza A virus (H1N1 and H3N2 subtypes) and influenza B virus. Ganciclovir, cidofovir, acyclovir, brivudin, zalcitabine, zanamivir, alovudine, mycophenolic acid, amantadine, 
rimantadine, ribavirin, dextran sulfate (molecular weight 10000, DS-10000) and Urtica dioica agglutinin (UDA) were used as the reference compounds. The antiviral activity was expressed as the $\mathrm{EC}_{50}$ : the compound concentration required to reduce virus plaque formation (VZV) by $50 \%$ or to reduce virus-induced cytopathicity by $50 \%$ (other viruses). The cytotoxicity of the compounds tested toward the uninfected host cells was defined as the minimum cytotoxic concentration (MCC) that causes a microscopically detectable alteration of normal cell morphology. The $50 \%$ cytotoxic concentration $\left(\mathrm{CC}_{50}\right)$, causing a $50 \%$ decrease in cell viability was determined using a colorimetric MTS assay system. None of the tested compounds showed appreciable antiviral activity toward any of the tested DNA and RNA viruses at the concentration up to $100 \mu \mathrm{M}$. At the same time, none of them affected the cell morphologies of used uninfected host cells.<smiles>CCCCCCCN1C(=O)[C@@H](O)C[C@H]1Cn1ccc(=O)[nH]c1=O</smiles><smiles>CC(C)(C)N1C(=O)[C@H](O)C[C@H]1Cn1ccc(=O)[nH]c1=O</smiles><smiles>CN1C(=O)C(O)C[C@H]1CN1CCC(=O)NC1=O</smiles>

trans-15g/cis-15g NBS, DMF, rt, 24h (for trans-15d/cis-15d) or NCS, Pyridine, $100^{\circ} \mathrm{C}, 1 \mathrm{~h}$ (for trans-15e/cis-15e)<smiles>[Y]c1cn(C[C@@H]2C[C@H](O)C(=O)N2C)c(=O)[nH]c1=O</smiles>

trans-15e<smiles>[X]c1cn(C[C@@H]2C[C@H](O)C(=O)N2C)c(=O)[nH]c1=O</smiles>

cis-15d<smiles>CN1C(=O)C(O)C[C@H]1CN1CCC(=O)NC1=O</smiles>
trans-15g/cis-15g

\subsubsection{Cytostatic Activity}

The $50 \%$ cytostatic inhibitory concentration $\left(\mathrm{IC}_{50}\right)$ causing a $50 \%$ decrease in cell proliferation was determined for all isolated isoxazolidines 14 and $\gamma$-lactams 15 toward nine cancerous cell lines (Capan-1 (pancreatic adenocarcinoma), Hap1 (chronic myeloid leukemia), HCT-116 (colorectal carcinoma), NCI-H460 (lung carcinoma), DND-41 (acute lymphoblastic leukemia), HL-60 (acute myeloid leukemia), K-562 (chronic myeloid leukemia), MM.1S (multiple myeloma) and Z-138 (non-Hodgkin lymphoma)) and normal retina (non-cancerous) cells (hTERT RPE-1). Docetaxel, etoposide and stauroporine were used as the reference compounds.

All of the compounds tested were not toxic to non-cancerous retina cells (hTERT RPE-1) at concentrations up to $100 \mu \mathrm{M}$. They were also not active against DND-41, HL-60, K-562, MM.1S or Z-138 cancer cells. All isoxazolidines 14 and $\gamma$-lactams 15 we tested, except cis-14c (B = F-Ura), exhibited moderate activity against pancreatic adenocarcinoma cells (Capan-1) $\left(\mathrm{IC}_{50}=18.2\right.$ to $\left.95 \mu \mathrm{M}\right)$, and among 
them, $\gamma$-lactams trans-15e (Cl-Ura) and cis-15h (Theo) were the most active, with $\mathrm{IC}_{50}$ values of 21.5 and $18.2 \mu \mathrm{M}$, respectively (Table 3). In most cases, both cis-configured isoxazolidines $\mathbf{1 4}$ and cis-configured $\gamma$-lactams 15 were slightly less active when compared to the respective trans-isomers (e.g., cis-14b-f versus trans-14b-f, cis-14h-i versus trans-14h-I and cis-15b versus trans-15b, cis-15d vs. trans-15d); however, that correlation did to apply for uracil, dihydrouracil and theophiline-derivatives 14a, 15g and 15h. Moreover, several isoxazolidines 14 and $\gamma$-lactams 15 inhibited the proliferation of Hap1 $\left(\mathrm{IC}_{50}=40.9\right.$ to $\left.58.5 \mu \mathrm{M}\right), \mathrm{HCT}-116\left(\mathrm{IC}_{50}=26.7\right.$ to $\left.68,4 \mu \mathrm{M}\right)$ and NCI-H460 cells ( $\mathrm{IC}_{50}=28.6$ to $\left.62.3 \mu \mathrm{M}\right)$ (Table 3).

Table 3. Inhibitory effect of isoxazolidines 14 and $\gamma$-lactams 15 against the proliferation of cancerous cells.

\begin{tabular}{|c|c|c|c|c|c|c|}
\hline \multirow{3}{*}{ Base } & \multirow{3}{*}{ Compound } & \multicolumn{5}{|c|}{$\mathrm{IC}_{50}(\mu \mathrm{M})$} \\
\hline & & hTERT RPE-1 & Capan-1 & Hap1 & НCT-116 & NCI-H460 \\
\hline & & $\begin{array}{l}\text { Retina (Non } \\
\text { Cancerous) }\end{array}$ & $\begin{array}{c}\text { Pancreatic } \\
\text { Adenocarcinoma }\end{array}$ & $\begin{array}{c}\text { Chronic Myeloid } \\
\text { Leukemia }\end{array}$ & $\begin{array}{l}\text { Colorectal } \\
\text { Carcinoma }\end{array}$ & $\begin{array}{c}\text { Lung } \\
\text { Carcinoma }\end{array}$ \\
\hline Ura & cis-14a & $>100$ & 54.8 & $>100$ & $>100$ & $>100$ \\
\hline Ura & trans-14a & $>100$ & 62.6 & $>100$ & $>100$ & 90.3 \\
\hline Thy & cis-14b & $>100$ & 55.2 & 63.0 & $>100$ & 60.3 \\
\hline Thy & trans $-\mathbf{1 4 b}$ & $>100$ & 51.3 & $>100$ & $>100$ & $>100$ \\
\hline F-Ura & cis-14c & $>100$ & $>100$ & $>100$ & $>100$ & $>100$ \\
\hline F-Ura & trans-14c & $>100$ & 49.0 & $>100$ & $>100$ & $>100$ \\
\hline Br-Ura & cis-14d & $>100$ & 95.0 & $>100$ & 86.4 & 62.3 \\
\hline Br-Ura & trans-14d & $>100$ & 67.8 & $>100$ & $>100$ & 76.1 \\
\hline Cl-Ura & cis-14e & $>100$ & 51.2 & 44.2 & 26.7 & 48.8 \\
\hline Cl-Ura & trans-14e & $>100$ & 38.5 & 42.7 & 43.5 & 41.9 \\
\hline I-Ura & cis-14f & 97.1 & 42.0 & 40.9 & 57.9 & 44.6 \\
\hline I-Ura & trans-14f & $>100$ & 41.4 & 47.0 & 53.5 & 41.1 \\
\hline dihydro-Ura & trans-14g & $>100$ & 38.3 & 58.1 & 61.0 & 48.6 \\
\hline Theo & cis-14h & $>100$ & 62.2 & 45.1 & 49.0 & 33.2 \\
\hline Theo & trans $-\mathbf{1 4 h}$ & $>100$ & 43.2 & 53.6 & 60.9 & 51.2 \\
\hline Ade & $\begin{array}{c}\text { cis-14i:trans-14i } \\
(99: 1)\end{array}$ & $>100$ & 73.5 & $>100$ & $>100$ & $>100$ \\
\hline Ade & $\begin{array}{c}\text { cis-14i:trans-14i } \\
(36: 64)\end{array}$ & $>100$ & 58.1 & $>100$ & 68.4 & 85.7 \\
\hline Thy & $\begin{array}{c}\text { cis-15b:trans-15b } \\
(64: 36)\end{array}$ & $>100$ & 58.0 & $>100$ & $>100$ & 50.0 \\
\hline Thy & trans $-\mathbf{1 5 b}$ & $>100$ & 49.2 & 86.5 & 53.3 & 55.6 \\
\hline Br-Ura & $\begin{array}{c}\text { cis-15d:trans-15d } \\
(53: 47)\end{array}$ & $>100$ & 52.1 & 49.9 & 90.0 & 49.4 \\
\hline Br-Ura & trans-15d & $>100$ & 24.8 & 58.5 & $>100$ & 42.1 \\
\hline Cl-Ura & cis-15e & $>100$ & 28.0 & 51.5 & 58.5 & 28.6 \\
\hline Cl-Ura & trans-15e & $>100$ & 18.2 & 54.5 & $>100$ & 47.7 \\
\hline dihydro-Ura & cis-15g & $>100$ & 41.3 & 56.3 & $>100$ & 42.7 \\
\hline dihydro-Ura & trans-15g & $>100$ & 46.7 & 49.4 & $>100$ & 69.3 \\
\hline Theo & cis-15h & $>100$ & 21.5 & 50.2 & 43.5 & 42.5 \\
\hline Theo & trans $-\mathbf{1 5 h}$ & $>100$ & 47.2 & $>100$ & 45.7 & 49.8 \\
\hline Ade & trans-15i & $>100$ & 53.7 & 47.8 & 65.7 & 54.7 \\
\hline Docetaxel & Docetaxel & 25.0 & 0.95 & 1.19 & 0.25 & 0.89 \\
\hline Etoposide & Etoposide & 0.23 & 0.15 & 0.04 & 1.03 & 1.35 \\
\hline Stauroporine & Stauroporine & 0.25 & 0.66 & 3.55 & 0.09 & 11.50 \\
\hline
\end{tabular}

\section{Experimental Section}

\subsection{General}

${ }^{1} \mathrm{H}-\mathrm{NMR}$ spectra were taken in $\mathrm{CDCl}_{3}, \mathrm{CD}_{3} \mathrm{OD}, \mathrm{D}_{2} \mathrm{O}$ and DMSO on the following spectrometers: Varian Gemini 2000BB (200 MHz), Varian Mercury-300 and Bruker Avance III spectrometers (600 MHz) with TMS as internal standard. ${ }^{13} \mathrm{C}$-NMR spectra were recorded in $\mathrm{CDCl}_{3}, \mathrm{CD}_{3} \mathrm{OD}, \mathrm{D}_{2} \mathrm{O}$ and DMSO on the Bruker Avance III spectrometer (at $150 \mathrm{MHz}$, Bruker Instruments, Karlsruhe, Germany) and a Varian Mercury-300 machine (Varian NMR Instrument, Palo Alto, CA, USA) at 75 MHz. IR spectra were measured on a Bruker Alpha-T FT-IR spectrometer (Bruker Optik GmbH, Ettlingen, Germany). Melting points were determined on Boetius apparatus and are reported uncorrected. Elemental analyses were performed by the Microanalytical Laboratory of our faculty on a Perkin-Elmer PE 2400 CHNS analyzer (Perkin-Elmer Corp., Norwalk, CT, USA). The following adsorbents were used: 
column chromatography, Merck silica gel 60 (70-230 mesh), analytical TLC, Merck TLC plastic sheets and silica gel $60 \mathrm{~F}_{254}$. The preparative HPLC experiment was performed on a Waters chromatograph equipped with a Waters 2545 binary gradient module (Waters Corporation, Milford, MA, USA) and a Waters 2998 photodiode array detector (190-600 nm).

${ }^{1} \mathrm{H}$ - and ${ }^{13} \mathrm{C}-\mathrm{NMR}$ spectra of all new synthesized compounds are provided in Supplementary Materials.

\subsection{General Procedure for the Synthesis of Isoxazolidines cis-14 and trans-14}

To a solution of a nitrone $(1.00 \mathrm{mmol})$ in methanol $(9 \mathrm{~mL})$, methyl acrylate $(10.0 \mathrm{~mL})$ was added. The mixture was stirred at $60^{\circ} \mathrm{C}$ for $24 \mathrm{~h}$. The solvent was removed in vacuo and crude products were purified on silica gel columns using chloroform-methanol (100:1, 50:1, 20:1, 10:1, v/v) as eluents. The respective fractions were subjected to HPLC on a X Bridge Prep, C18, $5 \mu \mathrm{m}$, OBD, $19 \times 100 \mathrm{~mm}$ column using water/methanol $(90: 10,85: 15, v / v)$ to afford pure isoxazolidines.

Methyl cis-3-\{[2,4-dioxo-3,4-dihydropyrimidin-1(2H)-yl]methyl\}-2-methylisoxazolidine-5-carboxylate (cis-14a). Yield: $26 \%$; a colorless amorphous solid; m.p. $=107-108^{\circ} \mathrm{C}$ (crystallized from chloroform-methanol). IR $\left(\mathrm{KBr}, \mathrm{cm}^{-1}\right) v_{\max }: 3478,3196,3097,3054,2958,1684,1457,1376,1252,1214,1078,811 ;{ }^{1} \mathrm{H}-\mathrm{NMR}(200$ $\left.\mathrm{MHz} \mathrm{CDCl}_{3}\right)$ ) $: 9.84(\mathrm{br} \mathrm{s}, 1 \mathrm{H}, \mathrm{NH}), 7.37\left(\mathrm{~d}, 1 \mathrm{H},{ }^{3} \mathrm{~J}=7.8 \mathrm{~Hz}\right), 5.67\left(\mathrm{~d}, 1 \mathrm{H},{ }^{3} \mathrm{~J}=7.8 \mathrm{~Hz}\right), 4.74(\mathrm{dd}, 1 \mathrm{H}$, $\left.{ }^{3} J_{(\mathrm{H} 5-\mathrm{H} 4 \alpha)}=9.9 \mathrm{~Hz},{ }^{3} J_{(\mathrm{H} 5-\mathrm{H} 4 \beta)}=5.1 \mathrm{~Hz}, \mathrm{HC} 5\right), 3.93\left(\mathrm{dd}, 1 \mathrm{H},{ }^{2} J_{(\mathrm{HCH})}=12.9 \mathrm{~Hz},{ }^{3} J_{(\mathrm{HCC}-\mathrm{H} 3)}=3.3 \mathrm{~Hz}\right.$, HCH-Ura), $3.78\left(\mathrm{~s}, 3 \mathrm{H}, \mathrm{C}(\mathrm{O}) \mathrm{OCH}_{3}\right), 3.55\left(\mathrm{dd}, 1 \mathrm{H},{ }^{2} J_{(\mathrm{HCH})}=12.9 \mathrm{~Hz},{ }^{3} J_{(\mathrm{HCC}-\mathrm{H} 3)}=9.6 \mathrm{~Hz}, \mathrm{HCH}-\mathrm{Hra}\right)$, $3.47\left(\mathrm{dddd}, 1 \mathrm{H},{ }^{3} J_{(\mathrm{H} 3-\mathrm{CCH})}=9.6 \mathrm{~Hz},{ }^{3} J_{(\mathrm{H} 3-\mathrm{H} 4 \alpha)}=7.8 \mathrm{~Hz},{ }^{3} J_{(\mathrm{H} 3-\mathrm{CCH})}=3.3 \mathrm{~Hz},{ }^{3} J_{(\mathrm{H} 3-\mathrm{H} 4 \beta)}=2.4 \mathrm{~Hz}, \mathrm{HC} 3\right)$, $2.86\left(\mathrm{ddd}, 1 \mathrm{H},{ }^{2} J_{(\mathrm{H} 4 \alpha-\mathrm{H} 4 \beta)}=13.5 \mathrm{~Hz},{ }^{3} J_{(\mathrm{H} 4 \alpha-\mathrm{H} 5)}=9.9 \mathrm{~Hz},{ }^{3} J_{(\mathrm{H} 4 \alpha-\mathrm{H} 3)}=7.8 \mathrm{~Hz}, \mathrm{H}_{\alpha} \mathrm{C} 4\right), 2.62(\mathrm{~s}, 3 \mathrm{H}$, $\left.\mathrm{CH}_{3} \mathrm{~N}\right), 2.17\left(\mathrm{ddd}, 1 \mathrm{H},{ }^{2} J_{(\mathrm{H} 4 \beta-\mathrm{H} 4 \alpha)}=13.5 \mathrm{~Hz},{ }^{3} J_{(\mathrm{H} 4 \beta-\mathrm{H} 5)}=5.1 \mathrm{~Hz},{ }^{3} J_{(\mathrm{H} 4 \beta-\mathrm{H} 3)}=2.4 \mathrm{~Hz}, \mathrm{H}_{\beta} \mathrm{C} 4\right) ;{ }^{13} \mathrm{C}-\mathrm{NMR}$ $\left(75 \mathrm{MHz}, \mathrm{CDCl}_{3}\right)$ 8: $171.45\left(\mathrm{C}(\mathrm{O}) \mathrm{OCH}_{3}\right), 164.29\left(\mathrm{C}^{\prime}\right), 151.34\left(\mathrm{C2}^{\prime}\right), 146.82\left(\mathrm{C}^{\prime}\right), 101.45\left(\mathrm{C}^{\prime}\right), 74.52(\mathrm{C} 5)$, $65.48(\mathrm{C} 3), 52.90\left(\mathrm{C}(\mathrm{O}) \mathrm{OCH}_{3}\right), 50.82\left(\mathrm{CH}_{2}-\mathrm{Ura}\right), 44.59\left(\mathrm{CH}_{3} \mathrm{~N}\right), 34.95(\mathrm{C} 4)$. Anal. Calcd for $\mathrm{C}_{11} \mathrm{H}_{15} \mathrm{~N}_{3} \mathrm{O}_{5}$ : C, $49.07 ; \mathrm{H}, 5.62 ; \mathrm{N}, 15.61$. Found: $\mathrm{C}, 48.99 ; \mathrm{H}, 5.82 ; \mathrm{N}, 15.80$.

Methyl trans-3-\{[2,4-dioxo-3,4-dihydropyrimidin-1(2H)-yl]methyl\}-2-methylisoxazolidine-5-carboxylate (trans-14a). Yield: 19\%; a colorless amorphous solid; m.p. $=151-152{ }^{\circ} \mathrm{C}$ (crystallized from chloroform-methanol). IR (KBr, cm $\left.{ }^{-1}\right) v_{\max }: 3192,3045,2961,2830,1730,1704,1675,1451,1212,1088$, 1039, 914; ${ }^{1} \mathrm{H}-\mathrm{NMR}\left(600 \mathrm{MHz}, \mathrm{CDCl}_{3}\right)$ ): $9.47(\mathrm{br} \mathrm{s}, 1 \mathrm{H}, \mathrm{NH}), 7.30\left(\mathrm{~d}, 1 \mathrm{H},{ }^{3} \mathrm{~J}=7.9 \mathrm{~Hz}\right), 5.68\left(\mathrm{~d}, 1 \mathrm{H},{ }^{3} \mathrm{~J}=\right.$ $7.9 \mathrm{~Hz}), 4.54\left(\mathrm{dd}, 1 \mathrm{H},{ }^{3} J_{(\mathrm{H} 5-\mathrm{H} 4 \beta)}=9.0 \mathrm{~Hz},{ }^{3} J_{(\mathrm{H} 5-\mathrm{H} 4 \alpha)}=7.4 \mathrm{~Hz}, \mathrm{HC} 5\right), 4.02\left(\mathrm{dd}, 1 \mathrm{H},{ }^{2} J_{(\mathrm{HCH})}=13.9 \mathrm{~Hz}\right.$, $\left.{ }^{3} J_{(\mathrm{HCC}-\mathrm{H} 3)}=3.8 \mathrm{~Hz}, \mathrm{HCH}-\mathrm{Ura}\right), 3.79\left(\mathrm{~s}, 3 \mathrm{H}, \mathrm{C}(\mathrm{O}) \mathrm{OCH}_{3}\right), 3.49\left(\mathrm{dddd}, 1 \mathrm{H},{ }^{3} J_{(\mathrm{H} 3-\mathrm{CCH})}=9.3 \mathrm{~Hz},{ }^{3} J_{(\mathrm{H} 3-\mathrm{H} 4 \alpha)}\right.$ $\left.=7.4 \mathrm{~Hz},{ }^{3} J_{(\mathrm{H} 3-\mathrm{CCH})}=3.8 \mathrm{~Hz},{ }^{3} J_{(\mathrm{H} 3-\mathrm{H} 4 \beta)}=2.4 \mathrm{~Hz} \mathrm{HC} 3\right), 3.36\left(\mathrm{dd}, 1 \mathrm{H},{ }^{2} J_{(\mathrm{HCH})}=13.9 \mathrm{~Hz},{ }^{3} J_{(\mathrm{HCC}-\mathrm{H} 3)}\right.$ $=9.3 \mathrm{~Hz}, \mathrm{HCH}-\mathrm{Ura}), 2.81\left(\mathrm{ddd}, 1 \mathrm{H},{ }^{2} J_{(\mathrm{H} 4 \alpha-\mathrm{H} 4 \beta)}=13.3 \mathrm{~Hz},{ }^{3} J_{(\mathrm{H} 4 \alpha-\mathrm{H} 5)}=7.4 \mathrm{~Hz},{ }^{3} J_{(\mathrm{H} 4 \alpha-\mathrm{H} 3)}=7.4 \mathrm{~Hz}\right.$, $\left.\mathrm{H}_{\alpha} \mathrm{C} 4\right), 2.68\left(\mathrm{~s}, 3 \mathrm{H}, \mathrm{CH}_{3} \mathrm{~N}\right), 2.38\left(\mathrm{ddd}, 1 \mathrm{H},{ }^{2} J_{(\mathrm{H} \beta 4-\mathrm{H} \alpha 4)}=13.3 \mathrm{~Hz},{ }^{3} J_{(\mathrm{H} 4 \beta-\mathrm{H} 5)}=9.0 \mathrm{~Hz},{ }^{3} J_{(\mathrm{H} 4 \beta-\mathrm{H} 3)}=2.4\right.$ $\left.\mathrm{Hz}, \mathrm{H}_{\beta} \mathrm{C} 4\right) ;{ }^{13} \mathrm{C}-\mathrm{NMR}\left(150 \mathrm{MHz}, \mathrm{CDCl}_{3}\right) \delta: 172.33\left(\mathrm{C}(\mathrm{O}) \mathrm{OCH}_{3}\right), 163.84\left(\mathrm{C}^{\prime}\right), 151.14\left(\mathrm{C}^{\prime}\right), 146.27\left(\mathrm{C}^{\prime}\right)$, $101.50\left(\mathrm{C}^{\prime}\right), 76.28(\mathrm{C} 5), 65.73(\mathrm{C} 3), 52.58\left(\mathrm{C}(\mathrm{O}) \mathrm{OCH}_{3}\right), 49.97\left(\mathrm{CH}_{2}-\mathrm{Ura}\right), 45.66\left(\mathrm{CH}_{3} \mathrm{~N}\right), 34.64(\mathrm{C} 4)$. Anal. Calcd for $\mathrm{C}_{11} \mathrm{H}_{15} \mathrm{~N}_{3} \mathrm{O}_{5} \times 0.25 \mathrm{H}_{2} \mathrm{O}: \mathrm{C}, 48.26 ; \mathrm{H}, 5.71 ; \mathrm{N}, 15.35$. Found: $\mathrm{C}, 48.10 ; \mathrm{H}, 5.53 ; \mathrm{N}, 15.02$.

Methyl cis-2-methyl-3-\{[5-methyl-2,4-dioxo-3,4-dihydropyrimidin-1(2H)-yl]methyllisoxazolidine-5-carboxylate (cis-14b). Yield: 7.4\%; a colorless amorphous solid; m.p. $=73-74{ }^{\circ} \mathrm{C}$ (crystallized from chloroform-methanol). IR ( $\left.\mathrm{KBr}, \mathrm{cm}^{-1}\right) v_{\max }: 3168,3037,2955,2893,2830,1746,1701,1469,1437,1214$, 1074, 891; ${ }^{1} \mathrm{H}-\mathrm{NMR}\left(200 \mathrm{MHz}, \mathrm{CDCl}_{3}\right) \delta: 8.63(\mathrm{br} \mathrm{s}, 1 \mathrm{H}, \mathrm{NH}), 7.15\left(\mathrm{q}, 1 \mathrm{H},{ }^{4} J=1.1 \mathrm{~Hz}\right), 3.82(\mathrm{dd}, 1 \mathrm{H}$, $\left.{ }^{3} J_{(\mathrm{H} 5-\mathrm{H} 4 \alpha)}=9.8 \mathrm{~Hz},{ }^{3} J_{(\mathrm{H} 5-\mathrm{H} 4 \beta)}=5.2 \mathrm{~Hz}, \mathrm{HC} 5\right), 3.82\left(\mathrm{dd}, 1 \mathrm{H},{ }^{2} J_{(\mathrm{HCH})}=12.9 \mathrm{~Hz},{ }^{3} J_{(\mathrm{HCC}-\mathrm{H} 3)}=3.3 \mathrm{~Hz}\right.$, HCH-Thy), 3.79 (s, 3H, C(O)OCH $\left.)_{3}\right), 3.55-3.45(\mathrm{~m}, 2 \mathrm{H}, \mathrm{HCH}-\mathrm{Thy}, \mathrm{HC} 3), 2.86\left(\mathrm{ddd}, 1 \mathrm{H},{ }^{2} J_{(\mathrm{H} 4 \alpha-\mathrm{H} 4 \beta)}=\right.$ $\left.13.6 \mathrm{~Hz},{ }^{3} J_{(\mathrm{H} 4 \alpha-\mathrm{H} 5)}=9.8 \mathrm{~Hz},{ }^{3} J_{(\mathrm{H} 4 \alpha-\mathrm{H} 3)}=7.6 \mathrm{~Hz}, \mathrm{H}_{\alpha} \mathrm{C} 4\right), 2.61\left(\mathrm{~s}, 3 \mathrm{H}, \mathrm{CH}_{3} \mathrm{~N}\right), 2.17\left(\mathrm{ddd}, 1 \mathrm{H},{ }^{2} J_{(\mathrm{H} 4 \beta-\mathrm{H} 4 \alpha)}\right.$ $\left.=13.6 \mathrm{~Hz},{ }^{3} J_{(\mathrm{H} 4 \beta-\mathrm{H} 5)}=5.2 \mathrm{~Hz},{ }^{3} J_{(\mathrm{H} 4 \beta-\mathrm{H} 3)}=2.1 \mathrm{~Hz}, \mathrm{H}_{\beta} \mathrm{C} 4\right), 1.91\left(\mathrm{~d}, 3 \mathrm{H},{ }^{4} J=1.1 \mathrm{~Hz}, \mathrm{CH}_{3}\right) ;{ }^{13} \mathrm{C}-\mathrm{NMR}$ $\left(150 \mathrm{MHz}, \mathrm{CDCl}_{3}\right)$ ): $171.45\left(\mathrm{C}(\mathrm{O}) \mathrm{OCH}_{3}\right), 164.16\left(\mathrm{C}^{\prime}\right), 150.97\left(\mathrm{C2}^{\prime}\right), 142.62\left(\mathrm{C}^{\prime}\right), 109.69\left(\mathrm{C}^{\prime}\right), 74.37$ (C5), $65.47(\mathrm{C} 3), 52.63\left(\mathrm{C}(\mathrm{O}) \mathrm{OCH}_{3}\right), 50.76\left(\mathrm{CH}_{2}-\mathrm{Thy}\right), 44.49\left(\mathrm{CH}_{3} \mathrm{~N}\right), 34.83(\mathrm{C} 4), 12.83\left(\mathrm{CH}_{3}\right)$. Anal. Calcd for $\mathrm{C}_{12} \mathrm{H}_{17} \mathrm{~N}_{3} \mathrm{O}_{5}$ : C, 50.88; H, 6.05; N, 14.83. Found: $\mathrm{C}, 50.83 ; \mathrm{H}, 5.86 ; \mathrm{N}, 14.86$. 
Methyl trans-2-methyl-3-\{[5-methyl-2,4-dioxo-3,4-dihydropyrimidin-1(2H)-yl]methyl\}isoxazolidine-5carboxylate (trans-14b). Yield: 17\%; a colorless amorphous solid; m.p. $=139-140{ }^{\circ} \mathrm{C}$ (crystallized from chloroform-methanol). IR (KBr, cm $\left.{ }^{-1}\right) v_{\text {max }}$ : 3472, 3175, 3038, 2958, 2929, 2855, 2822, 1745, 1688, 1468, 1436, 1202, 1058; ${ }^{1} \mathrm{H}-\mathrm{NMR}\left(600 \mathrm{MHz}, \mathrm{CDCl}_{3}\right) \delta: 8.59$ (br s, 1H, NH), $7.13(\mathrm{~s}, 1 \mathrm{H}), 4.56\left(\mathrm{dd}, 1 \mathrm{H},{ }^{3} J_{(\mathrm{H} 5-\mathrm{H} 4 \beta)}\right.$ $\left.=8.9 \mathrm{~Hz},{ }^{3} J_{(\mathrm{H} 5-\mathrm{H} 4 \alpha)}=7.4 \mathrm{~Hz}, \mathrm{HC} 5\right), 3.98\left(\mathrm{dd}, 1 \mathrm{H},{ }^{2} J_{(\mathrm{HCH})}=13.8 \mathrm{~Hz},{ }^{3} J_{(\mathrm{HCC}-\mathrm{H} 3)}=3.9 \mathrm{~Hz}, \mathrm{HCH}-\mathrm{Thy}\right)$, $3.81\left(\mathrm{~s}, 3 \mathrm{H}, \mathrm{C}(\mathrm{O}) \mathrm{OCH}_{3}\right), 3.50\left(\mathrm{dddd}, 1 \mathrm{H},{ }^{3} J_{(\mathrm{H} 3-\mathrm{CCH})}=9.1 \mathrm{~Hz},{ }^{3} J_{(\mathrm{H} 3-\mathrm{H} 4 \alpha)}=7.4 \mathrm{~Hz},{ }^{3} J_{(\mathrm{H} 3-\mathrm{CCH})}=3.9 \mathrm{~Hz}\right.$, $\left.{ }^{3} J_{(\mathrm{H} 3-\mathrm{H} 4 \beta)}=2.6 \mathrm{~Hz}, \mathrm{HC} 3\right), 3.36\left(\mathrm{dd}, 1 \mathrm{H},{ }^{2} \mathrm{~J}_{(\mathrm{HCH})}=13.8 \mathrm{~Hz}^{3} J_{(\mathrm{HCC}-\mathrm{H} 3)}=9.1 \mathrm{~Hz}, \mathrm{HCH}-\mathrm{Thy}\right), 2.82(\mathrm{ddd}$, $\left.1 \mathrm{H},{ }^{2} J_{(\mathrm{H} 4 \alpha-\mathrm{H} 4 \beta)}=13.5 \mathrm{~Hz},{ }^{3} J_{(\mathrm{H} 4 \alpha-\mathrm{H} 5)}=7.4 \mathrm{~Hz},{ }^{3} J_{(\mathrm{H} 4 \alpha-\mathrm{H} 3)}=7.4 \mathrm{~Hz}, \mathrm{H}_{\alpha} \mathrm{C} 4\right), 2.70\left(\mathrm{~s}, 3 \mathrm{H}, \mathrm{CH}_{3} \mathrm{~N}\right), 2.39$ $\left(\mathrm{ddd}, 1 \mathrm{H},{ }^{2} J_{(\mathrm{H} 4 \beta-\mathrm{H} 4 \alpha)}=13.5 \mathrm{~Hz},{ }^{3} J_{(\mathrm{H} 4 \beta-\mathrm{H} 5)}=8.9 \mathrm{~Hz},{ }^{3} J_{(\mathrm{H} 4 \beta-\mathrm{H} 3)}=2.6 \mathrm{~Hz}, \mathrm{H}_{\beta} \mathrm{C} 4\right), 1.94\left(\mathrm{~s}, 3 \mathrm{H}, \mathrm{CH}_{3}\right)$;

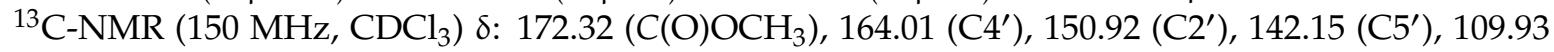
(C6') , 76.24 (C5), $65.81(\mathrm{C} 3), 52.59\left(\mathrm{C}(\mathrm{O}) \mathrm{OCH}_{3}\right), 50.00\left(\mathrm{CH}_{2}-\mathrm{Thy}\right), 45.72\left(\mathrm{CH}_{3} \mathrm{~N}\right), 34.73(\mathrm{C} 4), 12.21\left(\mathrm{CH}_{3}\right)$. Anal. Calcd for $\mathrm{C}_{12} \mathrm{H}_{17} \mathrm{~N}_{3} \mathrm{O}_{5}$ : C, 50.88; H, 6.05; N, 14.83. Found: C, 50.94; H, 6.03; N, 14.95 .

Methyl cis-3-\{[5-fluoro-2,4-dioxo-3,4-dihydropyrimidin-1(2H)-yl]metyl\}-2-methylisoxazolidine-5-carboxylate (cis-14c). Yield: 38\%; a colorless amorphous solid; m.p. $=139-140{ }^{\circ} \mathrm{C}$ (crystallized from chloroform-methanol). IR (KBr, cm $\left.{ }^{-1}\right) v_{\max }: 3441,3166,3055,3028,2958,2923,2850,1725,1691,1658$, 1470, 1436, 1242, 1074; ${ }^{1} \mathrm{H}-\mathrm{NMR}\left(600 \mathrm{MHz}, \mathrm{CDCl}_{3}\right) \delta: 9.81$ (br s, 1H, NH), 7.43 (d, 1H, $\left.{ }^{3} \mathrm{~J}=5.8 \mathrm{~Hz}\right)$, $4.75\left(\mathrm{dd}, 1 \mathrm{H},{ }^{3} J_{(\mathrm{H} 5-\mathrm{H} 4 \alpha)}=9.9 \mathrm{~Hz},{ }^{3} J_{(\mathrm{H} 5-\mathrm{H} 4 \beta)}=5.1 \mathrm{~Hz}, \mathrm{HC} 5\right), 3.93\left(\mathrm{dd}, 1 \mathrm{H},{ }^{2} J_{(\mathrm{HCH})}=13.5 \mathrm{~Hz},{ }^{3} J_{(\mathrm{HCC}-\mathrm{H} 3)}\right.$ $=3.3 \mathrm{~Hz}, \mathrm{HCH}-\mathrm{FUra}), 3.80\left(\mathrm{~s}, 3 \mathrm{H}, \mathrm{C}(\mathrm{O}) \mathrm{OCH}_{3}\right), 3.55\left(\mathrm{dd}, 1 \mathrm{H},{ }^{2} J_{(\mathrm{HCH})}=13.5 \mathrm{~Hz},{ }^{3} J_{(\mathrm{HCC}-\mathrm{H} 3)}=9.5 \mathrm{~Hz}\right.$, $\mathrm{HCH}-\mathrm{FUra}), 3.48$ (dddd, $1 \mathrm{H},{ }^{3} J_{(\mathrm{H} 3-\mathrm{CCH})}=9.5 \mathrm{~Hz},{ }^{3} J_{(\mathrm{H} 3-\mathrm{H} 4 \alpha)}=7.9 \mathrm{~Hz},{ }^{3} J_{(\mathrm{H} 3-\mathrm{CCH})}=3.3 \mathrm{~Hz},{ }^{3} J_{(\mathrm{H} 3-\mathrm{H} 4 \beta)}=$ $2.0 \mathrm{~Hz}, \mathrm{HC} 3), 2.87\left(\mathrm{ddd}, 1 \mathrm{H},{ }^{2} J_{(\mathrm{H} 4 \alpha-\mathrm{H} 4 \beta)}=13.4 \mathrm{~Hz},{ }^{3} J_{(\mathrm{H} 4 \alpha-\mathrm{H} 5)}=9.9 \mathrm{~Hz},{ }^{3} J_{(\mathrm{H} 4 \alpha-\mathrm{H} 3)}=7.9 \mathrm{~Hz}, \mathrm{H}_{\alpha} \mathrm{C} 4\right)$, $2.64\left(\mathrm{~s}, 3 \mathrm{H}, \mathrm{CH}_{3} \mathrm{~N}\right), 2.19\left(\mathrm{ddd}, 1 \mathrm{H},{ }^{2} J_{(\mathrm{H} 4 \beta-\mathrm{H} 4 \alpha)}=13.4 \mathrm{~Hz},{ }^{3} J_{(\mathrm{H} 4 \beta-\mathrm{H} 5)}=5.1 \mathrm{~Hz},{ }^{3} J_{(\mathrm{H} 4 \beta-\mathrm{H} 3)}=2.0 \mathrm{~Hz}\right.$, $\left.\mathrm{H}_{\beta} \mathrm{C} 4\right) ;{ }^{13} \mathrm{C}-\mathrm{NMR}\left(150 \mathrm{MHz}_{\mathrm{CDCl}}\right) \delta: 171.42\left(\mathrm{C}(\mathrm{O}) \mathrm{OCH}_{3}\right), 157.48\left(\mathrm{~d},{ }^{2} J_{(\mathrm{CCF})}=25.8 \mathrm{~Hz}, \mathrm{C}^{\prime}\right), 149.96$ $\left(\mathrm{C} 2^{\prime}\right), 139.83\left(\mathrm{~d},{ }^{1} J_{(\mathrm{CF})}=234.2 \mathrm{~Hz}, \mathrm{C}^{\prime}\right), 131.13\left(\mathrm{~d},{ }^{2} J_{(\mathrm{CCF})}=32.8 \mathrm{~Hz}, \mathrm{C} 6^{\prime}\right), 74.41(\mathrm{C} 5), 65.37(\mathrm{C} 3), 52.68$ $\left(\mathrm{C}(\mathrm{O}) \mathrm{OCH}_{3}\right), 50.57\left(\mathrm{CH}_{2}-\mathrm{FUra}\right), 44.27\left(\mathrm{CH}_{3} \mathrm{~N}\right), 34.61(\mathrm{C} 4)$. Anal. Calcd for $\mathrm{C}_{11} \mathrm{H}_{14} \mathrm{FN}_{3} \mathrm{O}_{5}: \mathrm{C}, 46.00 ; \mathrm{H}$, $4.91 ; \mathrm{N}, 14.63$. Found: C, 46.36; H, 4.62; N, 14.55 .

Methyl trans-3-\{[5-fluoro-2,4-dioxo-3,4-dihydropyrimidin-1(2H)-yl]metyl\}-2-methylisoxazolidine-5-carboxylate (trans-14c). Yield: 31\%; a colorless amorphous solid; m.p. $=179-180{ }^{\circ} \mathrm{C}$ (crystallized from chloroform-methanol). IR ( $\left.\mathrm{KBr}, \mathrm{cm}^{-1}\right) v_{\text {max }}: 3470,3167,3029,2960,2920,2836,1744,1722,1693,1658$, 1382, 1240, 1206, 1101, 907; ${ }^{1} \mathrm{H}-\mathrm{NMR}\left(600 \mathrm{MHz} \mathrm{CDCl}_{3}\right) \delta: 8.29$ (br s, $\left.1 \mathrm{H}, \mathrm{NH}\right), 7.47\left(\mathrm{~d}, 1 \mathrm{H},{ }^{3} \mathrm{~J}=5.7 \mathrm{~Hz}\right)$, $4.56\left(\mathrm{dd}, 1 \mathrm{H},{ }^{3} J_{(\mathrm{H} 5-\mathrm{H} 4 \beta)}=9.0 \mathrm{~Hz},{ }^{3} J_{(\mathrm{H} 5-\mathrm{H} 4 \alpha)}=7.5 \mathrm{~Hz}, \mathrm{HC} 5\right), 4.03\left(\mathrm{dd}, 1 \mathrm{H},{ }^{2} J_{(\mathrm{HCH})}=13.9 \mathrm{~Hz},{ }^{3} J_{(\mathrm{HCC}-\mathrm{H} 3)}\right.$ $=3.6 \mathrm{~Hz}, \mathrm{HCH}-\mathrm{FUra}), 3.83\left(\mathrm{~s}, 3 \mathrm{H}, \mathrm{C}(\mathrm{O}) \mathrm{OCH}_{3}\right), 3.52\left(\mathrm{dddd}, 1 \mathrm{H},{ }^{3} J_{(\mathrm{H} 3-\mathrm{CCH})}=9.5 \mathrm{~Hz},{ }^{3} J_{(\mathrm{H} 3-\mathrm{H} 4 \alpha)}=7.5\right.$ $\left.\mathrm{Hz},{ }^{3} J_{(\mathrm{H} 3-\mathrm{CCH})}=3.6 \mathrm{~Hz},{ }^{3} J_{(\mathrm{H} 3-\mathrm{H} 4 \beta)}=2.2 \mathrm{~Hz}, \mathrm{HC} 3\right), 3.31\left(\mathrm{dd}, 1 \mathrm{H},{ }^{2} J_{(\mathrm{HCH})}=13.9 \mathrm{~Hz},{ }^{3} J_{(\mathrm{HCC}-\mathrm{H} 3)}=9.5 \mathrm{~Hz}\right.$, $\mathrm{HCH}-\mathrm{FUra}), 2.86\left(\mathrm{ddd}, 1 \mathrm{H},{ }^{2} J_{(\mathrm{H} 4 \alpha-\mathrm{H} 4 \beta)}=13.4 \mathrm{~Hz},{ }^{3} J_{(\mathrm{H} 4 \alpha-\mathrm{H} 5)}=7.5 \mathrm{~Hz},{ }^{3} J_{(\mathrm{H} 4 \alpha-\mathrm{H} 3)}=7.5 \mathrm{~Hz}, \mathrm{H}_{\alpha} \mathrm{C} 4\right)$, $2.71\left(\mathrm{~s}, 3 \mathrm{H}, \mathrm{CH}_{3} \mathrm{~N}\right), 2.39\left(\mathrm{ddd}, 1 \mathrm{H},{ }^{2} J_{(\mathrm{H} 4 \beta-\mathrm{H} 4 \alpha)}=13.4 \mathrm{~Hz},{ }^{3} J_{(\mathrm{H} 4 \beta-\mathrm{H} 5)}=9.0 \mathrm{~Hz},{ }^{3} J_{(\mathrm{H} 4 \beta-\mathrm{H} 3)}=2.2 \mathrm{~Hz}\right.$, $\left.\mathrm{H}_{\beta} \mathrm{C} 4\right)$; signals of trans-14c were extracted from the ${ }^{13} \mathrm{C}-\mathrm{NMR}$ spectrum of a $60: 40$ mixture of trans-14c and cis-14c); ${ }^{13} \mathrm{C}-\mathrm{NMR}\left(150 \mathrm{MHz}_{2} \mathrm{CDCl}_{3}\right) \delta: 172.29\left(\mathrm{C}(\mathrm{O}) \mathrm{OCH}_{3}\right), 157.09\left(\mathrm{~d},{ }^{2} \mathrm{~J}_{(\mathrm{CCF})}=26.2 \mathrm{~Hz}, \mathrm{C}^{\prime}\right)$, $149.58\left(\mathrm{C} 2^{\prime}\right), 139.84\left(\mathrm{~d},{ }^{1} J_{(\mathrm{CF})}=235.6 \mathrm{~Hz}, \mathrm{C}^{\prime}\right), 130.71\left(\mathrm{~d},{ }^{2} J_{(\mathrm{CCF})}=33.0 \mathrm{~Hz}, \mathrm{C}^{\prime}\right), 76.35(\mathrm{C} 5), 65.75(\mathrm{C} 3)$, $52.69\left(\mathrm{C}(\mathrm{O}) \mathrm{OCH}_{3}\right), 49.96\left(\mathrm{CH}_{2}-\mathrm{FUra}\right), 45.61\left(\mathrm{CH}_{3} \mathrm{~N}\right), 34.42(\mathrm{C} 4)$. Anal. Calcd for $\mathrm{C}_{11} \mathrm{H}_{14} \mathrm{FN}_{3} \mathrm{O}_{5} \times 0.25$ $\mathrm{H}_{2} \mathrm{O}: \mathrm{C}, 45.29 ; \mathrm{H}, 5.01 ; \mathrm{N}, 14.40$. Found: $\mathrm{C}, 45.55 ; \mathrm{H}, 4.99 ; \mathrm{N}, 14.12$.

Methyl cis-3-\{[5-bromo-2,4-dioxo-3,4-dihydropyrimidin-1(2H)-yl]metyl\}-2-methylisoxazolidine-5-carboxylate (cis-14d). Yield: 3.5\%; a colorless amorphous solid; m.p. $=62-64{ }^{\circ} \mathrm{C}$ (crystallized from chloroform-methanol). IR (KBr, $\left.\mathrm{cm}^{-1}\right) v_{\max }: 3156,3094,3007,2959,2922,2876,2831,1759,1710$, 1679, 1461, 1285, 1044, 924; ${ }^{1} \mathrm{H}-\mathrm{NMR}\left(600 \mathrm{MHz}, \mathrm{CDCl}_{3}\right) \delta: 8.67$ (br s, 1H, NH), 7.74 (s, $\left.1 \mathrm{H}\right), 4.76$ $\left(\mathrm{dd}, 1 \mathrm{H},{ }^{3} J_{(\mathrm{H} 5-\mathrm{H} 4 \alpha)}=9.9 \mathrm{~Hz},{ }^{3} J_{(\mathrm{H} 5-\mathrm{H} 4 \beta)}=5.0 \mathrm{~Hz}, \mathrm{HC} 5\right), 3.95\left(\mathrm{dd}, 1 \mathrm{H},{ }^{2} J_{(\mathrm{HCH})}=13.9 \mathrm{~Hz},{ }^{3} J_{(\mathrm{HCC}-\mathrm{H} 3)}=\right.$ $3.8 \mathrm{~Hz}, \mathrm{HCH}-\mathrm{BrUra}), 3.83\left(\mathrm{~s}, 3 \mathrm{H}, \mathrm{C}(\mathrm{O}) \mathrm{OCH}_{3}\right), 3.59\left(\mathrm{dd}, 1 \mathrm{H},{ }^{2} J_{(\mathrm{HCH})}=13.9 \mathrm{~Hz},{ }^{3} J_{(\mathrm{HCC}-\mathrm{H} 3)}=9.6 \mathrm{~Hz}\right.$, $\mathrm{HCH}-\mathrm{BrUra}), 3.47$ (dddd, $1 \mathrm{H},{ }^{3} J_{(\mathrm{H} 3-\mathrm{CCH})}=9.6 \mathrm{~Hz},{ }^{3} J_{(\mathrm{H} 3-\mathrm{H} 4 \alpha)}=8.2 \mathrm{~Hz},{ }^{3} J_{(\mathrm{H} 3-\mathrm{CCH})}=3.8 \mathrm{~Hz},{ }^{3} J_{(\mathrm{H} 3-\mathrm{H} 4 \beta)}$ $=2.1 \mathrm{~Hz}, \mathrm{HC} 3), 2.88\left(\mathrm{ddd}, 1 \mathrm{H},{ }^{2} J_{(\mathrm{H} 4 \alpha-\mathrm{H} 4 \beta)}=13.4 \mathrm{~Hz},{ }^{3} J_{(\mathrm{H} 4 \alpha-\mathrm{H} 5)}=9.9 \mathrm{~Hz},{ }^{3} J_{(\mathrm{H} 4 \alpha-\mathrm{H} 3)}=8.2 \mathrm{~Hz}, \mathrm{H}_{\alpha} \mathrm{C} 4\right)$, $2.66\left(\mathrm{~s}, 3 \mathrm{H}, \mathrm{CH}_{3} \mathrm{~N}\right), 2.20\left(\mathrm{ddd}, 1 \mathrm{H},{ }^{2} J_{(\mathrm{H} 4 \beta-\mathrm{H} 4 \alpha)}=13.4 \mathrm{~Hz},{ }^{3} J_{(\mathrm{H} 4 \beta-\mathrm{H} 5)}=5.0 \mathrm{~Hz},{ }^{3} J_{(\mathrm{H} 4 \beta-\mathrm{H} 3)}=2.1 \mathrm{~Hz}\right.$, $\left.\mathrm{H}_{\beta} \mathrm{C} 4\right) ;{ }^{13} \mathrm{C}-\mathrm{NMR}\left(150 \mathrm{MHz}, \mathrm{CDCl}_{3}\right) \delta: 171.33\left(\mathrm{C}(\mathrm{O}) \mathrm{OCH}_{3}\right), 159.27\left(\mathrm{C}^{\prime}\right), 150.21\left(\mathrm{C}^{\prime}\right), 146.01\left(\mathrm{C}^{\prime}\right)$, 
$95.52\left(\mathrm{C6}^{\prime}\right), 74.44(\mathrm{C} 5), 65.29(\mathrm{C} 3), 52.74\left(\mathrm{C}(\mathrm{O}) \mathrm{OCH}_{3}\right), 50.73\left(\mathrm{CH}_{2}-\mathrm{BrUra}\right), 44.33\left(\mathrm{CH}_{3} \mathrm{~N}\right), 34.52(\mathrm{C} 4)$. Anal. Calcd for $\mathrm{C}_{11} \mathrm{H}_{14} \mathrm{BrN}_{3} \mathrm{O}_{5}$ : C, 37.95; H, 4.05; N, 12.07. Found: C, 37.95; H, 3.97; N, 11.90.

Methyl trans-3-\{[5-bromo-2,4-dioxo-3,4-dihydropyrimidin-1(2H)-yl]metyl\}-2-methylisoxazolidine-5-carboxylate (trans-14d). Yield: $15 \%$; a colorless amorphous solid; m.p. $=185-186{ }^{\circ} \mathrm{C}$ (crystallized from chloroform-methanol). IR (KBr, cm $\left.{ }^{-1}\right) v_{\max }$ : 3416, 3156, 3093, 3004, 2959, 2924, 2878, 2833, 1711, 1681, 1614, 1511, 1463, 1285, 1255, 1032; ${ }^{1} \mathrm{H}-\mathrm{NMR}\left(600 \mathrm{MHz}, \mathrm{CDCl}_{3}\right)$ 8: 8.32 (br s, $\left.1 \mathrm{H}, \mathrm{NH}\right), 7.67(\mathrm{~s}, 1 \mathrm{H}), 4.57$ $\left(\mathrm{dd}, 1 \mathrm{H},{ }^{3} J_{(\mathrm{H} 4 \beta-\mathrm{H} 5)}=9.0 \mathrm{~Hz},{ }^{3} J_{(\mathrm{H} 4 \alpha-\mathrm{H} 5)}=7.4 \mathrm{~Hz}, \mathrm{HC} 5\right), 4.04\left(\mathrm{dd}, 1 \mathrm{H},{ }^{2} J_{(\mathrm{HCH})}=13.9 \mathrm{~Hz},{ }^{3} J_{(\mathrm{HCC}-\mathrm{H} 3)}=\right.$ $3.7 \mathrm{~Hz}, \mathrm{HCH}-\mathrm{BrUra}), 3.83\left(\mathrm{~s}, 3 \mathrm{H}, \mathrm{C}(\mathrm{O}) \mathrm{OCH}_{3}\right), 3.50\left(\mathrm{dddd}, 1 \mathrm{H},{ }^{3} J_{(\mathrm{HCC}-\mathrm{H} 3)}=9.7 \mathrm{~Hz},{ }^{3} J_{(\mathrm{H} 4 \alpha-\mathrm{H} 3)}=7.4 \mathrm{~Hz}\right.$, $\left.{ }^{3} J_{(\mathrm{HCC}-\mathrm{H} 3)}=3.7 \mathrm{~Hz},{ }^{3} J_{(\mathrm{H} 4 \beta-\mathrm{H} 3)}=2.0 \mathrm{~Hz}, \mathrm{HC} 3\right), 3.33\left(\mathrm{dd}, 1 \mathrm{H},{ }^{2} J_{(\mathrm{HCH})}=13.9 \mathrm{~Hz},{ }^{3} J_{(\mathrm{HCC}-\mathrm{H} 3)}=9.7 \mathrm{~Hz}\right.$, $\mathrm{HCH}-\mathrm{BrUra}), 2.87\left(\mathrm{ddd}, 1 \mathrm{H},{ }^{2} J_{(\mathrm{H} 4 \alpha-\mathrm{H} 4 \beta)}=13.5 \mathrm{~Hz},{ }^{3} J_{(\mathrm{H} 4 \alpha-\mathrm{H} 5)}=7.4 \mathrm{~Hz},{ }^{3} J_{(\mathrm{H} 4 \alpha-\mathrm{H} 3)}=7.4 \mathrm{~Hz}, \mathrm{H}_{\alpha} \mathrm{C} 4\right)$, $2.70\left(\mathrm{~s}, 3 \mathrm{H}, \mathrm{CH}_{3} \mathrm{~N}\right), 2.38\left(\mathrm{ddd}, 1 \mathrm{H},{ }^{2} J_{(\mathrm{H} 4 \beta-\mathrm{H} 4 \alpha)}=13.5 \mathrm{~Hz},{ }^{3} J_{(\mathrm{H} 4 \beta-\mathrm{H} 5)}=9.0 \mathrm{~Hz},{ }^{3} J_{(\mathrm{H} 4 \beta-\mathrm{H} 3)}=2.0 \mathrm{~Hz}\right.$, $\left.\mathrm{H}_{\beta} \mathrm{C} 4\right) ;{ }^{13} \mathrm{C}-\mathrm{NMR}\left(150 \mathrm{MHz}, \mathrm{CDCl}_{3}\right) \delta: 172.28\left(\mathrm{C}(\mathrm{O}) \mathrm{OCH}_{3}\right), 159.10\left(\mathrm{C}^{\prime}\right), 150.07\left(\mathrm{C}^{\prime}\right), 145.66\left(\mathrm{C}^{\prime}\right)$, 95.68 (C6'), 76.34 (C5), $65.61(\mathrm{C} 3), 52.67\left(\mathrm{C}(\mathrm{O}) \mathrm{OCH}_{3}\right), 50.10\left(\mathrm{CH}_{2}-\mathrm{BrUra}\right), 45.65\left(\mathrm{CH}_{3} \mathrm{~N}\right), 34.33(\mathrm{C} 4)$. Anal. Calcd for $\mathrm{C}_{11} \mathrm{H}_{14} \mathrm{BrN}_{3} \mathrm{O}_{5}$ : C, 37.95; $\mathrm{H}, 4.05 ; \mathrm{N}, 12.07$. Found: $\mathrm{C}, 38.03 ; \mathrm{H}, 3.91 ; \mathrm{N}, 11.78$.

Methyl cis-3-\{[5-chloro-2,4-dioxo-3,4-dihydropyrimidin-1(2H)-yl]metyl\}-2-methylisoxazolidine-5-carboxylate (cis-14e). Yield: 5.7\%; a colorless amorphous solid; m.p. $=129-131{ }^{\circ} \mathrm{C}$ (crystallized from chloroform-methanol). IR (KBr, cm $\left.{ }^{-1}\right) v_{\max }$ : 3473, 3161, 3036, 2926, 2824, 1748, 1717, 1666, 1627, 1442, 1424, 1342, 1215, 1179, 1049, 1007, 902, 719; ${ }^{1} \mathrm{H}-\mathrm{NMR}\left(600 \mathrm{MHz}, \mathrm{CDCl}_{3}\right)$ 8: 9.32 (br s, $\left.1 \mathrm{H}, \mathrm{NH}\right), 7.63$ $(\mathrm{s}, 1 \mathrm{H}), 4.76\left(\mathrm{dd}, 1 \mathrm{H},{ }^{3} J_{(\mathrm{H} 5-\mathrm{H} 4 \alpha)}=9.9 \mathrm{~Hz},{ }^{3} J_{(\mathrm{H} 5-\mathrm{H} 4 \beta)}=5.0 \mathrm{~Hz}, \mathrm{HC} 5\right), 3.95\left(\mathrm{dd}, 1 \mathrm{H},{ }^{2} J_{(\mathrm{HCH})}=13.9 \mathrm{~Hz}\right.$, $\left.{ }^{3} J_{(\mathrm{HCC}-\mathrm{H} 3)}=3.8 \mathrm{~Hz}, \mathrm{HCH}-\mathrm{ClUra}\right), 3.82\left(\mathrm{~s}, 3 \mathrm{H}, \mathrm{C}(\mathrm{O}) \mathrm{OCH}_{3}\right), 3.58\left(\mathrm{dd}, 1 \mathrm{H},{ }^{2} J_{(\mathrm{HCH})}=13.9 \mathrm{~Hz},{ }^{3} J_{(\mathrm{HCC}-\mathrm{H} 3)}\right.$ $=9.5 \mathrm{~Hz}, \mathrm{HCH}-\mathrm{ClUra}), 3.48\left(\mathrm{dddd}, 1 \mathrm{H},{ }^{3} J_{(\mathrm{H} 3-\mathrm{CCH})}=9.5 \mathrm{~Hz},{ }^{3} J_{(\mathrm{H} 3-\mathrm{H} 4 \alpha)}=8.2 \mathrm{~Hz},{ }^{3} J_{(\mathrm{H} 3-\mathrm{CCH})}=3.8 \mathrm{~Hz}\right.$, $\left.{ }^{3} J_{(\mathrm{H} 3-\mathrm{H} 4 \beta)}=2.2 \mathrm{~Hz}, \mathrm{HC} 3\right), 2.88\left(\mathrm{ddd}, 1 \mathrm{H},{ }^{2} J_{(\mathrm{H} 4 \alpha-\mathrm{H} 4 \beta)}=13.5 \mathrm{~Hz},{ }^{3} J_{(\mathrm{H} 4 \alpha-\mathrm{H} 5)}=9.9 \mathrm{~Hz},{ }^{3} J_{(\mathrm{H} 4 \alpha-\mathrm{H} 3)}=8.2\right.$ $\left.\mathrm{Hz}, \mathrm{H}_{\alpha} \mathrm{C} 4\right), 2.65\left(\mathrm{~s}, 3 \mathrm{H}, \mathrm{CH}_{3} \mathrm{~N}\right), 2.20\left(\mathrm{ddd}, 1 \mathrm{H},{ }^{2} J_{(\mathrm{H} 4 \beta-\mathrm{H} 4 \alpha)}=13.5 \mathrm{~Hz},{ }^{3} J_{(\mathrm{H} 4 \beta-\mathrm{H} 5)}=5.0 \mathrm{~Hz},{ }^{3} J_{(\mathrm{H} 4 \beta-\mathrm{H} 3)}=\right.$ $\left.2.2 \mathrm{~Hz}, \mathrm{H}_{\beta} \mathrm{C} 4\right) ;{ }^{13} \mathrm{C}-\mathrm{NMR}\left(150 \mathrm{MHz}, \mathrm{CDCl}_{3}\right) \delta: 171.37\left(\mathrm{C}(\mathrm{O}) \mathrm{OCH}_{3}\right), 159.55\left(\mathrm{C}^{\prime}\right), 150.34\left(\mathrm{C}^{\prime}\right), 143.53$ $\left(\mathrm{C}^{\prime}\right), 107.94\left(\mathrm{C6}^{\prime}\right), 74.43(\mathrm{C} 5), 65.28(\mathrm{C} 3), 52.69\left(\mathrm{C}(\mathrm{O}) \mathrm{OCH}_{3}\right), 50.71\left(\mathrm{CH}_{2}-\mathrm{ClUra}\right), 44.30\left(\mathrm{CH}_{3} \mathrm{~N}\right), 34.57$ (C4). Anal. Calcd for $\mathrm{C}_{11} \mathrm{H}_{14} \mathrm{ClN}_{3} \mathrm{O}_{5}: \mathrm{C}, 43.50 ; \mathrm{H}, 4.65 ; \mathrm{N}, 13.84$; Found: $\mathrm{C}, 43.67 ; \mathrm{H}, 4.75 ; \mathrm{N}, 14.00$.

Methyl trans-3-\{[5-chloro-2,4-dioxo-3,4-dihydropyrimidin-1(2H)-yl]metyl\}-2-methylisoxazolidine-5-carboxylate (trans-14e). Yield: 5.0\%; a colorless amorphous solid; m.p. $=165-167{ }^{\circ} \mathrm{C}$ (crystallized from chloroform-methanol). IR (KBr, cm $\left.{ }^{-1}\right) v_{\text {max }}$ : 3453, 3165, 3029, 2952, 2843, 1756, 1697, 1678, 1628, $1468,1432,1365,1209,1181,1056,1028,903,752 ;{ }^{1} \mathrm{H}-\mathrm{NMR}\left(600 \mathrm{MHz}, \mathrm{CDCl}_{3}\right) \delta: 8.34$ (br s, $\left.1 \mathrm{H}, \mathrm{NH}\right)$, $7.57(\mathrm{~s}, 1 \mathrm{H}), 4.56\left(\mathrm{dd}, 1 \mathrm{H},{ }^{3} J_{(\mathrm{H} 5-\mathrm{H} 4 \beta)}=9.0 \mathrm{~Hz},{ }^{3} J_{(\mathrm{H} 5-\mathrm{H} 4 \alpha)}=7.5 \mathrm{~Hz}, \mathrm{HC} 5\right), 4.05\left(\mathrm{dd}, 1 \mathrm{H},{ }^{2} J_{(\mathrm{HCH})}=\right.$ $\left.13.9 \mathrm{~Hz},{ }^{3} J_{(\mathrm{HCC}-\mathrm{H} 3)}=3.7 \mathrm{~Hz}, \mathrm{HCH}-\mathrm{ClUra}\right), 3.83\left(\mathrm{~s}, 3 \mathrm{H}, \mathrm{C}(\mathrm{O}) \mathrm{OCH}_{3}\right), 3.50\left(\mathrm{dddd}, 1 \mathrm{H},{ }^{3} J_{(\mathrm{H} 3-\mathrm{CCH})}=\right.$ $\left.9.7 \mathrm{~Hz},{ }^{3} J_{(\mathrm{H} 3-\mathrm{H} 4 \alpha)}=7.5 \mathrm{~Hz},{ }^{3} J_{(\mathrm{H} 3-\mathrm{CCH})}=3.7 \mathrm{~Hz},{ }^{3} J_{(\mathrm{H} 3-\mathrm{H} 4 \beta)}=2.0 \mathrm{~Hz}, \mathrm{HC} 3\right), 3.32\left(\mathrm{dd}, 1 \mathrm{H},{ }^{2} J_{(\mathrm{HCH})}=\right.$ $\left.13.9 \mathrm{~Hz},{ }^{3} J_{(\mathrm{HCC}-\mathrm{H} 3)}=9.7 \mathrm{~Hz}, \mathrm{HCH}-\mathrm{ClUra}\right), 2.87\left(\mathrm{ddd}, 1 \mathrm{H},{ }^{2} J_{(\mathrm{H} 4 \alpha-\mathrm{H} 4 \beta)}=13.5 \mathrm{~Hz},{ }^{3} J_{(\mathrm{H} 4 \alpha-\mathrm{H} 5)}=7.5 \mathrm{~Hz}\right.$, $\left.{ }^{3} J_{(\mathrm{H} 4 \alpha-\mathrm{H} 3)}=7.5 \mathrm{~Hz}, \mathrm{H}_{\alpha} \mathrm{C} 4\right), 2.70\left(\mathrm{~s}, 3 \mathrm{H}, \mathrm{CH}_{3} \mathrm{~N}\right), 2.38\left(\mathrm{ddd}, 1 \mathrm{H},{ }^{2} J_{(\mathrm{H} 4 \beta-\mathrm{H} 4 \alpha)}=13.5 \mathrm{~Hz},{ }^{3} J_{(\mathrm{H} 4 \beta-\mathrm{H} 5)}=\right.$ $\left.9.0 \mathrm{~Hz},{ }^{3} J_{(\mathrm{H} 4 \beta-\mathrm{H} 3)}=2.0 \mathrm{~Hz}, \mathrm{H}_{\beta} \mathrm{C} 4\right) ;{ }^{13} \mathrm{C}-\mathrm{NMR}\left(150 \mathrm{MHz}, \mathrm{CDCl}_{3}\right) \delta: 172.26\left(\mathrm{C}(\mathrm{O}) \mathrm{OCH}_{3}\right), 158.89\left(\mathrm{C}^{\prime}\right)$, $149.74\left(\mathrm{C2}^{\prime}\right), 143.14\left(\mathrm{C}^{\prime}\right), 108.06\left(\mathrm{C}^{\prime}\right), 76.36(\mathrm{C} 5), 65.62(\mathrm{C} 3), 52.65\left(\mathrm{C}(\mathrm{O}) \mathrm{OCH}_{3}\right), 50.11\left(\mathrm{CH}_{2}-\mathrm{ClUra}\right)$, $45.64\left(\mathrm{CH}_{3} \mathrm{~N}\right)$, $34.34(\mathrm{C} 4)$. Anal. Calcd for $\mathrm{C}_{11} \mathrm{H}_{14} \mathrm{ClN}_{3} \mathrm{O}_{5}: \mathrm{C}, 43.50 ; \mathrm{H}, 4.65 ; \mathrm{N}, 13.84$; Found: $\mathrm{C}, 43.66$; $\mathrm{H}, 4.80 ; \mathrm{N}, 13.90$.

Methyl cis-3-\{[5-iodo-2,4-dioxo-3,4-dihydropyrimidin-1(2H)-yl]metyl\}-2-methylisoxazolidine-5-carboxylate (cis-14f). Yield: 2.7\%; a colorless amorphous solid; m.p. $=189-191{ }^{\circ} \mathrm{C}$ (crystallized from ethyl acetate-hexane). IR (KBr, cm $\left.{ }^{-1}\right) v_{\max }: 3407,3144,3089,3002,2918,2828,1759,1709,1667,1606,1427$, 1335, 1246, 1209, 1035, 886, 621; ${ }^{1} \mathrm{H}-\mathrm{NMR}\left(600 \mathrm{MHz}, \mathrm{CDCl}_{3}\right) \delta: 7.79(\mathrm{~s}, 1 \mathrm{H}), 4.76\left(\mathrm{dd}, 1 \mathrm{H},{ }^{3} J_{(\mathrm{H} 5-\mathrm{H} 4 \alpha)}=\right.$ $\left.9.8 \mathrm{~Hz},{ }^{3} J_{(\mathrm{H} 5-\mathrm{H} 4 \beta)}=5.3 \mathrm{~Hz}, \mathrm{HC} 5\right), 3.92\left(\mathrm{dd}, 1 \mathrm{H},{ }^{2} J_{(\mathrm{HCH})}=13.9 \mathrm{~Hz},{ }^{3} J_{(\mathrm{HCC}-\mathrm{H} 3)}=3.8 \mathrm{~Hz}, \mathrm{HCH}-\mathrm{IUra}\right)$, $3.83\left(\mathrm{~s}, 3 \mathrm{H}, \mathrm{C}(\mathrm{O}) \mathrm{OCH}_{3}\right), 3.59\left(\mathrm{dd}, 1 \mathrm{H},{ }^{2} J_{(\mathrm{HCH})}=13.9 \mathrm{~Hz},{ }^{3} J_{(\mathrm{HCC}-\mathrm{H} 3)}=9.6 \mathrm{~Hz}, \mathrm{HCH}-\mathrm{IUra}\right), 3.46$ (dddd, $\left.1 \mathrm{H},{ }^{3} J_{(\mathrm{H} 3-\mathrm{CCH})}=9.6 \mathrm{~Hz},{ }^{3} J_{(\mathrm{H} 3-\mathrm{H} 4 \alpha)}=8.4 \mathrm{~Hz},{ }^{3} J_{(\mathrm{H} 3-\mathrm{CCH})}=3.8 \mathrm{~Hz},{ }^{3} J_{(\mathrm{H} 3-\mathrm{H} 4 \beta)}=2.2 \mathrm{~Hz}, \mathrm{HC} 3\right), 2.87(\mathrm{ddd}$, $\left.1 \mathrm{H},{ }^{2} J_{(\mathrm{H} 4 \alpha-\mathrm{H} 4 \beta)}=13.6 \mathrm{~Hz},{ }^{3} J_{(\mathrm{H} 4 \alpha-\mathrm{H} 5)}=9.8 \mathrm{~Hz},{ }^{3} J_{(\mathrm{H} 4 \alpha-\mathrm{H} 3)}=8.4 \mathrm{~Hz}, \mathrm{H}_{\alpha} \mathrm{C} 4\right), 2.64\left(\mathrm{~s}, 3 \mathrm{H}, \mathrm{CH}_{3} \mathrm{~N}\right), 2.19$ $\left(\mathrm{ddd}, 1 \mathrm{H},{ }^{2} J_{(\mathrm{H} 4 \beta-\mathrm{H} 4 \alpha)}=13.6 \mathrm{~Hz},{ }^{3} J_{(\mathrm{H} 4 \beta-\mathrm{H} 5)}=5.3 \mathrm{~Hz},{ }^{3} J_{(\mathrm{H} 4 \beta-\mathrm{H} 3)}=2.2 \mathrm{~Hz}, \mathrm{H}_{\beta} \mathrm{C} 4\right) ;{ }^{13} \mathrm{C}-\mathrm{NMR}(150 \mathrm{MHz}$, 
$\left.\mathrm{CDCl}_{3}\right)$ 8: $171.32\left(\mathrm{C}(\mathrm{O}) \mathrm{OCH}_{3}\right), 160.27\left(\mathrm{C}^{\prime}\right), 150.94\left(\mathrm{C}^{\prime}\right), 150.51\left(\mathrm{C}^{\prime}\right), 74.43(\mathrm{C} 5), 66.62(\mathrm{C} 3), 65.33\left(\mathrm{C}^{\prime}\right)$, $52.76\left(\mathrm{C}(\mathrm{O}) \mathrm{OCH}_{3}\right), 50.73\left(\mathrm{CH}_{2}-\mathrm{IUra}\right), 44.36\left(\mathrm{CH}_{3} \mathrm{~N}\right), 34.53(\mathrm{C} 4)$. Anal. Calcd for $\mathrm{C}_{11} \mathrm{H}_{14} \mathrm{IN}_{3} \mathrm{O}_{5}$ : C, 33.44; H, 3.57; N, 10.63. Found: C, 33.34; H, 3.62; N, 10.51 .

Methyl trans-3-\{[5-iodo-2,4-dioxo-3,4-dihydropyrimidin-1(2H)-yl]metyl\}-2-methylisoxazolidine-5-carboxylate (tran-14f). Yield: 5.3\%; a colorless amorphous solid; m.p. $=214-216{ }^{\circ} \mathrm{C}$ (crystallized from chloroform-methanol). IR (KBr, cm ${ }^{-1}$ ) $v_{\max }$ : 3453, 3148, 3002, 2962, 2829, 1680, 1607, 1460, 1431, 1298, 1253, 1080, 895, 816, 721, 622; ${ }^{1} \mathrm{H}-\mathrm{NMR}\left(600 \mathrm{MHz}, \mathrm{CDCl}_{3}\right) \delta: 7.75(\mathrm{~s}, 1 \mathrm{H}), 4.56\left(\mathrm{dd}, 1 \mathrm{H},{ }^{3} J_{(\mathrm{H} 5-\mathrm{H} 4 \beta)}=\right.$ $\left.9.0 \mathrm{~Hz},{ }^{3} J_{(\mathrm{H} 5-\mathrm{H} 4 \alpha)}=7.5 \mathrm{~Hz}, \mathrm{HC} 5\right), 4.03\left(\mathrm{dd}, 1 \mathrm{H},{ }^{2} J_{(\mathrm{HCH})}=13.9 \mathrm{~Hz},{ }^{3} J_{(\mathrm{HCC}-\mathrm{H} 3)}=3.7 \mathrm{~Hz}\right.$, HCH-IUra) $3.83\left(\mathrm{~s}, 3 \mathrm{H}, \mathrm{C}(\mathrm{O}) \mathrm{OCH}_{3}\right), 3.55\left(\mathrm{dddd}, 1 \mathrm{H},{ }^{3} J_{(\mathrm{H} 3-\mathrm{CCH})}=9.7 \mathrm{~Hz},{ }^{3} J_{(\mathrm{H} 3-\mathrm{H} 4 \alpha)}=7.5 \mathrm{~Hz},{ }^{3} J_{(\mathrm{H} 3-\mathrm{CCH})}=3.7 \mathrm{~Hz}\right.$, $\left.{ }^{3} J_{(\mathrm{H} 3-\mathrm{H} 4 \beta)}=2.0 \mathrm{~Hz}, \mathrm{HC} 3\right), 3.34\left(\mathrm{dd}, 1 \mathrm{H},{ }^{2} J_{(\mathrm{HCH})}=13.9 \mathrm{~Hz},{ }^{3} J_{(\mathrm{HCC}-\mathrm{H} 3)}=9.7 \mathrm{~Hz}, \mathrm{HCH}-\mathrm{IUra}\right), 2.86$ (ddd, $\left.1 \mathrm{H},{ }^{2} J_{(\mathrm{H} 4 \alpha-\mathrm{H} 4 \beta)}=13.4 \mathrm{~Hz},{ }^{3} J_{(\mathrm{H} 4 \alpha-\mathrm{H} 5)}=7.5 \mathrm{~Hz},{ }^{3} J_{(\mathrm{H} 4 \alpha-\mathrm{H} 3)}=7.5 \mathrm{~Hz}, \mathrm{H}_{\alpha} \mathrm{C} 4\right), 2.70\left(\mathrm{~s}, 3 \mathrm{H}, \mathrm{CH}_{3} \mathrm{~N}\right), 2.37$ $\left(\mathrm{ddd}, 1 \mathrm{H},{ }^{2} J_{(\mathrm{H} 4 \beta-\mathrm{H} 4 \alpha)}=13.4 \mathrm{~Hz},{ }^{3} J_{(\mathrm{H} 4 \beta-\mathrm{H} 5)}=9.0 \mathrm{~Hz},{ }^{3} J_{(\mathrm{H} 4 \beta-\mathrm{H} 3)}=2.0 \mathrm{~Hz}, \mathrm{H}_{\beta} \mathrm{C} 4\right) ;{ }^{13} \mathrm{C}-\mathrm{NMR}(150 \mathrm{MHz}$, $\left.\mathrm{CDCl}_{3}\right)$ 8: $172.28\left(\mathrm{C}(\mathrm{O}) \mathrm{OCH}_{3}\right), 160.10\left(\mathrm{C}^{\prime}\right), 150.62\left(\mathrm{C}^{\prime}\right), 150.38\left(\mathrm{C}^{\prime}\right), 76.32(\mathrm{C} 5), 66.78(\mathrm{C} 3), 65.63\left(\mathrm{C}^{\prime}\right)$, $52.67\left(\mathrm{C}(\mathrm{O}) \mathrm{OCH}_{3}\right), 50.05\left(\mathrm{CH}_{2}-\mathrm{IUra}\right), 45.66\left(\mathrm{CH}_{3} \mathrm{~N}\right), 34.34(\mathrm{C} 4)$. Anal. Calcd for $\mathrm{C}_{11} \mathrm{H}_{14} \mathrm{IN}_{3} \mathrm{O}_{5}$ : C, 33.44; $\mathrm{H}, 3.57 ; \mathrm{N}, 10.63$. Found: $\mathrm{C}, 33.57 ; \mathrm{H}, 3.45 ; \mathrm{N}, 10.76$.

Methyl cis-3-\{[2,4-dioxotetrahydropyrimidin-1(2H)-yl]metyl\}-2-methylisoxazolidine-5-carboxylate (cis-14g). Yield: $6.4 \%$; a colorless amorphous solid; m.p. $=102-104{ }^{\circ} \mathrm{C}$ (crystallized from ethyl acetate-hexane). IR $\left(\mathrm{KBr}, \mathrm{cm}^{-1}\right) v_{\max }: 3366,3243,3110,2957,2921,1721,1675,1486,1440,1384,1331,1228,1205,1152,1060$, 801; ${ }^{1} \mathrm{H}-\mathrm{NMR}\left(600 \mathrm{MHz}, \mathrm{CDCl}_{3}\right) \delta: 5.61(\mathrm{br} \mathrm{s}, 1 \mathrm{H}, \mathrm{NH}), 4.61\left(\mathrm{dd}, 1 \mathrm{H},{ }^{3} J_{(\mathrm{H} 5-\mathrm{H} 4 \alpha)}=9.5 \mathrm{~Hz},{ }^{3} J_{(\mathrm{H} 5-\mathrm{H} 4 \beta)}=\right.$ $5.4 \mathrm{~Hz}, \mathrm{HC} 5), 3.96\left(\mathrm{dd}, 1 \mathrm{H},{ }^{2} J_{(\mathrm{HCH})}=13.7 \mathrm{~Hz},{ }^{3} J_{(\mathrm{HCC}-\mathrm{H} 3)}=4.8 \mathrm{~Hz}, \mathrm{HCH}\right.$-dihydroUra), $3.87(\mathrm{dd}, 1 \mathrm{H}$, ${ }^{2} J_{(\mathrm{HCH})}=13.7 \mathrm{~Hz},{ }^{3} J_{(\mathrm{HCC}-\mathrm{H} 3)}=6.9 \mathrm{~Hz}, \mathrm{HCH}$-dihydroUra), $3.80\left(\mathrm{~s}, 3 \mathrm{H}, \mathrm{C}(\mathrm{O}) \mathrm{OCH}_{3}\right), 3.41\left(\mathrm{td}, 2 \mathrm{H},{ }^{3} J=7.0\right.$ $\left.\mathrm{Hz},{ }^{2} \mathrm{~J}=2.7 \mathrm{~Hz}, \mathrm{CH}_{2} \mathrm{CH}_{2} \mathrm{~N}\right), 3.10-3.00(\mathrm{br} \mathrm{m}, 1 \mathrm{H}, \mathrm{HC}), 2.76-2.73\left(\mathrm{~m}, 5 \mathrm{H}, \mathrm{CH}_{3} \mathrm{~N}\right.$ and $\left.\mathrm{C}(\mathrm{O}) \mathrm{CH}_{2} \mathrm{CH}_{2} \mathrm{~N}\right)$, $2.67\left(\mathrm{ddd}, 1 \mathrm{H},{ }^{2} J_{(\mathrm{H} 4 \alpha-\mathrm{H} 4 \beta)}=12.9 \mathrm{~Hz},{ }^{3} J_{(\mathrm{H} 4 \alpha-\mathrm{H} 5)}=9.5 \mathrm{~Hz},{ }^{3} J_{(\mathrm{H} 4 \alpha-\mathrm{H} 3)}=7.8 \mathrm{~Hz}, \mathrm{H}_{\alpha} \mathrm{C} 4\right), 2.45(\mathrm{ddd}, 1 \mathrm{H}$, $\left.{ }^{2} J_{(\mathrm{H} 4 \beta-\mathrm{H} 4 \alpha)}=12.9 \mathrm{~Hz},{ }^{3} J_{(\mathrm{H} 4 \beta-\mathrm{H} 3)}=6.6 \mathrm{~Hz},{ }^{3} J_{(\mathrm{H} 4 \beta-\mathrm{H} 5)}=5.4 \mathrm{~Hz}, \mathrm{H}_{\beta} \mathrm{C} 4\right) ;{ }^{13} \mathrm{C}-\mathrm{NMR}\left(150 \mathrm{MHz}, \mathrm{CDCl}_{3}\right)$ ঠ: $172.25\left(\mathrm{C}(\mathrm{O}) \mathrm{OCH}_{3}\right), 169.61\left(\mathrm{C}^{\prime}\right), 154.65\left(\mathrm{C}^{\prime}\right), 74.19(\mathrm{C} 5), 66.42(\mathrm{C} 3), 52.36\left(\mathrm{C}(\mathrm{O}) \mathrm{OCH}_{3}\right), 44.31$ $\left(\mathrm{CH}_{2}\right.$-dihydroUra), $40.97\left(\mathrm{CH}_{3} \mathrm{~N}\right), 36.71\left(\mathrm{C}^{\prime}\right), 35.33(\mathrm{C} 4), 31.74\left(\mathrm{C}^{\prime}\right)$. Anal. Calcd for $\mathrm{C}_{11} \mathrm{H}_{17} \mathrm{~N}_{3} \mathrm{O}_{5}$ : $\mathrm{C}$, 48.70; H, 6.32; N, 15.49. Found: C, 48.91; H, 6.29; N, 15.33 .

Methyl trans-3-\{[2,4-dioxotetrahydropyrimidin-1(2H)-yl]metyl\}-2-methylisoxazolidine-5-carboxylate (trans-14g). Yield: 8.1\%; a colorless amorphous solid; m.p. $=73-75{ }^{\circ} \mathrm{C}$ (crystallized from ethyl acetate-hexane). IR ( $\left.\mathrm{KBr}, \mathrm{cm}^{-1}\right) v_{\max }: 3369,3241,3113,2959,2923,1724,1679,1486,1440,1387,1228$, 1154, 1098, 1010, 763; ${ }^{1} \mathrm{H}-\mathrm{NMR}\left(600 \mathrm{MHz}, \mathrm{CDCl}_{3}\right) \delta: 5.71(\mathrm{br} \mathrm{s}, 1 \mathrm{H}, \mathrm{NH}), 4.62\left(\mathrm{dd}, 1 \mathrm{H},{ }^{3} J_{(\mathrm{H} 5-\mathrm{H} 4 \beta)}=8.6\right.$ $\left.\mathrm{Hz},{ }^{3} J_{(\mathrm{H} 5-\mathrm{H} 4 \alpha)}=6.9 \mathrm{~Hz}, \mathrm{HC} 5\right), 3.91\left(\mathrm{dd}, 1 \mathrm{H},{ }^{2} J_{(\mathrm{HCH})}=13.5 \mathrm{~Hz},{ }^{3} J_{(\mathrm{HCC}-\mathrm{H} 3)}=5.9 \mathrm{~Hz}, \mathrm{HCH}-\right.$ dihydroUra $)$, $3.89\left(\mathrm{dd}, 1 \mathrm{H},{ }^{2} J_{(\mathrm{HCH})}=13.5 \mathrm{~Hz},{ }^{3} J_{(\mathrm{HCC}-\mathrm{H} 3)}=7.3 \mathrm{~Hz}, \mathrm{HCH}\right.$-dihydroUra $), 3.78\left(\mathrm{~s}, 3 \mathrm{H}, \mathrm{C}(\mathrm{O}) \mathrm{OCH}_{3}\right), 3.44$ $\left(\mathrm{td}, 2 \mathrm{H},{ }^{3} \mathrm{~J}=6.8 \mathrm{~Hz},{ }^{2} J=2.8 \mathrm{~Hz}\right), 3.32\left(\mathrm{dddd}, 1 \mathrm{H},{ }^{3} J_{(\mathrm{H} 3-\mathrm{CCH})}=7.3 \mathrm{~Hz},{ }^{3} J_{(\mathrm{H} 3-\mathrm{H} 4 \alpha)}=6.9 \mathrm{~Hz},{ }^{3} J_{(\mathrm{H} 3-\mathrm{CCH})}=\right.$ $\left.5.9 \mathrm{~Hz}^{3}{ }^{3} \mathrm{H}_{(\mathrm{H} 3-\mathrm{H} 4 \beta)}=4.9 \mathrm{~Hz}, \mathrm{HC} 3\right), 2.80\left(\mathrm{~s}, 3 \mathrm{H}, \mathrm{CH}_{3} \mathrm{~N}\right), 2.77\left(\mathrm{t}, 2 \mathrm{H},{ }^{3} \mathrm{~J}=6.8 \mathrm{~Hz}\right), 2.55\left(\mathrm{ddd}, 1 \mathrm{H},{ }^{2} J_{(\mathrm{H} 4 \alpha-\mathrm{H} 4 \beta)}\right.$ $\left.=12.9 \mathrm{~Hz},{ }^{3} J_{(\mathrm{H} 4 \alpha-\mathrm{H} 5)}=6.9 \mathrm{~Hz},{ }^{3} J_{(\mathrm{H} 4 \alpha-\mathrm{H} 3)}=6.9 \mathrm{~Hz}, \mathrm{H}_{\alpha} \mathrm{C} 4\right), 2.45\left(\mathrm{ddd}, 1 \mathrm{H},{ }^{2} J_{(\mathrm{H} 4 \beta-\mathrm{H} 4 \alpha)}=12.9 \mathrm{~Hz}\right.$, $\left.{ }^{3} J_{(\mathrm{H} 4 \beta-\mathrm{H} 5)}=8.6 \mathrm{~Hz},{ }^{3} J_{(\mathrm{H} 4 \beta-\mathrm{H} 3)}=4.9 \mathrm{~Hz}, \mathrm{H}_{\beta} \mathrm{C} 4\right) ;{ }^{13} \mathrm{C}-\mathrm{NMR}\left(150 \mathrm{MHz}, \mathrm{CDCl}_{3}\right) \delta: 172.54\left(\mathrm{C}(\mathrm{O}) \mathrm{OCH}_{3}\right)$, $169.65\left(\mathrm{C} 4^{\prime}\right), 154.71\left(\mathrm{C}^{\prime}\right), 75.71(\mathrm{C} 5), 65.62(\mathrm{C} 3), 52.31\left(\mathrm{C}(\mathrm{O}) \mathrm{OCH}_{3}\right), 45.31\left(\mathrm{CH}_{2}\right.$-dihydroUra), 41.19 $\left(\mathrm{CH}_{3} \mathrm{~N}\right), 36.14\left(\mathrm{C} 6^{\prime}\right), 35.39(\mathrm{C} 4), 31.64\left(\mathrm{C}^{\prime}\right)$. Anal. Calcd for $\mathrm{C}_{11} \mathrm{H}_{17} \mathrm{~N}_{3} \mathrm{O}_{5}: \mathrm{C}, 48.70 ; \mathrm{H}, 6.32 ; \mathrm{N}, 15.49$. Found: C, 49.05; H, 6.46; N, 15.58 .

Methyl cis-3-[(1,3-dimethyl-2,6-dioxo-1,2,3,6-tetrahydro-9H-purin-9-yl)methyl]-2-methylisoxazolidine-5carboxylate (cis-14h). Yield: $23 \%$; a colorless amorphous solid; m.p. $=139-141{ }^{\circ} \mathrm{C}$ (crystallized from chloroform-diethyl ether). IR (KBr, cm $\left.{ }^{-1}\right) v_{\text {max }}$ : 2999, 2941, 1738, 1702, 1660,1546, 1455, 1409, 1373, 1286, 1184, 1091, 724; ${ }^{1} \mathrm{H}-\mathrm{NMR}\left(600 \mathrm{MHz}, \mathrm{CDCl}_{3}\right) \delta: 7.71\left(\mathrm{~s}, 1 \mathrm{H}, \mathrm{HC} 8^{\prime}\right), 4.75\left(\mathrm{dd}, 1 \mathrm{H},{ }^{3} J_{(\mathrm{H} 5-\mathrm{H} 4 \alpha)}=\right.$ $\left.9.7 \mathrm{~Hz},{ }^{3} J_{(\mathrm{H} 5-\mathrm{H} 4 \beta)}=5.1 \mathrm{~Hz}, \mathrm{HC} 5\right), 4.38\left(\mathrm{dd}, 1 \mathrm{H},{ }^{2} J_{(\mathrm{HCH})}=13.7 \mathrm{~Hz},{ }^{3} J_{(\mathrm{HCC}-\mathrm{H} 3)}=4.7 \mathrm{~Hz}, \mathrm{HCH}-\mathrm{The}\right), 4.29$ $\left(\mathrm{dd}, 1 \mathrm{H},{ }^{2} J_{(\mathrm{HCH})}=13.7 \mathrm{~Hz},{ }^{3} J_{(\mathrm{HCC}-\mathrm{H} 3)}=8.8 \mathrm{~Hz}, \mathrm{HCH}-\mathrm{The}\right), 3.83\left(\mathrm{~s}, 3 \mathrm{H}, \mathrm{NCH}_{3}\right), 3.62\left(\mathrm{~s}, 3 \mathrm{H}, \mathrm{C}(\mathrm{O}) \mathrm{OCH}_{3}\right)$, $3.60\left(\right.$ dddd, $\left.1 \mathrm{H},{ }^{3} J_{(\mathrm{H} 3-\mathrm{CCH})}=8.8 \mathrm{~Hz},{ }^{3} J_{(\mathrm{H} 3-\mathrm{H} 4 \alpha)}=8.3 \mathrm{~Hz},{ }^{3} J_{(\mathrm{H} 3-\mathrm{CCH})}=4.7 \mathrm{~Hz},{ }^{3} J_{(\mathrm{H} 3-\mathrm{H} 4 \beta)}=3.0 \mathrm{~Hz}, \mathrm{HC} 3\right)$, $3.44\left(\mathrm{~s}, 3 \mathrm{H}, \mathrm{NCH}_{3}\right), 2.86\left(\mathrm{ddd}, 1 \mathrm{H},{ }^{2} J_{(\mathrm{H} 4 \alpha-\mathrm{H} 4 \beta)}=13.3 \mathrm{~Hz},{ }^{3} J_{(\mathrm{H} 4 \alpha-\mathrm{H} 5)}=9.7 \mathrm{~Hz},{ }^{3} J_{(\mathrm{H} 4 \alpha-\mathrm{H} 3)}=8.3 \mathrm{~Hz}\right.$, 
$\left.\mathrm{H}_{\alpha} \mathrm{C} 4\right), 2.59\left(\mathrm{~s}, 3 \mathrm{H}, \mathrm{CH}_{3} \mathrm{~N}\right), 2.25\left(\mathrm{ddd}, 1 \mathrm{H},{ }^{2} J_{(\mathrm{H} 4 \beta-\mathrm{H} 4 \alpha)}=13.3 \mathrm{~Hz},{ }^{3} J_{(\mathrm{H} 4 \beta-\mathrm{H} 5)}=5.1 \mathrm{~Hz},{ }^{3} J_{(\mathrm{H} 4 \beta-\mathrm{H} 3)}=3.0\right.$ $\left.\mathrm{Hz}, \mathrm{H}_{\beta} \mathrm{C} 4\right) ;{ }^{13} \mathrm{C}-\mathrm{NMR}\left(150 \mathrm{MHz}, \mathrm{CDCl}_{3}\right) \delta$ : $171.47\left(\mathrm{C}(\mathrm{O}) \mathrm{OCH}_{3}\right), 155.44\left(\mathrm{C}^{\prime}\right), 151.64\left(\mathrm{C}^{\prime}\right), 149.16\left(\mathrm{C}^{\prime}\right)$, $142.72\left(\mathrm{C}^{\prime}\right), 106.43\left(\mathrm{C}^{\prime}\right), 74.46(\mathrm{C} 5), 66.68(\mathrm{C} 3), 52.65\left(\mathrm{C}(\mathrm{O}) \mathrm{OCH}_{3}\right), 49.11\left(\mathrm{CH}_{2}-\mathrm{The}\right), 44.52\left(\mathrm{CH}_{3} \mathrm{~N}\right)$, $34.77(\mathrm{C} 4), 29.81\left(\mathrm{NCH}_{3}\right), 27.96\left(\mathrm{NCH}_{3}\right)$. Anal. Calcd for $\mathrm{C}_{14} \mathrm{H}_{19} \mathrm{~N}_{5} \mathrm{O}_{5}: \mathrm{C}, 49.85 ; \mathrm{H}, 5.68 ; \mathrm{N}, 20.76$. Found: $\mathrm{C}, 49.75 ; \mathrm{H}, 5.58 ; \mathrm{N}, 20.64$.

Methyl trans-3-[(1,3-dimethyl-2,6-dioxo-1,2,3,6-tetrahydro-9H-purin-9-yl)methyl]-2-methylisoxazolidine-5carboxylate (trans-14h). Yield: $13 \%$; a colorless amorphous solid; m.p. $=91-92{ }^{\circ} \mathrm{C}$ (crystallized from chloroform-diethyl ether). IR ( $\left.\mathrm{KBr}, \mathrm{cm}^{-1}\right) v_{\max }: 2953,2884,1738,1697,1649,1545,1430,1406,1286$, $1203,1024,973,745 ;{ }^{1} \mathrm{H}-\mathrm{NMR}\left(200 \mathrm{MHz}, \mathrm{CDCl}_{3}\right) \delta: 7.66\left(\mathrm{~s}, 1 \mathrm{H}, \mathrm{HC} 8^{\prime}\right), 4.54\left(\mathrm{dd}, 1 \mathrm{H},{ }^{3} J_{(\mathrm{H} 5-\mathrm{H} 4 \beta}\right)=8.9 \mathrm{~Hz}$, $\left.{ }^{3} J_{(\mathrm{H} 5-\mathrm{H} 4 \alpha)}=7.5 \mathrm{~Hz}, \mathrm{HC} 5\right), 4.43\left(\mathrm{dd}, 1 \mathrm{H},{ }^{2} J_{(\mathrm{HCH})}=13.7 \mathrm{~Hz},{ }^{3} J_{(\mathrm{HCC}-\mathrm{H} 3)}=4.3 \mathrm{~Hz}, \mathrm{HCH}-\mathrm{The}\right), 4.12(\mathrm{dd}$, $\left.1 \mathrm{H},{ }^{2} J_{(\mathrm{HCH})}=13.7 \mathrm{~Hz},{ }^{3} J_{(\mathrm{HCC}-\mathrm{H} 3)}=8.7 \mathrm{~Hz}, \mathrm{HCH}-\mathrm{The}\right), 3.78\left(\mathrm{~s}, 3 \mathrm{H}, \mathrm{NCH}_{3}\right), 3.60\left(\mathrm{~s}, 3 \mathrm{H}, \mathrm{C}(\mathrm{O}) \mathrm{OCH}_{3}\right)$, $3.55\left(\right.$ dddd, $\left.1 \mathrm{H},{ }^{3} J_{(\mathrm{H} 3-\mathrm{CCH})}=8.7 \mathrm{~Hz},{ }^{3} J_{(\mathrm{H} 3-\mathrm{H} 4 \alpha)}=7.5 \mathrm{~Hz},{ }^{3} J_{(\mathrm{H} 3-\mathrm{CCH})}=4.3 \mathrm{~Hz},{ }^{3} J_{(\mathrm{H} 3-\mathrm{H} 4 \beta)}=3.2 \mathrm{~Hz}, \mathrm{HC} 3\right)$, $3.42\left(\mathrm{~s}, 3 \mathrm{H}, \mathrm{NCH}_{3}\right), 2.80\left(\mathrm{ddd}, 1 \mathrm{H},{ }^{2} J_{(\mathrm{H} 4 \alpha-\mathrm{H} 4 \beta)}=13.3 \mathrm{~Hz},{ }^{3} J_{(\mathrm{H} 4 \alpha-\mathrm{H} 5)}=7.5 \mathrm{~Hz},{ }^{3} J_{(\mathrm{H} 4 \alpha-\mathrm{H} 3)}=7.5 \mathrm{~Hz}\right.$, $\left.\mathrm{H}_{\alpha} \mathrm{C} 4\right), 2.62\left(\mathrm{~s}, 3 \mathrm{H}, \mathrm{CH}_{3} \mathrm{~N}\right), 2.39\left(\mathrm{ddd}, 1 \mathrm{H},{ }^{2} J_{(\mathrm{H} 4 \beta-\mathrm{H} 4 \alpha)}=13.3 \mathrm{~Hz}^{3} J_{(\mathrm{H} 4 \beta-\mathrm{H} 5)}=8.9 \mathrm{~Hz},{ }^{3} J_{(\mathrm{H} 4 \beta-\mathrm{H} 3)}=3.2\right.$ $\left.\mathrm{Hz}, \mathrm{H}_{\beta} \mathrm{C} 4\right) ;{ }^{13} \mathrm{C}-\mathrm{NMR}\left(150 \mathrm{MHz}, \mathrm{CDCl}_{3}\right) \delta: 172.11\left(\mathrm{C}(\mathrm{O}) \mathrm{OCH}_{3}\right), 155.44\left(\mathrm{C2}^{\prime}\right), 151.60\left(\mathrm{C}^{\prime}\right), 149.02\left(\mathrm{C}^{\prime}\right)$, $142.51\left(\mathrm{C}^{\prime}\right), 106.46\left(\mathrm{C}^{\prime}\right), 76.08(\mathrm{C} 5), 66.70(\mathrm{C} 3), 52.55\left(\mathrm{C}(\mathrm{O}) \mathrm{OCH}_{3}\right), 48.55\left(\mathrm{CH}_{2}-\mathrm{The}\right), 45.65\left(\mathrm{CH}_{3} \mathrm{~N}\right)$, $34.99(\mathrm{C} 4), 29.80\left(\mathrm{NCH}_{3}\right), 27.96\left(\mathrm{NCH}_{3}\right)$. Anal. Calcd for $\mathrm{C}_{14} \mathrm{H}_{19} \mathrm{~N}_{5} \mathrm{O}_{5}: \mathrm{C}, 49.85 ; \mathrm{H}, 5.68 ; \mathrm{N}, 20.76$. Found: C, 49.60; H, 5.71; N, 20.65 .

Methyl cis-3-[(6-amino-9H-purin-9-yl)methyl]-2-methylisoxazolidine-5-carboxylate (cis-14i). NMR signals of cis-14i were extracted from the spectra of a 67:33 mixture of cis-14i and trans-14i. ${ }^{1} \mathrm{H}-\mathrm{NMR}(300 \mathrm{MHz}$, $\left.\mathrm{CDCl}_{3}\right) \delta: 8.34\left(\mathrm{~s}, 1 \mathrm{H}, \mathrm{HC2}^{\prime}\right), 7.97\left(\mathrm{~s}, 1 \mathrm{H}, \mathrm{HC} 8^{\prime}\right), 5.96\left(\mathrm{br} \mathrm{s}, 2 \mathrm{H}, \mathrm{NH}_{2}\right), 4.72\left(\mathrm{dd}, 1 \mathrm{H},{ }^{3} J_{(\mathrm{H} 5-\mathrm{H} 4 \alpha)}=9.7\right.$ $\left.\left.\mathrm{Hz},{ }^{3} J_{(\mathrm{H} 5-\mathrm{H} 4 \beta}\right)=5.1 \mathrm{~Hz}, \mathrm{HC} 5\right), 4.26-4.23\left(\mathrm{~m}, 2 \mathrm{H}, \mathrm{CH}_{2}-\mathrm{Ade}\right), 3.78\left(\mathrm{~s}, 3 \mathrm{H}, \mathrm{C}(\mathrm{O}) \mathrm{OCH}_{3}\right), 3.54-3.47(\mathrm{~m}$, $1 \mathrm{H}, \mathrm{HC} 3), 2.83\left(\mathrm{ddd}, 1 \mathrm{H},{ }^{2} J_{(\mathrm{H} 4 \alpha-\mathrm{H} 4 \beta)}=13.4 \mathrm{~Hz},{ }^{3} J_{(\mathrm{H} 4 \alpha-\mathrm{H} 5)}=9.7 \mathrm{~Hz},{ }^{3} J_{(\mathrm{H} 4 \alpha-\mathrm{H} 3)}=8.2 \mathrm{~Hz}, \mathrm{H}_{\alpha} \mathrm{C} 4\right), 2.58$ $\left(\mathrm{s}, 3 \mathrm{H}, \mathrm{CH}_{3} \mathrm{~N}\right), 2.25\left(\mathrm{ddd}, 1 \mathrm{H},{ }^{2} J_{(\mathrm{H} 4 \beta-\mathrm{H} 4 \alpha)}=13.4 \mathrm{~Hz},{ }^{3} J_{(\mathrm{H} 4 \beta-\mathrm{H} 5)}=5.1 \mathrm{~Hz},{ }^{3} J_{(\mathrm{H} 4 \beta-\mathrm{H} 3)}=3.3 \mathrm{~Hz}, \mathrm{H}_{\beta} \mathrm{C} 4\right)$; ${ }^{13} \mathrm{C}-\mathrm{NMR}\left(150 \mathrm{MHz}, \mathrm{CDCl}_{3}\right)$ 8: $172.09\left(\mathrm{C}(\mathrm{O}) \mathrm{OCH}_{3}\right), 155.49\left(\mathrm{C2}^{\prime}\right), 152.83\left(\mathrm{C6}^{\prime}\right), 150.05\left(\mathrm{C}^{\prime}\right), 141.72\left(\mathrm{C}^{\prime}\right)$, 119.33 (C5'), $76.04(\mathrm{C} 5), 66.34(\mathrm{C} 3), 52.52\left(\mathrm{C}(\mathrm{O}) \mathrm{OCH}_{3}\right), 45.54\left(\mathrm{CH}_{2}-\mathrm{Ade}\right), 45.36\left(\mathrm{CH}_{3} \mathrm{~N}\right), 35.16(\mathrm{C} 4)$. Anal. Calcd for $\mathrm{C}_{12} \mathrm{H}_{16} \mathrm{~N}_{6} \mathrm{O}_{3}: \mathrm{C}, 49.31 ; \mathrm{H}, 5.52 ; \mathrm{N}, 28.75$. Found: $\mathrm{C}, 49.22 ; \mathrm{H}, 5.71 ; \mathrm{N}, 28.52$ (obtained on a 67:33 mixture of cis-14i and trans-14i).

Methyl trans-3-[(6-amino-9H-purin-9-yl)methyl]-2-methylisoxazolidine-5-carboxylate (trans-14i). NMR signals of trans-14i were extracted from the spectra of a $68: 32$ mixture of cis-14i and trans-14i ${ }^{1} \mathrm{H}-\mathrm{NMR}$ $\left(300 \mathrm{MHz}, \mathrm{CDCl}_{3}\right)$ ) 8.35 (s, 1H, $\left.\mathrm{HC}^{\prime}\right), 7.95$ (s, 1H, $\left.\mathrm{HC} 8^{\prime}\right), 5.94\left(\mathrm{br} \mathrm{s}, 2 \mathrm{H}, \mathrm{NH}_{2}\right), 4.49$ (dd, $1 \mathrm{H},{ }^{3} J_{(\mathrm{H} 4 \beta-\mathrm{H} 5)}$ $\left.=8.7 \mathrm{~Hz},{ }^{3} J_{(\mathrm{H} 4 \alpha-\mathrm{H} 5)}=7.5 \mathrm{~Hz}, \mathrm{HC} 5\right), 4.28\left(\mathrm{dd}, 1 \mathrm{H},{ }^{2} J_{(\mathrm{HCH})}=14.1 \mathrm{~Hz},{ }^{3} J_{(\mathrm{HCC}-\mathrm{H} 3)}=4.5 \mathrm{~Hz}\right.$, HCH-Ade $)$, $4.14\left(\mathrm{dd}, 1 \mathrm{H},{ }^{2} J_{(\mathrm{HCH})}=14.1 \mathrm{~Hz},{ }^{3} \mathrm{~J}_{(\mathrm{HCC}-\mathrm{H} 3)}=8.0 \mathrm{~Hz}, \mathrm{HCH}-\mathrm{Ade}\right), 3.77\left(\mathrm{~s}, 3 \mathrm{H}, \mathrm{C}(\mathrm{O}) \mathrm{OCH}_{3}\right), 3.50$ (dddd, $\left.1 \mathrm{H},{ }^{3} J_{(\mathrm{HCC}-\mathrm{H} 3)}=8.0 \mathrm{~Hz},{ }^{3} J_{(\mathrm{H} 4 \alpha-\mathrm{H} 3)}=7.8 \mathrm{~Hz},{ }^{3} J_{(\mathrm{HCC}-\mathrm{H} 3)}=4.5 \mathrm{~Hz},{ }^{3} J_{(\mathrm{H} 4 \beta-\mathrm{H} 3)}=3.4 \mathrm{~Hz}, \mathrm{HC} 3\right), 2.77(\mathrm{ddd}$, $\left.1 \mathrm{H},{ }^{2} J_{(\mathrm{H} 4 \alpha-\mathrm{H} 4 \beta)}=13.2 \mathrm{~Hz},{ }^{3} J_{(\mathrm{H} 4 \alpha-\mathrm{H} 5)}=7.5 \mathrm{~Hz},{ }^{3} J_{(\mathrm{H} 4 \alpha-\mathrm{H} 3)}=7.8 \mathrm{~Hz}, \mathrm{H}_{\alpha} \mathrm{C} 4\right), 2.64\left(\mathrm{~s}, 3 \mathrm{H}, \mathrm{CH}_{3} \mathrm{~N}\right), 2.30$ $\left(\mathrm{ddd}, 1 \mathrm{H},{ }^{2} J_{(\mathrm{H} 4 \beta-\mathrm{H} 4 \alpha)}=13.2 \mathrm{~Hz},{ }^{3} J_{(\mathrm{H} 4 \beta-\mathrm{H} 5)}=8.7 \mathrm{~Hz},{ }^{3} J_{(\mathrm{H} 4 \beta-\mathrm{H} 3)}=3.4 \mathrm{~Hz}, \mathrm{H}_{\beta} \mathrm{C} 4\right) ;{ }^{13} \mathrm{C}-\mathrm{NMR}(150 \mathrm{MHz}$, $\left.\mathrm{CDCl}_{3}\right)$ \&: $171.39\left(\mathrm{C}(\mathrm{O}) \mathrm{OCH}_{3}\right), 155.42\left(\mathrm{C2}^{\prime}\right), 152.65\left(\mathrm{C6}^{\prime}\right), 149.98\left(\mathrm{C}^{\prime}\right), 142.01\left(\mathrm{C} 8^{\prime}\right), 119.44\left(\mathrm{C}^{\prime}\right), 74.48$ (C5), $66.11(\mathrm{C} 3), 52.62\left(\mathrm{C}(\mathrm{O}) \mathrm{OCH}_{3}\right), 45.88\left(\mathrm{CH}_{2}-\mathrm{Ade}\right), 44.41\left(\mathrm{CH}_{3} \mathrm{~N}\right), 34.99(\mathrm{C} 4)$. Anal. Calcd for $\mathrm{C}_{12} \mathrm{H}_{16} \mathrm{~N}_{6} \mathrm{O}_{3}: \mathrm{C}, 49.31 ; \mathrm{H}, 5.52 ; \mathrm{N}, 28.75$. Found: $\mathrm{C}, 49.17 ; \mathrm{H}, 5.24 ; \mathrm{N}, 28.39$ (obtained on a 67:33 mixture of cis-14i and trans-14i).

\subsection{General Procedure for the Synthesis of $\gamma$-Lactams trans-15 and cis-15}

A solution of the respective isoxazolidines cis-14 and trans-14 $(1.00 \mathrm{mmol})$ in methanol $(3 \mathrm{~mL})$ was stirred under atmospheric pressure of hydrogen over $\mathrm{Pd} / \mathrm{C}(0.05 \mathrm{mmol})$ with $\mathrm{Pd}(\mathrm{OH})_{2} / \mathrm{C}(0.05$ $\mathrm{mmol}$ ) at room temperature for 1-2 days. The suspension was filtered through a layer of Celite. The solvent was removed in vacuo and crude products were chromatographed on silica gel columns with chloroform:methanol mixtures (50:1, 20:1 and 10:1, v/v) and then on HPLC using a X Bridge Prep, C8, 5 $\mu \mathrm{m}, \mathrm{OBD}, 19 \times 100 \mathrm{~mm}$ column and a water:methanol mixture $(98: 2, v / v)$ as an eluent to give $\gamma$-lactams trans-15 and cis-15. 
trans-1-[(4-Hydroxy-1-methyl-5-oxopyrrolidin-2-yl)methyl]-5-methylpyrimidine-2,4(1H,3H)-dione (trans-15b). Yield: 29\%; a colorless amorphous solid; m.p. $>230{ }^{\circ} \mathrm{C}$ with decomposition (crystallized from methanol-chloroform). IR (KBr, $\left.\mathrm{cm}^{-1}\right) v_{\text {max }}: 3391,3171,3042,2938,2813,2518,1686,1472,1323$, 1093, 944; ${ }^{1} \mathrm{H}-\mathrm{NMR}\left(600 \mathrm{MHz}, \mathrm{CD}_{3} \mathrm{OD}\right) \delta: 7.38\left(\mathrm{q}, 1 \mathrm{H},{ }^{4} \mathrm{~J}=1.0 \mathrm{~Hz}\right), 4.29\left(\mathrm{dd}, 1 \mathrm{H},{ }^{3} J_{(\mathrm{H} 4-\mathrm{H} 3 \beta)}=9.0\right.$ $\left.\mathrm{Hz},{ }^{3} J_{(\mathrm{H} 4-\mathrm{H} 3 \alpha)}=8.1 \mathrm{~Hz}, \mathrm{HC} 4\right), 4.01\left(\mathrm{dd}, 1 \mathrm{H},{ }^{2} \mathrm{~J}_{(\mathrm{HCH})}=13.9 \mathrm{~Hz},{ }^{3} \mathrm{~J}_{(\mathrm{HCC}-\mathrm{H} 2)}=4.6 \mathrm{~Hz}, \mathrm{HCH}-\mathrm{Thy}\right), 3.92$ $\left(\mathrm{dddd}, 1 \mathrm{H},{ }^{3} J_{(\mathrm{H} 2-\mathrm{H} 3 \beta)}=9.0 \mathrm{~Hz},{ }^{3} J_{(\mathrm{H} 2-\mathrm{CCH})}=5.9 \mathrm{~Hz},{ }^{3} J_{(\mathrm{H} 2-\mathrm{CCH})}=4.6 \mathrm{~Hz},{ }^{3} J_{(\mathrm{H} 2-\mathrm{H} 3 \alpha)}=1.0 \mathrm{~Hz}, \mathrm{HC} 2\right)$, $3.84\left(\mathrm{dd}, 1 \mathrm{H},{ }^{2} J_{(\mathrm{HCH})}=13.9 \mathrm{~Hz},{ }^{3} J_{(\mathrm{HCC}-\mathrm{H} 2)}=5.9 \mathrm{~Hz}, \mathrm{HCH}-\mathrm{Thy}\right), 2.92\left(\mathrm{~s}, 3 \mathrm{H}, \mathrm{CH}_{3} \mathrm{~N}\right), 2.46(\mathrm{ddd}, 1 \mathrm{H}$, $\left.{ }^{2} J_{(\mathrm{H} 3 \alpha-\mathrm{H} 3 \beta)}=13.2 \mathrm{~Hz},{ }^{3} J_{(\mathrm{H} 3 \alpha-\mathrm{H} 4)}=8.1 \mathrm{~Hz},{ }^{3} J_{(\mathrm{H} 3 \alpha-\mathrm{H} 2)}=1.0 \mathrm{~Hz}, \mathrm{H}_{\alpha} \mathrm{C} 3\right), 2.02\left(\mathrm{ddd}, 1 \mathrm{H},{ }^{2} J_{(\mathrm{H} 3 \beta-\mathrm{H} 3 \alpha)}=\right.$ $\left.13.2 \mathrm{~Hz},{ }^{3} J_{(\mathrm{H} 3 \beta-\mathrm{H} 4)}=9.0 \mathrm{~Hz},{ }^{3} J_{(\mathrm{H} 3 \beta-\mathrm{H} 2)}=9.0 \mathrm{~Hz}, \mathrm{H}_{\beta} \mathrm{C} 3\right), 1.90\left(\mathrm{~d}, 3 \mathrm{H},{ }^{4} \mathrm{~J}=1.0 \mathrm{~Hz}, \mathrm{CH}_{3}\right) ;{ }^{13} \mathrm{C}-\mathrm{NMR}(150$

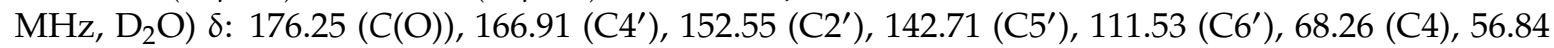
( $\mathrm{CH}_{2}$-Thy), 49.78 (C2), $31.81(\mathrm{C} 3), 29.19\left(\mathrm{CH}_{3} \mathrm{~N}\right), 11.32\left(\mathrm{CH}_{3}\right)$. Anal. Calcd for $\mathrm{C}_{11} \mathrm{H}_{15} \mathrm{~N}_{3} \mathrm{O}_{4}: \mathrm{C}, 52.17$; H, 5.97; N, 16.59. Found: C, 52.25; H, 5.67; N, 16.59 .

cis-1-[(4-Hydroxy-1-methyl-5-oxopyrrolidin-2-yl)methyl]-5-methylpyrimidine-2,4(1H,3H)-dione (cis-15b). Yield: 6.0\%; a colorless amorphous solid; m.p. $>230{ }^{\circ} \mathrm{C}$ (crystallized from methanol-chloroform). IR $\left(\mathrm{KBr}, \mathrm{cm}^{-1}\right) v_{\max }: 3552,3454,3389,3315,3175,3042,2952,2930,2832,1692,1661,1469,1127 ;{ }^{1} \mathrm{H}-\mathrm{NMR}$ $\left(600 \mathrm{MHz}, \mathrm{D}_{2} \mathrm{O}\right) \delta: 7.36\left(\mathrm{q}, 1 \mathrm{H},{ }^{4} \mathrm{~J}=1.1 \mathrm{~Hz}\right), 4.35\left(\mathrm{dd}, 1 \mathrm{H},{ }^{3} J_{(\mathrm{H} 4-\mathrm{H} 3 \alpha)}=8.3 \mathrm{~Hz},{ }^{3} J_{(\mathrm{H} 4-\mathrm{H} 3 \beta)}=6.1 \mathrm{~Hz}, \mathrm{HC} 4\right)$, $4.19\left(\mathrm{dd}, 1 \mathrm{H},{ }^{2} J_{(\mathrm{HCH})}=14.4 \mathrm{~Hz},{ }^{3} \mathrm{~J}_{(\mathrm{HCC}-\mathrm{H} 2)}=4.9 \mathrm{~Hz}, \mathrm{HCH}-\mathrm{Thy}\right), 3.94\left(\mathrm{dddd}, 1 \mathrm{H},{ }^{3} J_{(\mathrm{H} 2-\mathrm{H} 3 \alpha)}=7.6 \mathrm{~Hz}\right.$, $\left.{ }^{3} J_{(\mathrm{H} 2-\mathrm{CCH})}=5.9 \mathrm{~Hz},{ }^{3} J_{(\mathrm{H} 2-\mathrm{H} 3 \beta)}=5.8 \mathrm{~Hz},{ }^{3} J_{(\mathrm{H} 2-\mathrm{CCH})}=4.9 \mathrm{~Hz}, \mathrm{HC} 2\right), 3.90\left(\mathrm{dd}, 1 \mathrm{H},{ }^{2} J_{(\mathrm{HCH})}=14.4 \mathrm{~Hz}\right.$, $\left.{ }^{3} J_{(\mathrm{HCC}-\mathrm{H} 2)}=5.9 \mathrm{~Hz}, \mathrm{HCH}-\mathrm{Thy}\right), 2.88\left(\mathrm{~s}, 3 \mathrm{H}, \mathrm{CH}_{3} \mathrm{~N}\right), 2.56\left(\mathrm{ddd}, 1 \mathrm{H},{ }^{2} J_{(\mathrm{H} 3 \alpha-\mathrm{H} 3 \beta)}=13.7 \mathrm{~Hz},{ }^{3} J_{(\mathrm{H} 3 \alpha-\mathrm{H} 4)}=\right.$ $\left.8.3 \mathrm{~Hz},{ }^{3} J_{(\mathrm{H} 3 \alpha-\mathrm{H} 2)}=7.6 \mathrm{~Hz}, \mathrm{H}_{\alpha} \mathrm{C} 3\right), 1.86\left(\mathrm{q}, 3 \mathrm{H},{ }^{4} J=1.1 \mathrm{~Hz}, \mathrm{CH}_{3}\right), 1.68\left(\mathrm{ddd}, 1 \mathrm{H},{ }^{2} J_{(\mathrm{H} 3 \beta-\mathrm{H} 3 \alpha)}=13.7 \mathrm{~Hz}\right.$, $\left.{ }^{3} \mathrm{~J}_{(\mathrm{H} 3 \beta-\mathrm{H} 4)}=6.1 \mathrm{~Hz},{ }^{3} \mathrm{~J}_{(\mathrm{H} 3 \beta-\mathrm{H} 2)}=5.8 \mathrm{~Hz}, \mathrm{H}_{\beta} \mathrm{C} 3\right) ;{ }^{13} \mathrm{C}-\mathrm{NMR}\left(150 \mathrm{MHz}, \mathrm{D}_{2} \mathrm{O}\right) \delta: 176.48(\mathrm{C}(\mathrm{O})), 167.35$ $\left(\mathrm{C}^{\prime}\right), 152.94\left(\mathrm{C} 2^{\prime}\right), 143.01\left(\mathrm{C}^{\prime}\right), 111.23\left(\mathrm{C} 6^{\prime}\right), 69.11(\mathrm{C} 4), 56.82\left(\mathrm{CH}_{2}-\mathrm{Thy}\right), 50.26(\mathrm{C} 2), 31.06$ (C3), 28.82 $\left(\mathrm{CH}_{3} \mathrm{~N}\right), 11.38\left(\mathrm{CH}_{3}\right)$. Anal. Calcd for $\mathrm{C}_{11} \mathrm{H}_{15} \mathrm{~N}_{3} \mathrm{O}_{4}: \mathrm{C}, 52.17 ; \mathrm{H}, 5.97 ; \mathrm{N}, 16.59$. Found: $\mathrm{C}, 52.39 ; \mathrm{H}$, $5.55 ; \mathrm{N}, 16.60$.

trans-1-[(4-Hydroxy-1-methyl-5-oxopyrrolidin-2-yl)metyl]dihydropyrimidine-2,4(1H,3H)-dione (trans-15g). Yield: 4.0\%; a colorless amorphous solid; m.p. $>230{ }^{\circ} \mathrm{C}$ with decomposition (crystallized from methanol-chloroform). IR (KBr, cm $\left.{ }^{-1}\right) v_{\max }: 3226,3097,3048,2959,2873,1708,1670,1488,1462,1255$, 1140, 1048. ${ }^{1} \mathrm{H}-\mathrm{NMR}\left(600 \mathrm{MHz}, \mathrm{CD}_{3} \mathrm{OD}\right) \delta: 4.54$ (br s, $\left.1 \mathrm{H}, \mathrm{NH}\right), 4.42\left(\mathrm{dd}, 1 \mathrm{H},{ }^{3} J_{(\mathrm{H} 4-\mathrm{H} 3 \beta)}=8.7 \mathrm{~Hz}\right.$, $\left.{ }^{3} J_{(\mathrm{H} 4-\mathrm{H} 3 \alpha)}=8.1 \mathrm{~Hz}, \mathrm{HC} 4\right), 3.85\left(\mathrm{dddd}, 1 \mathrm{H},{ }^{3} J_{(\mathrm{H} 2-\mathrm{H} 3 \beta)}=8.7 \mathrm{~Hz},{ }^{3} J_{(\mathrm{H} 2-\mathrm{CCH})}=6.5 \mathrm{~Hz},{ }^{3} J_{(\mathrm{H} 2-\mathrm{CCH})}=4.8\right.$ $\left.\mathrm{Hz},{ }^{3} J_{(\mathrm{H} 2-\mathrm{H} 3 \alpha)}=1.6 \mathrm{~Hz}, \mathrm{HC} 2\right), 3.71\left(\mathrm{dd}, 1 \mathrm{H},{ }^{2} J_{(\mathrm{HCH})}=14.1 \mathrm{~Hz},{ }^{3} J_{(\mathrm{HCC}-\mathrm{H} 2)}=4.8 \mathrm{~Hz}, \mathrm{HCH}-\right.$ dihydroUra $)$, $3.58-3.49(\mathrm{~m}, 2 \mathrm{H}), 3.46\left(\mathrm{dd}, 1 \mathrm{H},{ }^{2} J_{(\mathrm{HCH})}=14.1 \mathrm{~Hz},{ }^{3} J_{(\mathrm{HCC}-\mathrm{H} 2)}=6.5 \mathrm{~Hz}, \mathrm{HCH}\right.$-dihydroUra), $2.94(\mathrm{~s}$, $\left.3 \mathrm{H}, \mathrm{CH}_{3} \mathrm{~N}\right), 2.72-2.63(\mathrm{~m}, 2 \mathrm{H}), 2.43\left(\mathrm{ddd}, 1 \mathrm{H},{ }^{2} J_{(\mathrm{H} 3 \alpha-\mathrm{H} 3 \beta)}=13.1 \mathrm{~Hz},{ }^{3} J_{(\mathrm{H} 3 \alpha-\mathrm{H} 4)}=8.1 \mathrm{~Hz},{ }^{3} J_{(\mathrm{H} 3 \alpha-\mathrm{H} 2)}\right.$ $\left.=1.6 \mathrm{~Hz}, \mathrm{H}_{\alpha} \mathrm{C} 3\right), 2.02\left(\mathrm{ddd}, 1 \mathrm{H},{ }^{2} J_{(\mathrm{H} 3 \beta-\mathrm{H} 3 \alpha)}=13.1 \mathrm{~Hz},{ }^{3} J_{(\mathrm{H} 3 \beta-\mathrm{H} 4)}=8.7 \mathrm{~Hz},{ }^{3} J_{(\mathrm{H} 3 \beta-\mathrm{H} 2)}=8.7 \mathrm{~Hz}\right.$, $\left.\mathrm{H}_{\beta} \mathrm{C} 3\right) ;{ }^{13} \mathrm{C}-\mathrm{NMR}\left(150 \mathrm{MHz}, \mathrm{CD}_{3} \mathrm{OD}\right) \delta$ : $175.44(\mathrm{C}(\mathrm{O})), 171.24\left(\mathrm{C}^{\prime}\right), 154.34$ (C2'), 68.17 (C4), 56.28 ( $\mathrm{CH}_{2}$-dihydroUra), $48.60(\mathrm{C} 2), 43.19\left(\mathrm{C}^{\prime}\right)$, $32.44\left(\mathrm{C}^{\prime}\right), 30.50\left(\mathrm{CH}_{3} \mathrm{~N}\right), 27.81$ (C3). Anal. Calcd for $\mathrm{C}_{10} \mathrm{H}_{15} \mathrm{~N}_{3} \mathrm{O}_{4}$ : C, 49.79; H, 6.27; N, 17.42. Found: C, 49.80; H, 6.26; N, 17.40.

cis-1-[(4-Hydroxy-1-methyl-5-oxopyrrolidin-2-yl)metyl]dihydropyrimidine-2,4(1H,3H)-dione (cis-15g). Yield: 23\%; a colorless amorphous solid; m.p. $>230{ }^{\circ} \mathrm{C}$ with decomposition (crystallized from methanol-chloroform). IR (KBr, cm $\left.{ }^{-1}\right) v_{\max }:$ 3298, 3243, 3047, 2959, 2822, 1674, 1461, $1239,1062$. ${ }^{1} \mathrm{H}-\mathrm{NMR}\left(600 \mathrm{MHz}, \mathrm{CD}_{3} \mathrm{OD}\right) \delta: 4.63$ (br s, $\left.1 \mathrm{H}, \mathrm{NH}\right), 4.26\left(\mathrm{dd}, 1 \mathrm{H},{ }^{3} J_{(\mathrm{H} 4-\mathrm{H} 3 \alpha)}=8.2 \mathrm{~Hz},{ }^{3} J_{(\mathrm{H} 4-\mathrm{H} 3 \beta)}=7.0\right.$ $\mathrm{Hz}, \mathrm{HC} 4), 3.93\left(\mathrm{dd}, 1 \mathrm{H},{ }^{2} J_{(\mathrm{HCH})}=14.3 \mathrm{~Hz},{ }^{3} \mathrm{~J}_{(\mathrm{HCC}-\mathrm{H} 2)}=4.6 \mathrm{~Hz}, \mathrm{HCH}-\right.$ dihydroUra $), 3.79-3.75(\mathrm{~m}, 1 \mathrm{H}$, HC2), 3.56-3.53 (m, 2H), $3.45\left(\mathrm{dd}, 1 \mathrm{H},{ }^{2} J_{(\mathrm{HCH})}=14.3 \mathrm{~Hz},{ }^{3} J_{(\mathrm{HCC}-\mathrm{H} 2)}=5.9 \mathrm{~Hz}, \mathrm{HCH}\right.$-dihydroUra), 2.93 $\left(\mathrm{s}, 3 \mathrm{H}, \mathrm{CH}_{3} \mathrm{~N}\right), 2.70\left(\mathrm{td}, 2 \mathrm{H},{ }^{3} J=6.6 \mathrm{~Hz},{ }^{2} J=2.9 \mathrm{~Hz}\right), 2.56\left(\mathrm{ddd}, 1 \mathrm{H},{ }^{2} J_{(\mathrm{H} 3 \alpha-\mathrm{H} 3 \beta)}=13.4 \mathrm{~Hz},{ }^{3} J_{(\mathrm{H} 3 \alpha-\mathrm{H} 4)}=\right.$ $\left.8.2 \mathrm{~Hz},{ }^{3} J_{(\mathrm{H} 3 \alpha-\mathrm{H} 2)}=7.5 \mathrm{~Hz}, \mathrm{H}_{\alpha} \mathrm{C} 3\right), 1.73\left(\mathrm{ddd}, 1 \mathrm{H},{ }^{2} J_{(\mathrm{H} 3 \beta-\mathrm{H} 3 \alpha)}=13.4 \mathrm{~Hz},{ }^{3} J_{(\mathrm{H} 3 \beta-\mathrm{H} 4)}=7.0 \mathrm{~Hz},{ }^{3} J_{(\mathrm{H} 3 \beta-\mathrm{H} 2)}\right.$ $\left.=6.5 \mathrm{~Hz}, \mathrm{H}_{\beta} \mathrm{C} 3\right) ;{ }^{13} \mathrm{C}-\mathrm{NMR}\left(150 \mathrm{MHz}, \mathrm{CD}_{3} \mathrm{OD}\right) \delta: 175.79(\mathrm{C}(\mathrm{O})), 171.29\left(\mathrm{C}^{\prime}\right), 154.26\left(\mathrm{C}^{\prime}\right), 68.99(\mathrm{C} 4)$, $55.97\left(\mathrm{CH}_{2}\right.$-dihydroUra), $49.14(\mathrm{C} 2), 43.16\left(\mathrm{C}^{\prime}\right), 31.93\left(\mathrm{C}^{\prime}\right), 30.38\left(\mathrm{CH}_{3} \mathrm{~N}\right), 27.50(\mathrm{C} 3)$. Anal. Calcd for $\mathrm{C}_{10} \mathrm{H}_{15} \mathrm{~N}_{3} \mathrm{O}_{4}$ : C, 49.79; H, 6.27; N, 17.42. Found: C, 49.68; H, 6.17; N, 17.30. 
trans-9-[(4-Hydroxy-1-methyl-5-oxopyrrolidin-2-yl)methyl]-1,3-dimethyl-3,9-dihydro-1H-purine-2,6-dione (trans-15h). Yield: 34\%; a colorless amorphous solid; m.p. $>230{ }^{\circ} \mathrm{C}$ (crystallized from methanol-chloroform). IR (KBr, $\left.\mathrm{cm}^{-1}\right) v_{\max }: 3345,3103,2923,2853,1709,1680,1665,1546,1469$, 1407,1316, 1237, 1085, 761. ${ }^{1} \mathrm{H}-\mathrm{NMR}\left(600 \mathrm{MHz}, \mathrm{CDCl}_{3}\right) \delta: 7.52(\mathrm{~s}, 1 \mathrm{H}), 4.67\left(\mathrm{dd}, 1 \mathrm{H},{ }^{2} J_{(\mathrm{HCH})}=13.9 \mathrm{~Hz}\right.$, $\left.{ }^{3} J_{(\mathrm{HCC}-\mathrm{H} 2)}=4.8 \mathrm{~Hz}, \mathrm{HCH}-\mathrm{The}\right), 4.21\left(\mathrm{dd}, 1 \mathrm{H},{ }^{2} J_{(\mathrm{HCH})}=13.9 \mathrm{~Hz},{ }^{3} J_{(\mathrm{HCC}-\mathrm{H} 2)}=6.4 \mathrm{~Hz}, \mathrm{HCH}-\mathrm{The}\right), 4.16$ $\left(\mathrm{dd}, 1 \mathrm{H},{ }^{3} J_{(\mathrm{H} 4-\mathrm{H} 3 \alpha)}=8.6 \mathrm{~Hz},{ }^{3} J_{(\mathrm{H} 4-\mathrm{H} 3 \beta)}=8.6 \mathrm{~Hz}, \mathrm{HC} 4\right), 4.07-4.04(\mathrm{~m}, 1 \mathrm{H}, \mathrm{HC} 2), 3.62\left(\mathrm{~s}, 3 \mathrm{H}, \mathrm{CH}_{3}\right), 3.45$ $\left(\mathrm{s}, 3 \mathrm{H}, \mathrm{CH}_{3}\right), 2.94\left(\mathrm{~s}, 3 \mathrm{H}, \mathrm{CH}_{3} \mathrm{~N}\right), 2.38\left(\mathrm{ddd}, 1 \mathrm{H},{ }^{2} J_{(\mathrm{H} 3 \alpha-\mathrm{H} 3 \beta)}=13.4 \mathrm{~Hz}^{3} J_{(\mathrm{H} 3 \alpha-\mathrm{H} 4)}=8.6 \mathrm{~Hz},{ }^{3} J_{(\mathrm{H} 3 \alpha-\mathrm{H} 2)}=\right.$ $\left.8.0 \mathrm{~Hz}, \mathrm{H}_{\alpha} \mathrm{C} 3\right), 2.14\left(\mathrm{ddd}, 1 \mathrm{H},{ }^{2} J_{(\mathrm{H} 3 \beta-\mathrm{H} 3 \alpha)}=13.4 \mathrm{~Hz}^{3} J_{(\mathrm{H} 3 \beta-\mathrm{H} 2)}=9.0 \mathrm{~Hz},{ }^{3} J_{(\mathrm{H} 3 \beta-\mathrm{H} 4)}=8.6 \mathrm{~Hz}, \mathrm{H}_{\beta} \mathrm{C} 3\right)$;

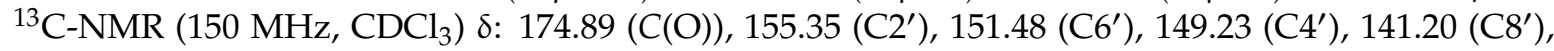
$106.92\left(\mathrm{C5}^{\prime}\right), 67.79(\mathrm{C} 4), 57.33\left(\mathrm{CH}_{2}-\mathrm{The}\right), 48.56(\mathrm{C} 2), 31.70\left(\mathrm{CH}_{3}\right), 29.89\left(\mathrm{CH}_{3} \mathrm{~N}\right), 29.07(\mathrm{C} 3), 28.09\left(\mathrm{CH}_{3}\right)$. Anal. Calcd for $\mathrm{C}_{13} \mathrm{H}_{17} \mathrm{~N}_{5} \mathrm{O}_{4} \times 0.2 \mathrm{H}_{2} \mathrm{O}: \mathrm{C}, 50.22 ; \mathrm{H}, 5.64 ; \mathrm{N}, 22.53$. Found: $\mathrm{C}, 50.06 ; \mathrm{H}, 5.46 ; \mathrm{N}, 22.40$.

cis-9-[(4-Hydroxy-1-methyl-5-oxopyrrolidin-2-yl)methyl]-1,3-dimethyl-3,9-dihydro-1H-purine-2,6-dione (cis-15h). Yield: 26\%; a colorless amorphous solid; m.p. $>230{ }^{\circ} \mathrm{C}$ (crystallized from methanol-chloroform). IR ( $\left.\mathrm{KBr}, \mathrm{cm}^{-1}\right) v_{\max }$ : 3284, 3112, 2999, 2961, 2920, 1694, 1679, 1654, 1457, 1296, 1238, 1085, 749. ${ }^{1} \mathrm{H}-\mathrm{NMR}\left(600 \mathrm{MHz}, \mathrm{CDCl}_{3}\right) \delta: 7.65(\mathrm{~s}, 1 \mathrm{H}), 4.83\left(\mathrm{dd}, 1 \mathrm{H},{ }^{2} J_{(\mathrm{HCH})}=13.4 \mathrm{~Hz}\right.$, $\left.{ }^{3} J_{(\mathrm{HCC}-\mathrm{H} 2)}=4.8 \mathrm{~Hz}, \mathrm{HCH}-\mathrm{The}\right), 4.31\left(\mathrm{dd}, 1 \mathrm{H},{ }^{3} \mathrm{~J}_{(\mathrm{H} 4-\mathrm{H} 3 \alpha)}=7.6 \mathrm{~Hz},{ }^{3} J_{(\mathrm{H} 4-\mathrm{H} 3 \beta)}=4.0 \mathrm{~Hz}, \mathrm{HC} 4\right), 4.23(\mathrm{dd}$, $\left.1 \mathrm{H},{ }^{2} J_{(\mathrm{HCH})}=13.4 \mathrm{~Hz},{ }^{3} J_{(\mathrm{HCC}-\mathrm{H} 2)}=7.9 \mathrm{~Hz}, \mathrm{HCH}-\mathrm{The}\right), 3.94\left(\mathrm{dddd}, 1 \mathrm{H},{ }^{3} J_{(\mathrm{H} 2-\mathrm{CCH})}=7.9 \mathrm{~Hz},{ }^{3} J_{(\mathrm{H} 2-\mathrm{H} 3 \alpha)}\right.$ $\left.=7.6 \mathrm{~Hz},{ }^{3} J_{(\mathrm{H} 2-\mathrm{H} 3 \beta)}=4.0 \mathrm{~Hz},{ }^{3} J_{(\mathrm{H} 2-\mathrm{CCH})}=4.8 \mathrm{~Hz}, \mathrm{HC} 2\right), 3.62\left(\mathrm{~s}, 3 \mathrm{H}, \mathrm{CH}_{3}\right), 3.44\left(\mathrm{~s}, 3 \mathrm{H}, \mathrm{CH}_{3}\right), 2.96(\mathrm{~s}$, $\left.3 \mathrm{H}, \mathrm{CH}_{3} \mathrm{~N}\right), 2.38\left(\mathrm{ddd}, 1 \mathrm{H},{ }^{2} J_{(\mathrm{H} 3 \alpha-\mathrm{H} 3 \beta)}=13.8 \mathrm{~Hz},{ }^{3} J_{(\mathrm{H} 3 \alpha-\mathrm{H} 4)}=7.6 \mathrm{~Hz},{ }^{3} J_{(\mathrm{H} 3 \alpha-\mathrm{H} 2)}=7.6 \mathrm{~Hz}, \mathrm{H}_{\alpha} \mathrm{C} 3\right)$, $1.76\left(\mathrm{ddd}, 1 \mathrm{H},{ }^{2} J_{(\mathrm{H} 3 \beta-\mathrm{H} 3 \alpha)}=13.8 \mathrm{~Hz},{ }^{3} J_{(\mathrm{H} 3 \beta-\mathrm{H} 4)}=4.0 \mathrm{~Hz},{ }^{3} J_{(\mathrm{H} 3 \beta-\mathrm{H} 2)}=4.0 \mathrm{~Hz}, \mathrm{H}_{\beta} \mathrm{C} 3\right) ;{ }^{13} \mathrm{C}-\mathrm{NMR}(150$

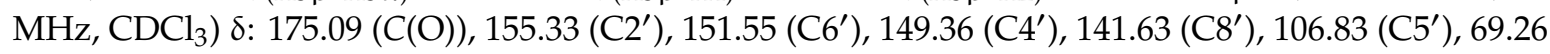
(C4), $57.75\left(\mathrm{CH}_{2}-\mathrm{The}\right), 50.21(\mathrm{C} 2), 31.31\left(\mathrm{CH}_{3}\right), 29.89\left(\mathrm{CH}_{3} \mathrm{~N}\right), 28.82(\mathrm{C} 3), 28.06\left(\mathrm{CH}_{3}\right)$. Anal. Calcd for $\mathrm{C}_{13} \mathrm{H}_{17} \mathrm{~N}_{5} \mathrm{O}_{4}: \mathrm{C}, 50.81 ; \mathrm{H}, 5.58 ; \mathrm{N}, 22.79$. Found: C, 50.73; H, 5.67; N, 22.96.

trans-5-[(6-Amino-9H-purin-9-yl)methyl]-3-hydroxy-1-methylpyrrolidin-2-one (trans-15i). Yield: 28\%; a colorless amorphous solid; m.p. $>230{ }^{\circ} \mathrm{C}$ with decomposition (crystallized from water). IR (KBr, $\left.\mathrm{cm}^{-1}\right) v_{\text {max }}: 3319,2955,2923,2853,1687,1603,1483,1326,1244,1132,1000,797 .{ }^{1} \mathrm{H}-\mathrm{NMR}(300 \mathrm{MHz}$,

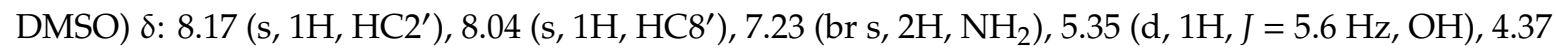
$\left(\mathrm{dAB}, 1 \mathrm{H},{ }^{2} J_{\mathrm{AB}}=14.6 \mathrm{~Hz},{ }^{3} J_{(\mathrm{HCC}-\mathrm{H} 2)}=3.8 \mathrm{~Hz}, \mathrm{HCH}-\mathrm{Ade}\right), 4.32\left(\mathrm{dAB}, 1 \mathrm{H},{ }^{2} J_{\mathrm{AB}}=14.6 \mathrm{~Hz},{ }^{3} J_{(\mathrm{HCC}-\mathrm{H} 2)}\right.$ $=4.5 \mathrm{~Hz}, \mathrm{HCH}-\mathrm{Ade}), 3.96-3.94(\mathrm{~m}, 1 \mathrm{H}), 3.26-3.22(\mathrm{~m}, 1 \mathrm{H}), 2.82\left(\mathrm{~s}, 3 \mathrm{H}, \mathrm{CH}_{3} \mathrm{~N}\right), 2.30-2.23(\mathrm{dd}, 1 \mathrm{H}$, $\left.{ }^{2} J_{(\mathrm{H} 3 \beta-\mathrm{H} 3 \alpha)}=13.1 \mathrm{~Hz},{ }^{3} \mathrm{~J}=8.3 \mathrm{~Hz}, \mathrm{H}_{\alpha} \mathrm{C} 3\right), 1.82\left(\mathrm{ddd}, 1 \mathrm{H},{ }^{2} J_{(\mathrm{H} 3 \beta-\mathrm{H} 3 \alpha)}=13.1 \mathrm{~Hz},{ }^{3} \mathrm{~J}=9.1 \mathrm{~Hz},{ }^{3} \mathrm{~J}=9.0 \mathrm{~Hz}\right.$, $\left.\mathrm{H}_{\beta} \mathrm{C} 3\right) ;{ }^{13} \mathrm{C}-\mathrm{NMR}(150 \mathrm{MHz}, \mathrm{DMSO}) \delta: 174.34(\mathrm{C}(\mathrm{O})), 156.52\left(\mathrm{C}^{\prime}\right), 153.15\left(\mathrm{C}^{\prime}\right), 150.41\left(\mathrm{C}^{\prime}\right), 141.54$ $\left(\mathrm{C}^{\prime}\right), 118.89$ (C5'), 67.09 (C4), $56.52\left(\mathrm{CH}_{2}-\mathrm{Ade}\right), 44.56(\mathrm{C} 2), 32.58(\mathrm{C} 3), 28.52\left(\mathrm{CH}_{3} \mathrm{~N}\right)$. Anal. Calcd for $\mathrm{C}_{11} \mathrm{H}_{14} \mathrm{~N}_{6} \mathrm{O}_{2}:$ C, 50.38; H, 5.38; N, 32.04. Found: C, 50.30; H, 5.20; N, 32.34.

cis-5-[(6-Amino-9H-purin-9-yl)methyl]-3-hydroxy-1-methylpyrrolidin-2-one (cis-15i). A colorless oil. IR $\left(\mathrm{KBr}, \mathrm{cm}^{-1}\right) v_{\text {max }}: 3469,3341,3173,3071,2959,2922,2852,1745,1601,1511,1473,1303,1270,1038$. NMR signals of cis-15i were extracted from the spectra of a $32: 78$ mixture of trans-15i and cis-15i ${ }^{1} \mathrm{H}-\mathrm{NMR}$

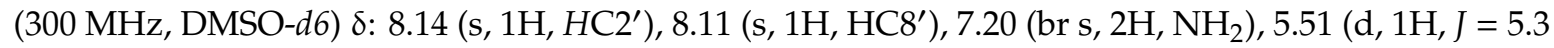
$\mathrm{Hz}, \mathrm{OH}), 4.50\left(\mathrm{dd}, 1 \mathrm{H},{ }^{2} \mathrm{~J}_{(\mathrm{HCH})}=14.3 \mathrm{~Hz},{ }^{3} J_{(\mathrm{HCC}-\mathrm{H} 2)}=4.7 \mathrm{~Hz}, \mathrm{HCH}-\mathrm{Ade}\right), 4.29\left(\mathrm{dd}, 1 \mathrm{H},{ }^{2} J_{(\mathrm{HCH})}=14.3\right.$ $\left.\mathrm{Hz}^{3} \mathrm{~J}_{(\mathrm{HCC}-\mathrm{H} 2)}=6.1 \mathrm{~Hz}, \mathrm{HCH}-\mathrm{Ade}\right), 4.05-4.01(\mathrm{~m}, 1 \mathrm{H}), 3.90-3.85(\mathrm{~m}, 1 \mathrm{H}), 2.77\left(\mathrm{~s}, 3 \mathrm{H}, \mathrm{CH}_{3} \mathrm{~N}\right), 2.27-2.23$ $\left(\mathrm{m}, 1 \mathrm{H}, \mathrm{H}_{\alpha} \mathrm{C} 3\right), 1.45\left(\mathrm{dt}, 1 \mathrm{H}^{2} \mathrm{~J}=14.2 \mathrm{~Hz},{ }^{3} \mathrm{~J}=7.0 \mathrm{~Hz}, \mathrm{H}_{\beta} \mathrm{C} 3\right) ;{ }^{13} \mathrm{C}-\mathrm{NMR}(150 \mathrm{MHz}, \mathrm{DMSO}) \delta: 175.09$ $(\mathrm{C}(\mathrm{O})), 156.47\left(\mathrm{C}^{\prime}\right), 153.04\left(\mathrm{C}^{\prime}\right), 150.42\left(\mathrm{C}^{\prime}\right), 141.53\left(\mathrm{C}^{\prime}\right), 119.02\left(\mathrm{C}^{\prime}\right), 68.61(\mathrm{C} 4), 55.78\left(\mathrm{CH}_{2}-\mathrm{Ade}^{\prime}\right)$, $45.84(\mathrm{C} 2), 32.34(\mathrm{C} 3), 28.57\left(\mathrm{CH}_{3} \mathrm{~N}\right)$. Anal. Calcd for $\mathrm{C}_{11} \mathrm{H}_{14} \mathrm{~N}_{6} \mathrm{O}_{2}: \mathrm{C}, 50.38 ; \mathrm{H}, 5.38 ; \mathrm{N}, 32.04$. Found: C, 50.23; H, 5.08; N, 31.95 (obtained on a 40:60 mixture of trans-15i and cis-15i).

\subsection{Synthesis of $\gamma$-Lactams cis-15d and trans-15d}

A solution of a 53:35:8:2 mixture of $\gamma$-lactams trans-15a, cis-15a, trans-15g and trans-15g $(0.130$ $\mathrm{g}, 0.54 \mathrm{mmol})$ and $N$-bromosuccinimide $(0.106 \mathrm{~g}, 0.594 \mathrm{mmol})$ in DMF $(4 \mathrm{~mL})$ was stirred at room temperature for $24 \mathrm{~h}$. The solvent was removed in vacuo and the crude product was purified on a silica gel column using chloroform-methanol $(100: 1, v / v)$ as an eluent. The respective fractions were subjected 
to chromatography on a X Bridge Prep, C8, $5 \mu \mathrm{m}$, OBD, $19 \times 100 \mathrm{~mm}$ column using water/methanol $(98: 2, v / v)$ to give pure $\gamma$-lactams trans-15d $(0.051 \mathrm{~g}, 30 \%)$ and cis-15d $(0.016 \mathrm{~g}, 9.3 \%)$.

trans-5-Bromo-1-[(4-hydroxy-1-methyl-5-oxopyrrolidin-2-yl)methyl]pyrimidine-2,4(1H,3H)-dione (trans-15d). Yield: 30\%; a colorless amorphous solid; m.p. $=199-200{ }^{\circ} \mathrm{C}$ with decomposition (crystallized from methanol-chloroform). IR (KBr, cm $\left.{ }^{-1}\right) v_{\text {max }}$ : 3381, 3123, 3022, 2908, 2818, 1681, 1502, 1461, 12121017 , 939. ${ }^{1} \mathrm{H}-\mathrm{NMR}\left(600 \mathrm{MHz}, \mathrm{D}_{2} \mathrm{O}\right) \delta: 8.00(\mathrm{~s}, 1 \mathrm{H}), 4.41\left(\mathrm{dd}, 1 \mathrm{H},{ }^{3} J_{(\mathrm{H} 4-\mathrm{H} 3 \beta)}=8.9 \mathrm{~Hz},{ }^{3} J_{(\mathrm{H} 4-\mathrm{H} 3 \alpha)}=8.7 \mathrm{~Hz}\right.$, $\mathrm{HC} 4), 4.03\left(\mathrm{dd}, 1 \mathrm{H},{ }^{2} J_{(\mathrm{HCH})}=13.4 \mathrm{~Hz},{ }^{3} J_{(\mathrm{HCC}-\mathrm{H} 2)}=4.9 \mathrm{~Hz}, \mathrm{HCH}-\mathrm{BrUra}\right), 4.00\left(\mathrm{dddd}, 1 \mathrm{H},{ }^{3} J_{(\mathrm{H} 2-\mathrm{H} 3 \beta)}\right.$ $\left.=8.9 \mathrm{~Hz},{ }^{3} J_{(\mathrm{H} 2-\mathrm{CCH})}=5.0 \mathrm{~Hz},{ }^{3} J_{(\mathrm{H} 2-\mathrm{CCH})}=4.9 \mathrm{~Hz},{ }^{3} J_{(\mathrm{H} 2-\mathrm{H} 3 \alpha)}=5.7 \mathrm{~Hz}, \mathrm{HC} 2\right), 3.92\left(\mathrm{dd}, 1 \mathrm{H},{ }^{2} J_{(\mathrm{HCH})}=\right.$ $\left.13.4 \mathrm{~Hz},{ }^{3} J_{(\mathrm{HCC}-\mathrm{H} 2)}=5.0 \mathrm{~Hz}, \mathrm{HCH}-\mathrm{BrUra}\right), 2.88\left(\mathrm{~s}, 3 \mathrm{H}, \mathrm{CH}_{3} \mathrm{~N}\right), 2.46\left(\mathrm{ddd}, 1 \mathrm{H},{ }^{2} J_{(\mathrm{H} 3 \alpha-\mathrm{H} 3 \beta)}=13.5 \mathrm{~Hz}\right.$, $\left.{ }^{3} J_{(\mathrm{H} 3 \alpha-\mathrm{H} 4)}=8.7 \mathrm{~Hz},{ }^{3} J_{(\mathrm{H} 3 \alpha-\mathrm{H} 2)}=5.7 \mathrm{~Hz}, \mathrm{H}_{\alpha} \mathrm{C} 3\right), 2.07\left(\mathrm{ddd}, 1 \mathrm{H},{ }^{2} J_{(\mathrm{H} 3 \beta-\mathrm{H} 3 \alpha)}=13.5 \mathrm{~Hz},{ }^{3} \mathrm{~J}_{(\mathrm{H} 3 \beta-\mathrm{H} 4)}=8.9\right.$ $\left.\mathrm{Hz},{ }^{3} J_{(\mathrm{H} 3 \beta-\mathrm{H} 2)}=8.9 \mathrm{~Hz}, \mathrm{H}_{\beta} \mathrm{C} 3\right) ;{ }^{13} \mathrm{C}-\mathrm{NMR}\left(150 \mathrm{MHz}, \mathrm{CD}_{3} \mathrm{OD}\right) \delta: 175.66(\mathrm{C}(\mathrm{O})), 160.46\left(\mathrm{C}^{\prime}\right), 151.08$ $\left(\mathrm{C}^{\prime}\right), 145.19\left(\mathrm{C}^{\prime}\right), 95.73\left(\mathrm{C6}^{\prime}\right), 68.04(\mathrm{C} 4), 56.46\left(\mathrm{CH}_{2}-\mathrm{BrUra}\right), 49.47(\mathrm{C} 2), 32.13(\mathrm{C} 3), 28.26\left(\mathrm{CH}_{3} \mathrm{~N}\right)$. Anal. Calcd for $\mathrm{C}_{10} \mathrm{H}_{12} \mathrm{BrN}_{3} \mathrm{O}_{4}$ : C, 37.76; H, 3.80; N, 13.21. Found: C, 37.99; H, 3.85; N, 13.42.

cis-5-Bromo-1-[(4-hydroxy-1-methyl-5-oxopyrrolidin-2-yl)methyl]pyrimidine-2,4(1H,3H)-dione (cis-15d). Yield: 9.3\%; a colorless amorphous solid; m.p. $=209-210{ }^{\circ} \mathrm{C}$ with decomposition (crystallized from methanol-chloroform). IR (KBr, cm $\left.{ }^{-1}\right) v_{\max }: 3550,3452,3170,3040,2960,2853,2780,1678,1629$, 1460, 1344, 1133. ${ }^{1} \mathrm{H}-\mathrm{NMR}\left(600 \mathrm{MHz}, \mathrm{D}_{2} \mathrm{O}\right) \delta: 7.90(\mathrm{~s}, 1 \mathrm{H}), 4.34\left(\mathrm{dd}, 1 \mathrm{H},{ }^{3} J_{(\mathrm{H} 4-\mathrm{H} 3 \alpha)}=8.1 \mathrm{~Hz},{ }^{3} J_{(\mathrm{H} 4-\mathrm{H} 3 \beta)}\right.$ $=6.1 \mathrm{~Hz}, \mathrm{HC} 4), 4.21\left(\mathrm{dd}, 1 \mathrm{H},{ }^{2} J_{(\mathrm{HCH})}=14.3 \mathrm{~Hz},{ }^{3} J_{(\mathrm{HCC}-\mathrm{H} 2)}=4.9 \mathrm{~Hz}, \mathrm{HCH}-\mathrm{BrUra}\right), 3.94(\mathrm{dddd}, 1 \mathrm{H}$, $\left.{ }^{3} J_{(\mathrm{H} 2-\mathrm{CCH})}=9.8 \mathrm{~Hz},{ }^{3} J_{(\mathrm{H} 2-\mathrm{H} 3 \alpha)}=7.8 \mathrm{~Hz},{ }^{3} J_{(\mathrm{H} 2-\mathrm{H} 3 \beta)}=7.1 \mathrm{~Hz},{ }^{3} J_{(\mathrm{H} 2-\mathrm{CCH})}=4.9 \mathrm{~Hz}, \mathrm{HC} 2\right), 3.87(\mathrm{dd}, 1 \mathrm{H}$, $\left.{ }^{2} J_{(\mathrm{HCH})}=14.3 \mathrm{~Hz},{ }^{3} J_{(\mathrm{HCC}-\mathrm{H} 2)}=9.8 \mathrm{~Hz}, \mathrm{HCH}-\mathrm{BrUra}\right), 2.88\left(\mathrm{~s}, 3 \mathrm{H}, \mathrm{CH}_{3} \mathrm{~N}\right), 2.56\left(\mathrm{ddd}, 1 \mathrm{H},{ }^{2} J_{(\mathrm{H} 3 \alpha-\mathrm{H} 3 \beta)}\right.$ $\left.=13.7 \mathrm{~Hz},{ }^{3} J_{(\mathrm{H} 3 \alpha-\mathrm{H} 4)}=8.1 \mathrm{~Hz},{ }^{3} J_{(\mathrm{H} 3 \alpha-\mathrm{H} 2)}=7.8 \mathrm{~Hz}, \mathrm{H}_{\alpha} \mathrm{C} 3\right), 1.68\left(\mathrm{ddd}, 1 \mathrm{H},{ }^{2} J_{(\mathrm{H} 3 \beta-\mathrm{H} 3 \alpha)}=13.7 \mathrm{~Hz}\right.$, $\left.{ }^{3} J_{(\mathrm{H} 3 \beta-\mathrm{H} 2)}=7.1 \mathrm{~Hz},{ }^{3} J_{(\mathrm{H} 3 \beta-\mathrm{H} 4)}=6.1 \mathrm{~Hz}, \mathrm{H}_{\beta} \mathrm{C} 3\right) .{ }^{13} \mathrm{C}-\mathrm{NMR}$ signals of cis-15d were extracted from the spectra of a 53:47 mixture of cis-15d and trans-15d ${ }^{13} \mathrm{C}-\mathrm{NMR}\left(150 \mathrm{MHz}, \mathrm{CD}_{3} \mathrm{OD}\right) \delta: 175.44(\mathrm{C}(\mathrm{O}))$, $160.57\left(\mathrm{C}^{\prime}\right), 151.16\left(\mathrm{C}^{\prime}\right), 145.36\left(\mathrm{C}^{\prime}\right), 95.52\left(\mathrm{C6}^{\prime}\right), 67.79(\mathrm{C} 4), 56.14\left(\mathrm{CH}_{2}-\mathrm{BrUra}\right), 50.47$ (C2), 31.48 (C3), $27.71\left(\mathrm{CH}_{3} \mathrm{~N}\right)$. Anal. Calcd for $\mathrm{C}_{10} \mathrm{H}_{12} \mathrm{BrN}_{3} \mathrm{O}_{4}: \mathrm{C}, 37.76 ; \mathrm{H}, 3.80 ; \mathrm{N}, 13.21$. Found: $\mathrm{C}, 38.00 ; \mathrm{H}, 3.98 ; \mathrm{N}$, 13.50 .

\subsection{Synthesis of $\gamma$-Lactams cis-15e and trans-15e}

A solution of a 53:35:8:2 mixture of $\gamma$-lactams trans-15a, cis-15a, trans-15g and trans-15g $(0.136 \mathrm{~g}$, $0.61 \mathrm{mmol})$ and $N$-chlorosuccinimide $(0.163 \mathrm{~g}, 1.22 \mathrm{mmol})$ in freshly distilled pyridine $(12 \mathrm{~mL}) \mathrm{was}$ stirred at $100{ }^{\circ} \mathrm{C}$ for $1 \mathrm{~h}$. The solvent was removed in vacuo and the crude product was purified on a silica gel column using chloroform-methanol $(100: 1, v / v)$ as an eluent. The respective fractions were subjected to chromatography on an X Bridge Prep, C8, $5 \mu \mathrm{m}$, OBD, $19 \times 100 \mathrm{~mm}$ column using water/methanol $(98: 2, v / v)$ to give pure $\gamma$-lactams trans-15e $(0.01 \mathrm{~g}, 6 \%)$ and cis-15d $(0.007 \mathrm{~g}, 4.2 \%)$.

trans-5-Chloro-1-[(4-hydroxy-1-methyl-5-oxopyrrolidin-2-yl)methyl]pyrimidine-2,4(1H,3H)-dione (trans-15e). Yield: 4.2\%; a colorless amorphous solid; m.p. $>230{ }^{\circ} \mathrm{C}$ with decomposition (crystallized from methanol-chloroform). IR (KBr, cm $\left.{ }^{-1}\right) v_{\text {max }}: 3404,3160,3035,2957,2824,1749,1716,1665,1627,1442$, $1342,1214,1069,878,750 .{ }^{1} \mathrm{H}-\mathrm{NMR}\left(600 \mathrm{MHz}, \mathrm{CD}_{3} \mathrm{OD}\right) \delta: 7.90(\mathrm{~s}, 1 \mathrm{H}), 4.33\left(\mathrm{dd}, 1 \mathrm{H},{ }^{3} J_{(\mathrm{H} 4-\mathrm{H} 3 \beta)}=8.9\right.$ $\left.\mathrm{Hz},{ }^{3} J_{(\mathrm{H} 4-\mathrm{H} 3 \alpha)}=8.1 \mathrm{~Hz}, \mathrm{HC} 4\right), 4.03\left(\mathrm{dd}, 1 \mathrm{H},{ }^{2} J_{(\mathrm{HCH})}=13.9 \mathrm{~Hz},{ }^{3} J_{(\mathrm{HCC}-\mathrm{H} 2)}=4.6 \mathrm{~Hz}, \mathrm{HCH}-\mathrm{ClUra}\right), 4.00$ $\left(\mathrm{dddd}, 1 \mathrm{H},{ }^{3} J_{(\mathrm{H} 2-\mathrm{H} 3 \beta)}=8.9 \mathrm{~Hz},{ }^{3} J_{(\mathrm{H} 2-\mathrm{CCH})}=6.2 \mathrm{~Hz},{ }^{3} J_{(\mathrm{H} 2-\mathrm{CCH})}=4.6 \mathrm{~Hz},{ }^{3} J_{(\mathrm{H} 2-\mathrm{H} 3 \alpha)}=0.8 \mathrm{~Hz}, \mathrm{HC} 2\right)$, $3.86\left(\mathrm{dd}, 1 \mathrm{H},{ }^{2} J_{(\mathrm{HCH})}=13.9 \mathrm{~Hz},{ }^{3} J_{(\mathrm{HCC}-\mathrm{H} 2)}=6.2 \mathrm{~Hz}, \mathrm{HCH}-\mathrm{ClUra}\right), 2.93\left(\mathrm{~s}, 3 \mathrm{H}, \mathrm{CH}_{3} \mathrm{~N}\right), 2.41(\mathrm{ddd}, 1 \mathrm{H}$, $\left.{ }^{2} J_{(\mathrm{H} 3 \alpha-\mathrm{H} 3 \beta)}=13.3 \mathrm{~Hz},{ }^{3} J_{(\mathrm{H} 3 \alpha-\mathrm{H} 4)}=8.1 \mathrm{~Hz},{ }^{3} J_{(\mathrm{H} 3 \alpha-\mathrm{H} 2)}=0.8 \mathrm{~Hz}, \mathrm{H}_{\alpha} \mathrm{C} 3\right), 2.02\left(\mathrm{ddd}, 1 \mathrm{H},{ }^{2} J_{(\mathrm{H} 3 \beta-\mathrm{H} 3 \alpha)}=\right.$ $\left.13.3 \mathrm{~Hz},{ }^{3} J_{(\mathrm{H} 3 \beta-\mathrm{H} 4)}=8.9 \mathrm{~Hz},{ }^{3} J_{(\mathrm{H} 3 \beta-\mathrm{H} 2)}=8.9 \mathrm{~Hz}, \mathrm{H}_{\beta} \mathrm{C} 3\right) .{ }^{13} \mathrm{C}-\mathrm{NMR}\left(150 \mathrm{MHz}, \mathrm{CD}_{3} \mathrm{OD}\right) \delta: 175.47$ (C(O)), $163.12\left(\mathrm{C}^{\prime}\right), 153.08$ (C2'), $142.11\left(\mathrm{C}^{\prime}\right), 108.39$ (C6'), 67.83 (C4), $56.23\left(\mathrm{CH}_{2}-\mathrm{ClUra}\right), 49.65$ (C2), 32.02 (C3), $28.03\left(\mathrm{CH}_{3} \mathrm{~N}\right)$. Anal. Calcd for $\mathrm{C}_{10} \mathrm{H}_{12} \mathrm{ClN}_{3} \mathrm{O}_{4}$ : C, 43.89; $\mathrm{H}, 4.42 ; \mathrm{N}, 15.35$. Found: C, 43.78; $\mathrm{H}, 4.40 ; \mathrm{N}, 15.37$

cis-5-Chloro-1-[(4-hydroxy-1-methyl-5-oxopyrrolidin-2-yl)methyl]pyrimidine-2,4(1H,3H)-dione (cis-15e). Yield: 6.0\%; a colorless amorphous solid; m.p. $>230{ }^{\circ} \mathrm{C}$ with decomposition (crystallized from 
methanol-chloroform). IR ( $\left.\mathrm{KBr}, \mathrm{cm}^{-1}\right) v_{\max }: 3393,3328,3162,3030,2952,2843,1756,1676,1627$, $1468,1431,1335,1196,903,781 .{ }^{1} \mathrm{H}-\mathrm{NMR}\left(600 \mathrm{MHz}, \mathrm{CD}_{3} \mathrm{OD}\right) \delta: 7.85$ (s, 1H), 4.25-4.21 (m, 2H, HC4, HCH-ClUra), $3.90-3.86(\mathrm{~m}, 1 \mathrm{H}, \mathrm{HC} 2), 3.84\left(\mathrm{dd}, 1 \mathrm{H},{ }^{2} J_{(\mathrm{HCH})}=13.4 \mathrm{~Hz},{ }^{3} \mathrm{~J}_{(\mathrm{HCC}-\mathrm{H} 2)}=6.5 \mathrm{~Hz}, \mathrm{HCH}-\mathrm{ClUra}\right)$, $2.92\left(\mathrm{~s}, 3 \mathrm{H}, \mathrm{CH}_{3} \mathrm{~N}\right), 2.48\left(\mathrm{ddd}, 1 \mathrm{H},{ }^{2} J_{(\mathrm{H} 3 \alpha-\mathrm{H} 3 \beta)}=13.6 \mathrm{~Hz},{ }^{3} \mathrm{~J}=7.8 \mathrm{~Hz},{ }^{3} \mathrm{~J}=7.6 \mathrm{~Hz}, \mathrm{H}_{\alpha} \mathrm{C} 3\right), 1.75$ (ddd, $\left.1 \mathrm{H},{ }^{2} J_{(\mathrm{H} 3 \beta-\mathrm{H} 3 \alpha)}=13.6 \mathrm{~Hz},{ }^{3} \mathrm{~J}=5.6 \mathrm{~Hz},{ }^{3} \mathrm{~J}=5.3 \mathrm{~Hz}, \mathrm{H}_{\beta} \mathrm{C} 3\right) .{ }^{13} \mathrm{C}-\mathrm{NMR}\left(150 \mathrm{MHz}, \mathrm{CD}_{3} \mathrm{OD}\right) \delta: 175.69$ $(\mathrm{C}(\mathrm{O})), 160.42\left(\mathrm{C}^{\prime}\right), 153.48\left(\mathrm{C}^{\prime}\right), 142.36\left(\mathrm{C}^{\prime}\right), 108.24\left(\mathrm{C}^{\prime}\right), 68.93(\mathrm{C} 4), 56.27\left(\mathrm{CH}_{2}-\mathrm{BrUra}\right), 50.81(\mathrm{C} 2)$, 31.58 (C3), $27.72\left(\mathrm{CH}_{3} \mathrm{~N}\right)$. Anal. Calcd for $\mathrm{C}_{10} \mathrm{H}_{12} \mathrm{ClN}_{3} \mathrm{O}_{4}$ : C, 43.89; $\mathrm{H}, 4.42 ; \mathrm{N}, 15.35$. Found: C, 43.80; $\mathrm{H}, 4.37 ; \mathrm{N}, 15.30$.

\subsection{Antiviral Activity Assays}

The compounds were evaluated against different herpesviruses, including herpes simplex virus type 1 (HSV-1) strain KOS, thymidine kinase-deficient $\left(\mathrm{TK}^{-}\right) \mathrm{HSV}-1 \mathrm{KOS}$ strain resistant to ACV $\left(\mathrm{ACV}^{\mathrm{r}}\right)$, herpes simplex virus type 2 (HSV-2) strain G, adeno virus-2, human coronavirus, varicella-zoster virus (VZV) TK ${ }^{+}$strain Oka, TK ${ }^{-}$VZV strains 07-1, human cytomegalovirus (HCMV) strains AD-169 and Davis; para-influenza-3 virus, reovirus-1, Sindbis virus, Coxsackie virus B4, Punta Toro virus, respiratory syncytial virus (RSV), vesicular stomatitis virus, yellow fever virus, influenza A virus subtypes H1N1 (A/PR/8) and H3N2 (A/HK/7/87); and influenza B virus (B/HK/5/72). The antiviral assays were based on inhibition of virus-induced cytopathicity or plaque formation (for VZV) in human embryonic lung (HEL) fibroblasts, African green monkey kidney cells (Vero), human epithelial cervix carcinoma cells (HeLa), or Madin Darby canine kidney cells (MDCK). Confluent cell cultures in microtiter 96-well plates were inoculated with $100 \mathrm{CCID}_{50}$ of virus $\left(1 \mathrm{CCID}_{50}\right.$ being the virus dose to infect $50 \%$ of the cell cultures) or with 20 plaque forming units (PFU) (for VZV) and the cell cultures were incubated in the presence of varying concentrations of the test compounds. Viral cytopathicity or plaque formation (VZV) was recorded as soon as it reached completion in the control virus-infected cell cultures that were not treated with the test compounds. Antiviral activity was expressed as the $\mathrm{EC}_{50}$ or compound concentration required to reduce virus-induced cytopathicity or viral plaque formation by $50 \%$. Cytotoxicity of the test compounds was expressed as the minimum cytotoxic concentration (MCC) or the compound concentration that caused a microscopically detectable alteration of cell morphology.

\subsection{Cytostatic Activity against Immortalized Cell Lines}

All assays were performed in 96-well microtiter plates. To each well was added (5-7.5) $\times 10^{4}$ tumor cells and a given amount of the test compound. The cells were allowed to proliferate at $37^{\circ} \mathrm{C}$ in a humidified, $\mathrm{CO}_{2}$-controlled atmosphere. At the end of the incubation period, the cells were counted in a Coulter counter. The $\mathrm{IC}_{50}(50 \%$ inhibitory concentration) was defined as the concentration of the compound that inhibited cell proliferation by $50 \%$.

\section{Conclusions}

A series of isoxazolidine analogues of homonucleosides cis-14 and trans-14 was synthesized by 1,3-dipolar cycloaddition of nucleobase-derived nitrones 13 and methyl acrylate. Based on ${ }^{1} \mathrm{H}-\mathrm{NMR}$ vicinal coupling constants the preferred ${ }^{2} E$ conformations were established for the isoxazolidine ring in both cis-14 and trans-14. Hydrogenolytic transformation of isoxazolidines cis-14 and trans-14 into $\gamma$-lactams trans-15 and cis-15 was then performed to produce the respective $\gamma$-lactams containing thymine (trans-15b/cis-15b), dihydrouracil (trans-15g/cis-15g), theophylline (trans-15h/cis-15h) and adenine (trans-15i/cis-15i) as nucleobases by the application of the established protocol.

Since, during the hydrogenation of 5-halogenated uracil-containing isoxazolidine homonucleosides, the halogen atom was removed from a nucleobase skeleton, 5-bromouracil and 5-chlorouracil derivatives trans-15d/cis-15d (Br-Ura) and trans-15e/cis-15e (Cl-Ura) were obtained via the treatment of uracil-containing $\gamma$-lactams with NBS and NCS, respectively.

All obtained isoxazolidine and $\gamma$-lactam homonucleosides were evaluated against a broad-spectrum of DNA and RNA viruses and appeared inactive at concentrations up to $100 \mu \mathrm{M}$. 
Antiproliferative properties of the obtained isoxazolidines and $\gamma$-lactams were evaluated on nine cancerous cell lines and several of them exhibited moderate inhibitory activity, and at the same time they were inactive toward normal retina cells.

Supplementary Materials: The Supplementary Materials are available online.

Author Contributions: The research group from the Medical University of Lodz (D.G.P., I.E.G., and J.G.) conceived the research project, participated in all steps of the research, interpreted the results, discussed the experimental data and prepared the manuscript. The research group from KU Leuven (D.S., R.S. and G.A.) conducted the biological assays and provided the experimental procedures and results. All authors commented on and approved the manuscript.

Funding: This work was funded by the National Science Centre (grant UMO-2013/11/N/NZ7/00723—synthetic part of the project) and KU Leuven (GOA 15/19 TBA—biological screening).

Acknowledgments: Special thanks are forwarded to the Rega Institute collaborators: Leentje Persoons, Ellen De Waegenaere, Bianca Stals, Kirsten Lepaige, Neils Willems and Nathalie Van Winkel.

Conflicts of Interest: The authors declare no conflict of interest.

\section{References}

1. Chu, C.K. (Ed.) Antiviral Nucleosides: Chiral Synthesis and Chemotheraphy; Elsevier: Amsterdam, The Netherlands, 2003.

2. De Clercq, E. New developments in anti-HIV chemotherapy. Biochim. Biophys. Acta 2002, 1587, $258-275$. [CrossRef]

3. Jordheim, L.P.; Durantel, D.; Zoulim, F.; Dumontet, C. Advances in the development of nucleoside and nucleotide analogues for cancer and viral diseases. Nat. Rev. Drug Discov. 2013, 12, 447-464. [CrossRef] [PubMed]

4. De Clercq, E. Highlights in antiviral drug research: Antivirals at the horizon. Med. Res. Rev. 2013, 33, 1215-1248. [CrossRef] [PubMed]

5. De Clercq, E. A 40-year journey in search of selective antiviral chemotherapy. Annu. Rev. Pharmacol. Toxicol. 2011, 51, 1-24. [CrossRef] [PubMed]

6. De Clercq, E. HIV resistance to reverse transcriptase inhibitors. Biochem. Pharmacol. 1994, 47, $155-169$. [CrossRef]

7. Vince, R.; Hua, M.; Brownell, J.; Daluge, S.; Lee, F.; Shannon, W.M.; Lavelle, G.C.; Qualls, J.; Weislow, O.S.; Kiser, R.; et al. Potent and selective activity of a new carbocyclic nucleoside analog (Carbovir: NSC 614846) against human immunodeficiency virus In vitro. Biochem. Biophys. Res. Commun. 1988, 156, 1046-1053. [CrossRef]

8. Tenney, D.J.; Yamanaka, G.; Voss, S.M.; Cianci, C.W.; Tuomari, A.V.; Sheaffer, A.K.; Alam, M.; Colonno, R.J. Lobucavir is phosphorylated in human cytomegalovirus-infected and -uninfected cells and inhibits the viral DNA polymerase. Antimicrob. Agents Chemother. 1997, 41, 2680-2685. [CrossRef]

9. Norbeck, D.W.; Spanton, S.; Broder, S.; Mitsuya, H. ( \pm )-Dioxolane-T (( \pm )-1-[(2 $\beta, 4 \beta)$-2-(hydroxymethyl)-4-dioxolanyl]thymine): A new $2^{\prime}, 3^{\prime}$-dideoxynucleoside prototype with in vitro activity against HIV. Tetrahedron Lett. 1989, 30, 6263-6266. [CrossRef]

10. Balzarini, J.; Naesens, L.; De Clercq, E. New antivirals-Mechanism of action and resistance development. Curr. Opin. Microbiol. 1998, 1, 535-546. [CrossRef]

11. Galmarini, C.M.; Jordheim, L.; Dumontet, C. Pyrimidine nucleoside analogs in cancer treatment. Expert Rev. Anticancer Ther. 2003, 3, 717-728. [CrossRef]

12. Ewald, B.; Sampath, D.; Plunkett, W. Nucleoside analogs: Molecular mechanisms signaling cell death. Oncogene 2008, 27, 6522-6537. [CrossRef] [PubMed]

13. Deeks, E.D. Cladribine Tablets: A Review in Relapsing MS. CNS Drugs 2018, 32, 785-796. [CrossRef] [PubMed]

14. Noble, S.; Goa, K.L. Gemcitabine. A review of its pharmacology and clinical potential in non-small cell lung cancer and pancreatic cancer. Drugs 1997, 54, 447-472. [CrossRef]

15. Scott, L.J. Azacitidine: A Review in Myelodysplastic Syndromes and Acute Myeloid Leukaemia. Drugs 2016, 76, 889-900. [CrossRef] [PubMed] 
16. Reese, N.D.; Schiller, G.J. High-Dose Cytarabine (HD araC) in the Treatment of Leukemias: A Review. Curr. Hematol. Malig. Rep. 2013, 8, 141-148. [CrossRef] [PubMed]

17. Bonate, P.L.; Arthaud, L.; Cantrell, W.R., Jr.; Stephenson, K.; Secrist III, J.A.; Weitman, S. Discovery and development of clofarabine: A nucleoside analogue for treating cancer. Nat. Rev. Drug Discov. 2006, 5, 855-863. [CrossRef] [PubMed]

18. Wróblewski, A.E.; Głowacka, I.E.; Piotrowska, D.G. 1'-Homonucleosides and their structural analogues: A review. Eur. J. Med. Chem. 2016, 118, 121-142. [CrossRef]

19. Hossain, N.; Hendrix, C.; Lescrinier, E.; Van Aerschot, A.; Busson, R.; De Clercq, E.; Herdewijn, P. Homo-N-nucleosides: Incorporation into oligonucleotides and antiviral activity. Bioorg. Med. Chem. Lett. 1996, 6, 1465-1468. [CrossRef]

20. De Clercq, E.; Descamps, J.; Verhelst, G.; Walker, R.T.; Jones, A.S.; Torrence, P.F.; Shugar, D. Comparative efficacy of antiherpes drugs against different strains of herpes simplex virus. J. Infect. Dis. 1980, 141, 563-574. [CrossRef]

21. De Clercq, E.; Hols, A.; Rosenberg, I.; Sakuma, T.; Balzarini, J.; Maudgal, P.C.A. A novel selective broad-spectrum anti-DNA virus agent. Nature 1986, 323, 464-467. [CrossRef]

22. Saladino, R.; Neri, V.; Checconi, P.; Celestino, I.; Nencioni, L.; Palmara, A.T.; Crucianelli, M. Synthesis of 2'-deoxy-1'-homo- $N$-nucleosides with anti-influenza activity by catalytic methyltrioxorhenium $(\mathrm{MTO}) / \mathrm{H}_{2} \mathrm{O}_{2}$ oxyfunctionalization. Chem. Eur. J. 2013, 19, 2392-2404. [CrossRef] [PubMed]

23. Sekino, Y.; Bruner, S.D.; Verdine, G.L. Selective inhibition of herpes simplex virus type-1 uracil-DNA glycosylase by designed substrate analogs. J. Biol. Chem. 2000, 275, 36506-36508. [CrossRef] [PubMed]

24. Tronchet, J.M.J.; Winter-Mihaly, E.; Habashi, F.; Schwarzenbach, D.; Likic, U.; Geoffroy, M. Dérivés de désoxy-hydroxylamino-sucres et radicaux libres diglycosylnitroxydes correspondants. Communication préliminaire. Helv. Chem. Acta 1981, 64, 610-616. [CrossRef]

25. Tronchet, J.M.J.; Iznaden, M.; Barbalat-Rey, F.; Dhimane, H.; Ricca, A.; Balzarini, J.; De Clercq, E. Isoxazolidine analogs of nucleosides. Eur. J. Med. Chem. 1992, 27, 555-560. [CrossRef]

26. Loh, B.; Vozzolo, L.; Mok, B.J.; Lee, C.C.; Fitzmaurice, R.J.; Caddick, S.; Fassati, A. Inhibition of HIV-1 replication by isoxazolidine and isoxazole sulfonamides. Chem. Biol. Drug Des. 2010, 75, 461-474. [CrossRef]

27. Hirano, K.; Kubota, T.; Tsuda, M.; Mikami, Y.; Kobayashi, J. Pyrinodemins B-D, potent cytotoxic bis-pyridine alkaloids from marine sponge amphimedon sp. Chem. Pharm. Bull. 2000, 48, 974-977. [CrossRef]

28. Rescifina, A.; Chiacchio, M.A.; Corsaro, A.; De Clerq, E.; Iannazzo, D.; Mastino, A.; Piperno, A.; Romeo, G.; Romeo, R.; Valveri, V. Synthesis and Biological Activity of Isoxazolidinyl Polycyclic Aromatic Hydrocarbons: Potential DNA Intercalators. J. Med. Chem. 2006, 49, 709-715. [CrossRef]

29. Lee, L.W.; Taylor, C.C.E.; Desaulniers, J.P.; Zhang, M.; Hojfeldt, J.W.; Pan, Q.; Mapp, A.K. Inhibition of ErbB2(Her2) expression with small molecule transcription factor mimics. Bioorg. Med. Chem. Lett. 2009, 19, 6233-6236. [CrossRef]

30. Rescifina, A.; Chiacchio, U.; Corsaro, A.; Piperno, A.; Romeo, R. Isoxazolidinyl polycyclic aromatic hydrocarbons as DNA-intercalating antitumor agents. Eur. J. Med. Chem. 2011, 46, 129-136. [CrossRef]

31. Piotrowska, D.G.; Cieślak, M.; Królewska, K.; Wróblewski, A.E. Design, synthesis and cytotoxicity of a new series of isoxazolidine based nucleoside analogues. Arch. Pharm. Chem. Life Sci. 2011, 344, 301-310. [CrossRef]

32. Damodiran, M.; Sivakumar, P.M.; Senthil Kumar, R.; Muraligharan, D.; Phani Kumar, B.V.; Doble, M.; Perumal, P.T. Antibacterial activity, quantitative structure-activity relationship and diastereoselective synthesis of isoxazolidine derivatives via 1,3-dipolar cycloaddition of D-glucose derived nitrone with olefin. Chem. Biol. Drug Des. 2009, 74, 494-506. [CrossRef] [PubMed]

33. Sadashiva, M.P.; Mallesha, H.; Murthy, K.K.; Rangappa, K.S. Enhancement in antimicrobial activity of 2-(phenyl)-3-(2-butyl-4-chloro-1H-imidazolyl)-5-butylate isoxazolidine. Bioorg. Med. Chem. Lett. 2005, 15, 1811-1814. [CrossRef] [PubMed]

34. Chiacchio, U.; Corsaro, A.; Iannazzo, D.; Piperno, A.; Pistara, V.; Rescifina, A.; Romeo, R.; Valveri, V.; Mastino, A.; Romeo, G. Enantioselective Syntheses and Cytotoxicity of N,O-Nucleosides. J. Med. Chem. 2003, 46, 3696-3702. [CrossRef] [PubMed]

35. Piperno, A.; Giofre, S.V.; Iannazzo, D.; Romeo, R.; Romeo, G.; Chiacchio, U.; Rescifina, A.; Piotrowska, D.G. Synthesis of C-4'Truncated Phosphonated Carbocyclic 2'-Oxa-3'-azanucleosides as Antiviral Agents. J. Org. Chem. 2010, 75, 2798-2805. [CrossRef] 
36. Chiacchio, U.; Balestrieri, E.; Macchi, B.; Iannazzo, D.; Piperno, A.; Rescifina, A.; Romeo, R.; Saglimbeni, M.; Sciortino, M.T.; Valveri, V.; et al. Synthesis of Phosphonated Carbocyclic 2'-Oxa-aza-nucleosides: Novel Inhibitors of Reverse Transcriptase. J. Med. Chem. 2005, 48, 1389-1394. [CrossRef]

37. Chiacchio, U.; Rescifina, A.; Iannazzo, D.; Piperno, A.; Romeo, R.; Borrello, L.; Sciortino, M.T.; Balestrieri, E.; Macchi, B.; Mastino, A.; et al. Phosphonated Carbocyclic 2'-Oxa-3'-azanucleosides as New Antiretroviral Agents. J. Med. Chem. 2007, 50, 3747-3750. [CrossRef]

38. Balestrieri, E.; Matteucci, C.; Ascolani, A.; Piperno, A.; Romeo, R.; Romeo, G.; Chiacchio, U.; Mastino, A.; Macchi, B. Effect of phosphonated carbocyclic $2^{\prime}$-oxa-3'-aza-nucleoside on human T-cell leukemia virus type 1 infection in vitro. Antimicrob. Agents Chemother. 2008, 52, 54-64. [CrossRef]

39. Chiacchio, U.; Corsaro, A.; Iannazzo, D.; Piperno, A.; Pistara, V.; Rescifina, A.; Romeo, R.; Sindona, G.; Romeo, G. Diastereo- and enantioselective synthesis of N,O-nucleosides. Tetrahedron Asymmetry 2003, 14, 2717-2723. [CrossRef]

40. Chiacchio, U.; Saita, M.G.; Crispino, L.; Gumina, G.; Mangiafico, S.; Pistara, V.; Romeo, G.; Piperno, A.; De Clercq, E. Enantioselective synthesis of homocarbocyclic-2'-oxo-3'-azanucleosides. Tetrahedron 2006, 62, 1171-1181. [CrossRef]

41. Chiacchio, U.; Genovese, F.; Iannazzo, D.; Librando, V.; Merino, P.; Rescifina, A.; Romeo, R.; Procopio, A.; Romeo, G. Diastereoselective synthesis of homo-N,O-nucleosides. Tetrahedron 2004, 60, 441-448. [CrossRef]

42. Mannucci, V.; Cordero, F.M.; Piperno, A.; Romeo, G.; Brandi, A. Diastereoselective synthesis of a collection of new homonucleoside mimetics containing pyrrolo[1,2-b]isoxazoline and pyrrolidine rings. Tetrahedron Asymmetry 2008, 19, 1204-1209. [CrossRef]

43. Romeo, G.; Giofre, S.A.; Piperno, A.; Romeo, R.; Chiacchio, M.A. Synthesis of N,O-homonucleosides with high conformational freedom. Arkivoc 2009, 8, 168-176.

44. Pan, S.; Amankulor, N.M.; Zhao, K. Syntheses of isoxazolinyl and isoxazolidinyl nucleoside analogues. Tetrahedron 1998, 54, 6587-6604. [CrossRef]

45. Gotkowska, J.; Balzarini, J.; Piotrowska, D.G. Synthesis of novel isoxazolidine analogues of homonucleosides. Tetrahedron Lett. 2012, 53, 7097-7100. [CrossRef]

46. Piotrowska, D.G.; Balzarini, J.; Andrei, G.; Schols, D.; Snoeck, R.; Wróblewski, A.E.; Gotkowska, J. Novel isoxazolidine analogues of homonucleosides and homonucleotides. Tetrahedron 2016, 72, 8294-8308. [CrossRef]

47. Takahashi, K.; Kawabata, M.; Uemura, D.; Iwadare, S.; Mitomo, R.; Nakano, F.; Matsuzaki, A. Structure of neooxazolomycin, an antitumor antibiotic. Tetrahedron Lett. 1985, 26, 1077-1078. [CrossRef]

48. Kawazu, K.; Kanzaki, H.; Kawabata, G.; Kawai, S.; Kobayashi, A. Oxazolomycin Esters, Specific Inhibitors of Plant Transformation. Biosci. Biotechnol. Biochem. 1992, 56, 1382-1385. [CrossRef]

49. Andrés, J.M.; de Elena, N.; Pedrosa, R.; Pérez-Encabo, A. Stereoselective synthesis of $(5 S, 6 S)-$ and (5S,6R)-aza-muricatacin from an L-glutamic acid derivative. Tetrahedron Asymmetry 2001, 12, 1503-1509. [CrossRef]

50. Rieser, M.J.K.; John, F.; Wood, K.V.; McLaughlin, J.L. Muricatacin: A simple biologically active acetogenin derivative from the seeds of annona muricata (annonaceae). Tetrahedron Lett. 1991, 32, 1137-1140. [CrossRef]

51. Baussanne, I.; Schwardt, O.; Royer, J.; Pichon, M.; Figadere, B.; Cavé, A. Synthesis of aza-muricatacin: An analogue of the bioactive muricatacin an acetogenin of Annonaceae. Tetrahedron Lett. 1997, 38, 2259-2262. [CrossRef]

52. Cavé, A.; Chaboche, C.; Figadère, B.; Harmange, J.-C.; Laurens, A.; Peyrat, J.F.; Pichon, M.; Szlosek, M.; Cotte-Lafitte, J.; Quéro, A.M. Study of the structure-activity relationships of the acetogenin of annonaceae, muricatacin and analogues. Eur. J. Med. Chem. 1997, 32, 617-623. [CrossRef]

53. Janecka, A.; Wyrębska, A.; Gach, K.; Fichna, J.; Janecki, T. Natural and synthetic $\alpha$-methylenelactones and $\alpha$-methylenelactams with anticancer potential. Drug Discov. Today 2012, 17, 561-572. [CrossRef] [PubMed]

54. Baures, P.W.; Eggleston, D.S.; Erhard, K.F.; Cieslinski, L.B.; Torphy, T.J.; Christensen, S.B. Crystal structure, absolute configuration, and phosphodiesterase inhibitory activity of (+)-1-(4-bromobenzyl)-4-[(3-cyclopentyloxy)-4-methoxyphenyl]-2-pyrrolidinone. J. Med. Chem. 1993, 36, 3274-3277. [CrossRef] [PubMed]

55. Akah, P.A.; Nwambie, A.I. Evaluation of Nigerian traditional medicines: 1. Plants used for rheumatic (inflammatory) disorders. J. Ethnopharmacol. 1994, 42, 179-182. [CrossRef] 
56. Barrett, A.G.M.; Head, J.; Smith, M.L.; Stock, N.S.; White, A.J.P.; Williams, D.J. Fleming-Tamao Oxidation and Masked Hydroxyl Functionality: Total Synthesis of (+)-Pramanicin and Structural Elucidation of the Antifungal Natural Product (-)-Pramanicin. J. Org. Chem. 1999, 64, 6005-6018. [CrossRef]

57. Scgwartz, R.E.; Helms, G.L.; Bolessa, E.A.; Wilson, K.E.; Giacobbe, R.A.; Tkacz, J.S.; Bills, G.F.; Liesch, J.M.; Zink, D.L.; Curotto, J.E.; et al. Pramanicin, a novel antimicrobial agent from a fungal fermentation. Tetrahedron 1994, 50, 1675-1686. [CrossRef]

58. Caruano, J.; Muccioli, G.G.; Robiette, R. Biologically active $\gamma$-lactams: Synthesis and natural sources. Org. Biomol. Chem. 2016, 14, 10134-10156. [CrossRef] [PubMed]

59. Srivastav, N.C.; Shakya, N.; Bhavanam, S.; Agrawal, A.; Tse, C.; Desroches, N.; Kunimoto, D.Y.; Kumar, R. Antimycobacterial activities of 5-alkyl (or halo)-3'-substituted pyrimidine nucleoside analogs. Bioorg. Med. Chem. Lett. 2012, 22, 1091-1094. [CrossRef]

60. Lazrek, H.B.; Taourirte, M.; Oulih, T.; Barascut, J.L.; Imbach, J.L.; Pannecouque, C.; Witrouw, M.; De Clercq, E. Synthesis and anti-HIV activity of new modified 1,2,3-triazole acyclonucleosides. Nucleosides Nucleotides Nucleic Acids 2001, 20, 1949-1960. [CrossRef]

61. Strittmatter, T.; Aschenbrenner, J.; Hardt, N.; Marx, A. Synthesis of 4'-C-alkylated-5-iodo-2'-deoxypyrimidine nucleosides. Arkivoc 2013, 2, 46-59.

Sample Availability: Sample Availability: Samples are not avaliable. 